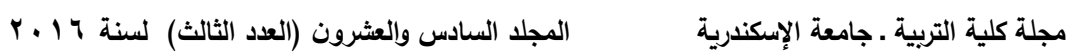

\title{
النزاع الهندي البرتغالي حول المستعمرات البرتغالية في الهند
}

$$
(1971-1908)
$$

د. د. أميرة السعيد الطنطاوى

\section{المقدمـة}

ظهرت حركات التحرر من الاستعمار الأوروبي بصورة جلية في

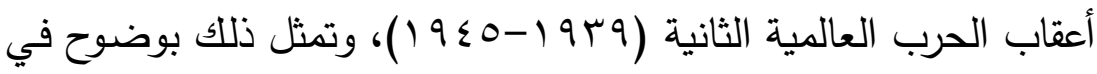
الهند التي حررت أراضيها من الاستعمار البريطاني في الخامس عشر من أغسطس V 9 ( م، ثم تبع ذللك القرار الفرنسي باستقلال المستعمرات

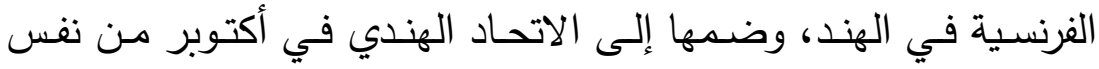

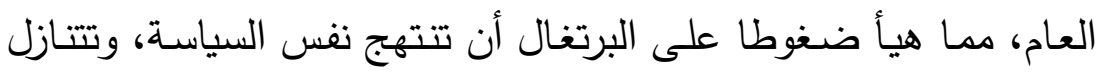
طواعية عن مستعمراتها في الهند، ولكن موقف الحكومة البرتغالية كان

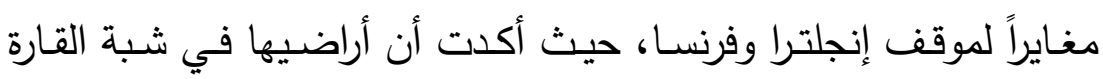
الهندية ليست مستعمرات، ولكنها جزء من الأراضـي البرتغالية لا يمكن

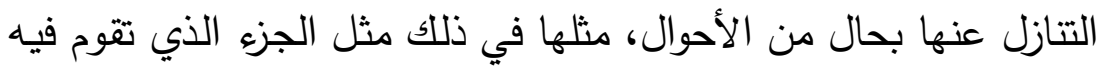

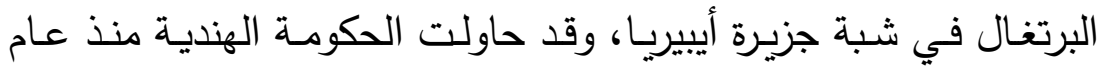

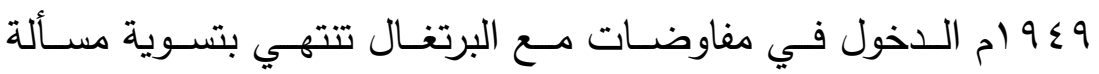
المستعمرات البرتغالية في الهند، لكن البرتغال ضـربت بتلك المحاولات عرض الحائط، فأصبح النزاع حتمياً بين الدولتين.

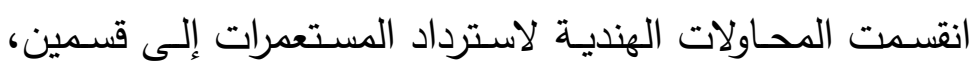

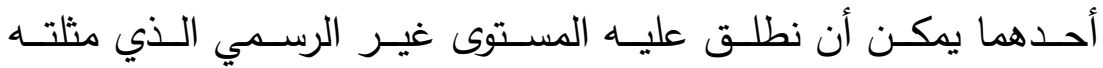

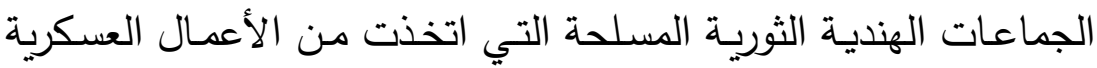

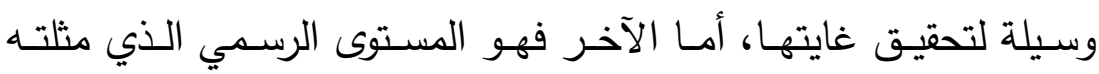
الحكومـة الهنديـة والمنظمـات غيـر المسـلحة، التـي اتخــت مـن أفكـار 


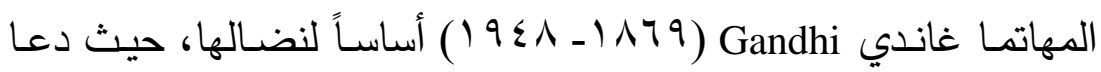
إلى استرداد المناطق الخاضعة للاستعمار في الهند دون إراقـة للدماء،

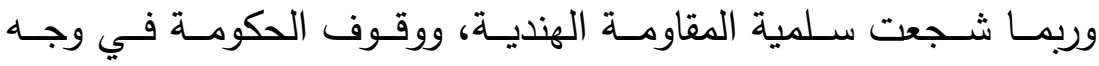
الجماعات المسلحة البرتغال على التمسك بمستعمراتها، ورفض كل سبل التفاهم؛ حتى قامت الهند بقطع علاقاتها الدبلوماسية مع البرتغال نهائيا

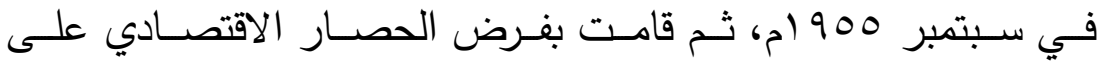

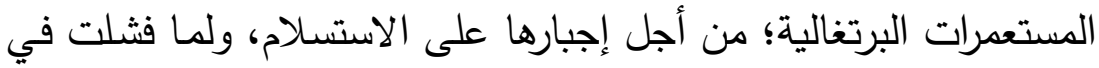
ذلك أصبح اللجوء إلى الخيار العسكري هو الحل الأخير أمام الحكومة الحيا الهندية لاسترداد تلك المستعمرات. وقد قسمت البحث إلى تمهيد، وثلاثة نقاط أساسية تمثلت في: ا ـ الخلفية التاريخية للنزاع حول المستعمرات البرتغالية في الهند. r. مراحل النزاع الهندي البرتغالي حول المستعمرات:

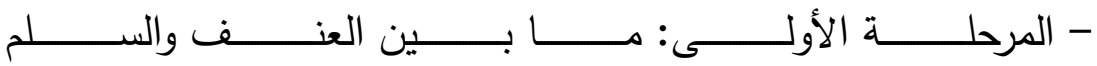

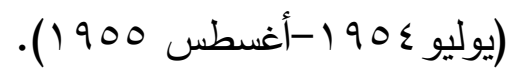

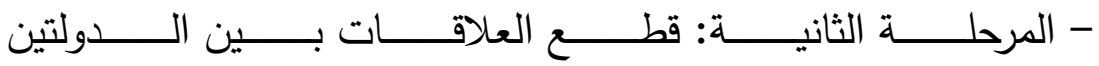
(سبتمبر 1900 - نوفمبر (الير (197) ). - المرحلة الثالثة: التدخل العسكري الهندي وضم المستعمرات البرتغالية (ديسمبر (197 (19). r. ردود الفعل الدولية على ضم الهند للمستعمرات البرتغالية. أمـا عن مصـادر البحث فقد اعتمدت في المقام الأول على وثائق

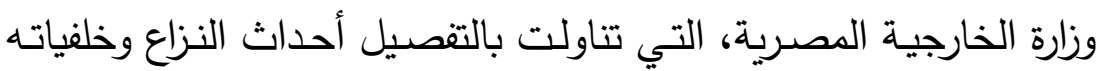

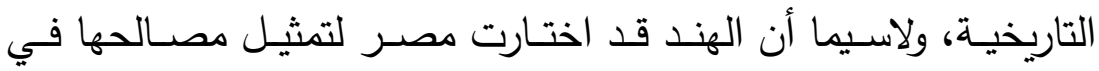
البرتغال، أثناء فترة انقطاع العلاقات الدبلوماسية بين البلدين، كما اعتمد البحث على وثائق وزارة الخارجية الأمريكية التي أوضحت ردود الأفعال الدولية بصفة عامة والأمريكية بصفة خاصة فيما يتعلق بموضوع النزاع، 
وكذلك بعض المقالات باللغة البرتغالية التي كتبها الضباط البرتغاليون

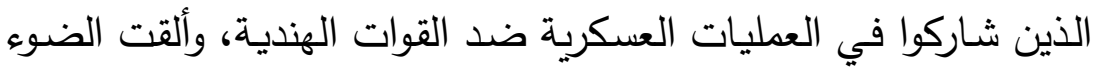
على الموقف البرتغالي في المستعمرات بشكل واضـح، هذا إلى جانب

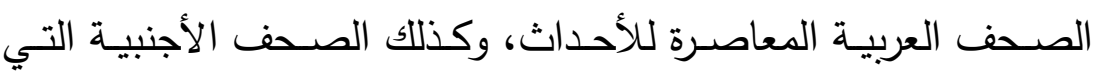
حصلت عليها عبر شبكة المعلومات الدولية.

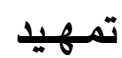

تعد البرتغـال من أولى الدول الأوروبيـة التي حرصت على تكوين إمبراطوريـة استعمارية، مستفيدة في ذلك من حركة الكثوف الجغرافيـة،

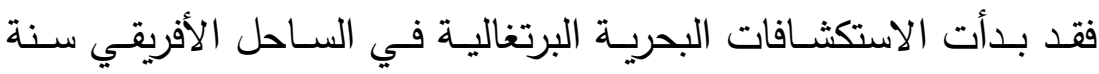

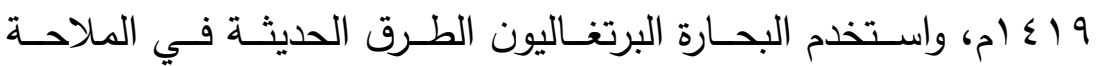

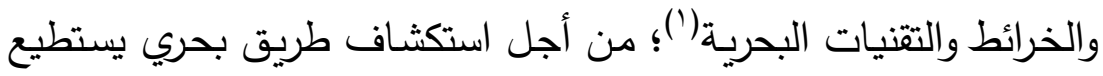
البرتغاليون من خلالهه التحكم في التجارة الثـرقية بصفة عامـة، وتجارة التوابل على وجه الخصوص، حيث يقوم وسطاؤهم بنقلها إلى البرتغال؛

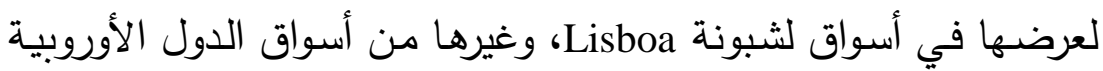

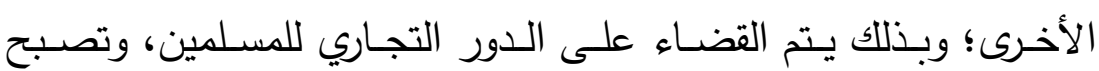

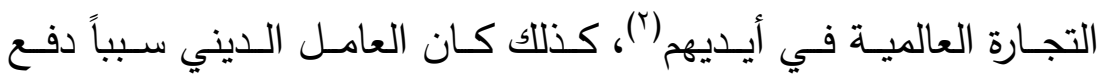
البرتغاليون للتوجه نحو الثرق، ويتضـح ذلك من القرارات البابوية التي

(1) منذ منتصف القرن الخامس عشر الميلادي حدث تقدم كبير أثر في انتعاش حركة الكشوف البرتغالية؛ حيث ظهرت

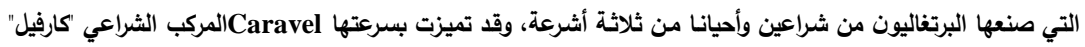

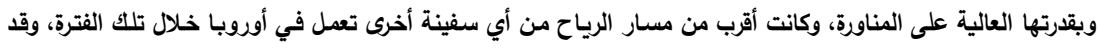

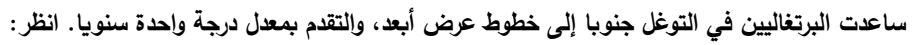

- Boxer, Charles Ralph, The Portuguese Seaborne Empire 1415- 1825, London: Hutchinson, 1969, p. 29 ; Russell-Wood, A.J.R., The Portuguese Empire 1415-1808, London: John Hopkins University, 1998. p. 9.

(†) السيد عادل محمد حسين، "الصراع البرتغالي - الهولندي في المحيط الهندي"، مجلة سامراء، المجلد الثاني، العدد الثالث، 
صدرت إثر التوسع البرتغالي في المياه الثرقية(')، وتأكيد الأمير هنري

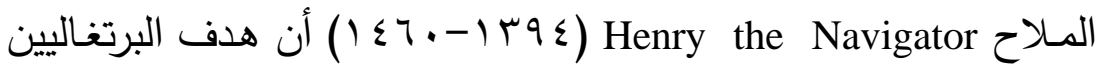
من هذه التوسعات هو "تطويق العالم الإسـلامي للقضـاء على الطاعون

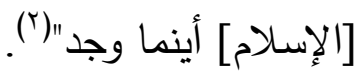

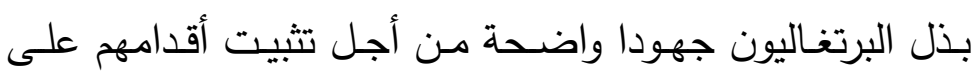
السواحل الأفريقية التي امتد لها الكثف البرتغالي، واستطاع بارثلميو دياز Bartholomew Diaz

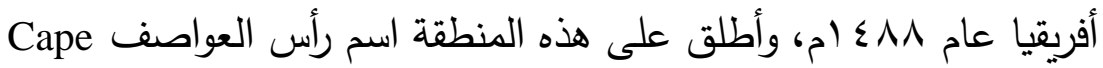

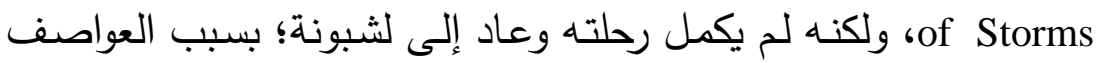
الشديدة التي واجهته، هذا بالإضافة إلى خلاف حدث بينه وبين بحارته،

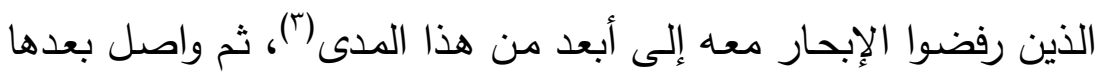
Vasco da Gama المستكثف البرتغالي فاسكو داجاما

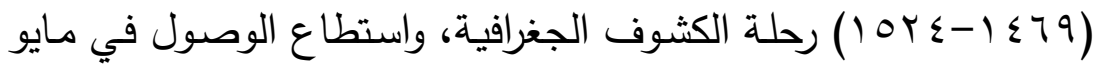

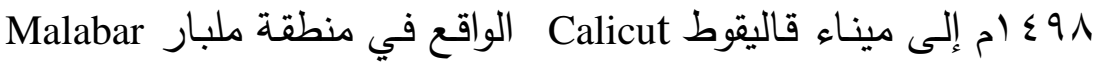
السـاحلية على الثـاطئ الغربي للهند، وهذه المنطقة كانت من المراكز

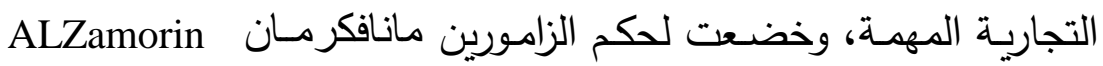
Manavikraman ظلت البرتغال ترسل الحملات إلى الهند لترصين مركزها فيها حتى عام

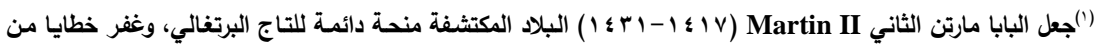

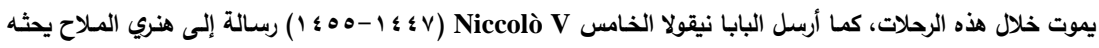

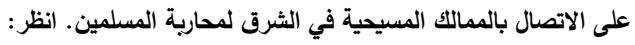
- حسن أحمد محمود، "التهايد البرتغالي لسواحل جزيرة العرب"، مجلة المؤخخ العربي، المجلد الثاني عشر، بغداد، ، ـ919 19، (2) Coupland, Reginald, East Africa and Its Invaders from the Earliest Times to the Death of Seyyid Said in 1856, Oxford: Clarendon Press, 1968, p. 46-47.

${ }^{(3)}$ Alchin, K.L, "Bartholomeu Dias", From Elizabethan Era. www.elizabethan-era.org, (11 November 2015).

(4) Narayanan, M. G. S, Calicut: The City of Truth Revisited, University of Calicut, 2006, p. 126. 


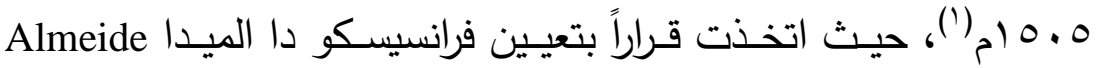
Francisco de 9 • (1)، وأمرته بإنشاء مزيد من القلاع لتأمين الوجود البرتغالي في هذه

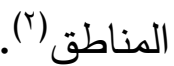

خلـف ألفـونس دي البـوكيرك Albuquerque de

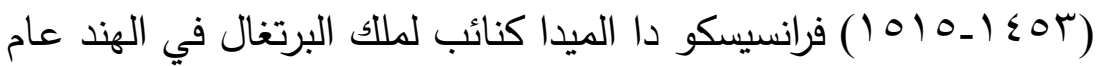

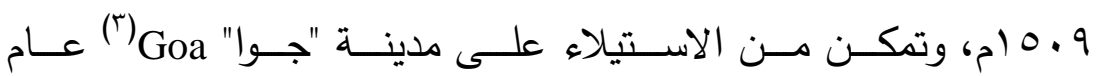
• (0 ام(ع)، وجعلها المركز الرئيسي للبرتغال في الشرق، وعاصمة للهند البرتغالية، وقد عززت سيطرته على "جـوا" النفوذ البرتغـالي في الهند،

(1) تبع حملة فاسكو دا داجاما حملة أخرى بقيادة النبيل البرتغالي كابرال Cabral الذي وصل قاليقوط في الثالث عشر من

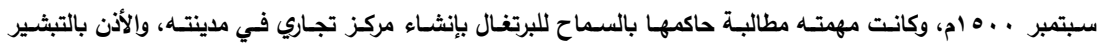

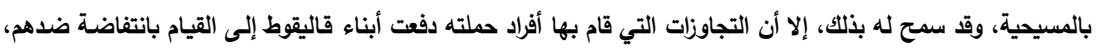

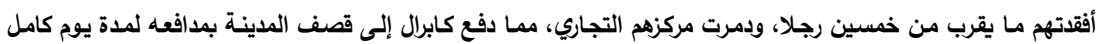

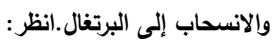

- Sreedhara Menon.A, A Survey of Kerala History, Kottayam: D.C.Books, 1967, p.152.

(ץ) استطاع فرانسيسكو دا الميدا أن يؤسس أربعة حصون على الساحل الجنوبي الغربي للهند. انظر: - Logan, William, Malabar Manual, Vol.1, Fourth Edition, New Delhi: 2004, p. 312.

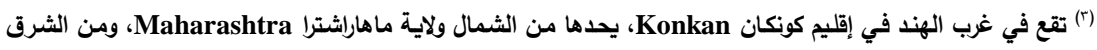
والجنوب ولاية كارناتاكا Karnataka ، وتطل على بحر العرب في الغرب، وتبعد عن بومباي بمسافة مائتي ميل، وتبلغ

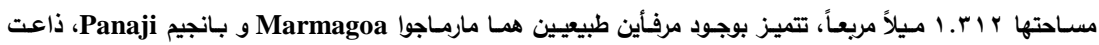

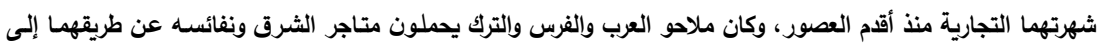

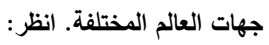

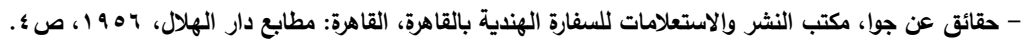

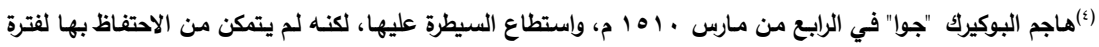

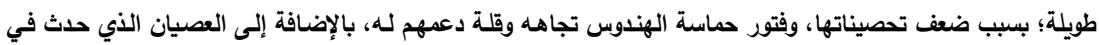

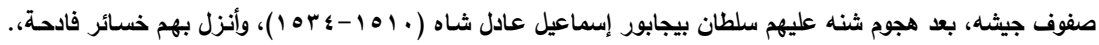

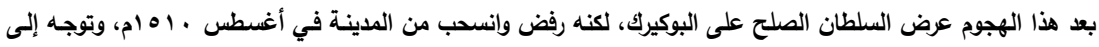

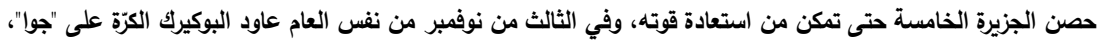

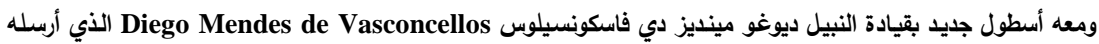

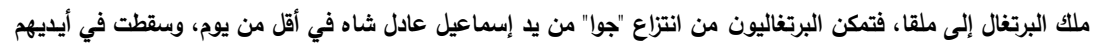

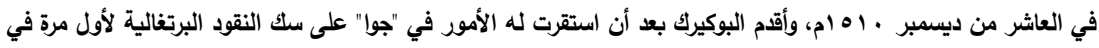

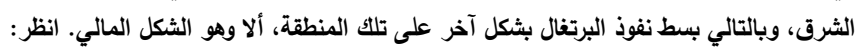
- Diffie, Winius, Foundations of the Portuguese Empire, 1415-1580 (Europe and the World in the Age of Expansion), Vol. I, Minneapolis: University of Minnesota Press, 1977, p. 253. ; De Souza, Teotonio R, (ed) "Goa through the Ages: An economic history", Goa University publication series, No 6, New Delhi: 1982, p. 220-221. 
ومكنتهه مـن السـيطرة على الطـرق البحريـة بـين الهنـد ومنطقـة الثـرق الأقصـى (')، بعـدها سـيطر البرتغـاليون علىى مقاطعـة دمـان (r) عـام اسه ام، وجزيرة ديو (r) عـام ع سه (م، ورغم ذلك لـ يحاول البرتغاليون إقامـة إمبراطوريـة في الهند، واكتفوا بإنشـاء سلسلة من المراكز السـاحلية المحصـنة، على السـاحل الهنـدي أمثـال كوشـين Cochin ، بنجـالور Bengalur على شبه جزيرة ملقا، واتخاذها قاعدة استراتيجية في توسعهم التجاري مع الصين وجنوب شرق آسيا، وقد حافظت البرتغال على السيادة البحرية في هذه الأماكن قرابة قرن من الزمان (). وخـلال القـرن السـابع عشر ضـف مركز البرتغـاليين في آسـيا

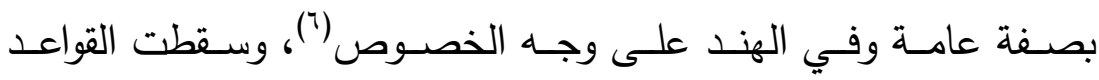
البرتغالية واحدة تلو الأخرى على يـ الهولنديين أولا ثم الإنجليز، مدـا

(1) De Mendonca, Vitor Delio Jacinto, conversions and citizenry goa under Portugal (15101610), New Delhi: 2002, p. 82.

(r) تقع على ساحل جوجيرات Gujarat، عند مدخل خليج كامباي Cambay على بعد • 11 ميلاً تقريبا شمال بومباي،

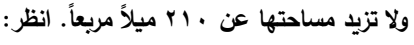

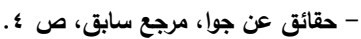

(r) عبارة عن جزيرة صغيرة لا تتجاوز مساحتها ؛ ؛ ميلاً مربعاً، يفصلها عن أرض الهند ممر بحري ضيق. انظر :

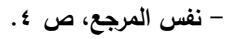

(4) Prabhakar, Peter Wilson, Wars, Proxy-wars and Terrorism: Post Independent India, New Delhi: Mittal Publication, 2003, p. 35.

${ }^{(5)}$ Lach, Donald Frederick, Asia in the Making of Europe, Vol.1, the Century of Discovery, Chicago: the University of Chicago Press, 1965, p. 520.

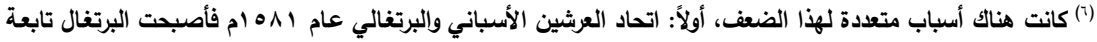

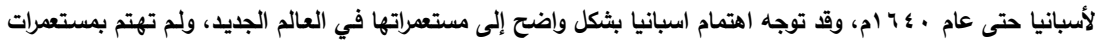

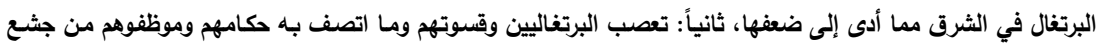

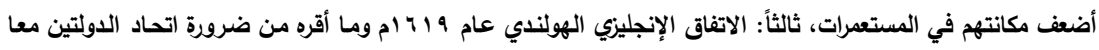

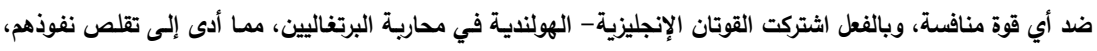

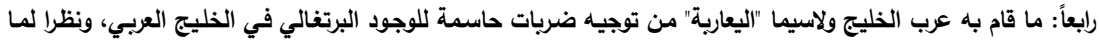

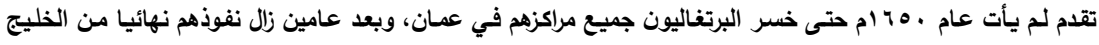
العربي. انظر. - العيد عادل حسين، مرجع سابق، ص NV. 
اضطر البرتغاليين إلى اللجوء إلى الإنجليز طلبا للعون، وتُعبِر المعاهدة

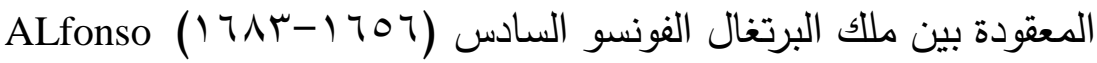

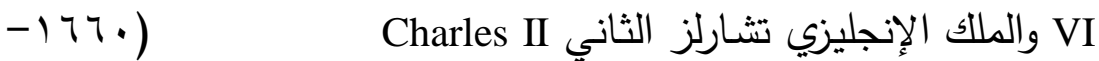
011 ( ) في الثالث والعشرين من يونيو (77 (م عن معالم ذلك الضعف؛ إذ تتازلت البرتغال بموجب المعاهدة المذكورة لإنجلترا عن بومباي في الهند و طنجة في شمال المغرب، مقابل دفاع الإنجليز عن رعايا ملك البرتغـال ومسـاعدتهم وحمـايتهم (')، وكذللك أسـهمت الحـرب الهولنديـة

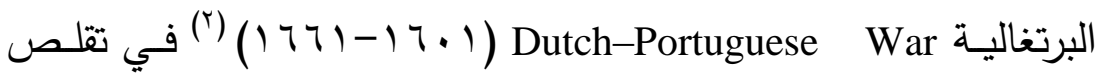
النفوذ البرتغالي في آسيا بشكل واضـح، وفقدانها لمستعمراتها واحدة تلو

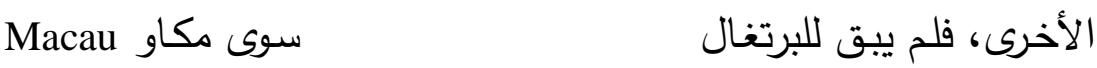

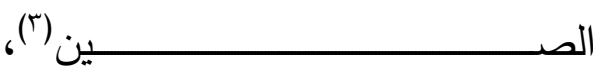

وجزيرة تيمور الشرقية East Timor (؛)، إلى جانب مستعدراتها في الهند (')

(') كانت المعاهدة المذكورة ثمرة زواج الملك الإنجليزي تثارلز الثاني من أخت ملك البرتغال كاترين Catherine دوقة

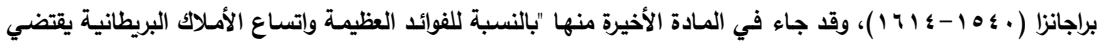

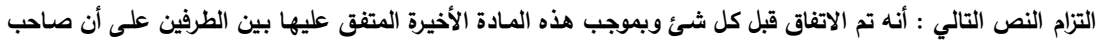

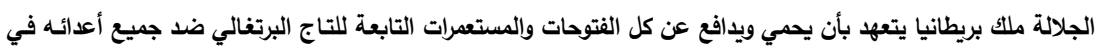

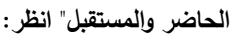

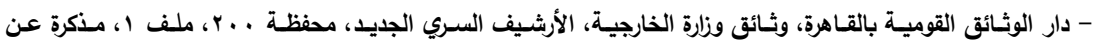

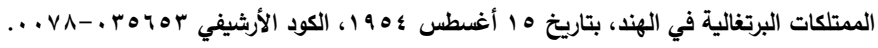

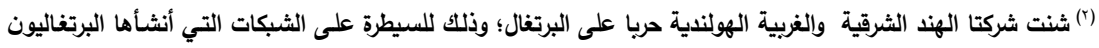

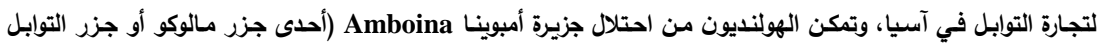

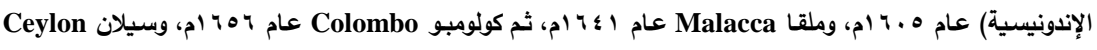

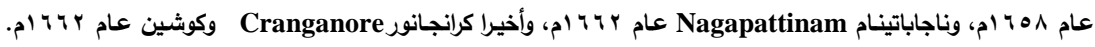

- Russell-Wood, A.J.R., op.cit., p. 24.

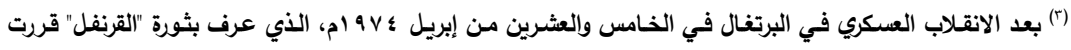

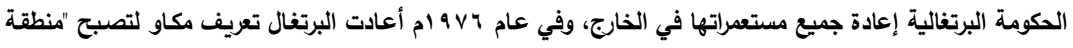

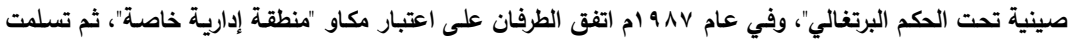

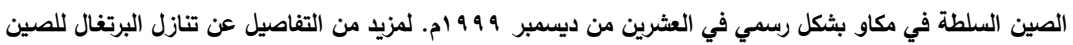
-"Macau and the end of empire", BBC News Online, news.bbc.co.uk, (21 April 2015). عن مكاو. انظر:

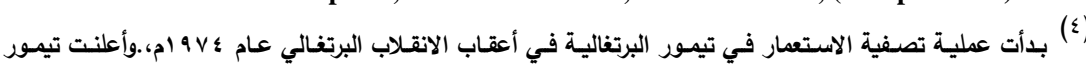

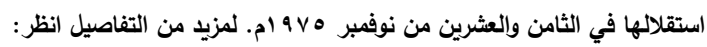




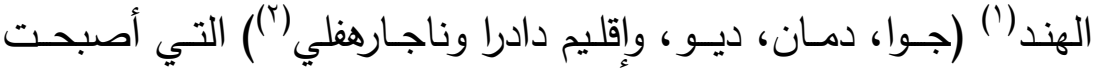

رمزاً للعظمة البرتغالية في آسيا (r).

ا ـ الخلفية التاريخية للنزاع حول المستعمرات البرتغالية في الهند.

عمد الفونس دي البوكيرك إلى تشجيع الزواج المختلط كوسيلة

لـدمج البرتغـاليين مـع سـكان المستعمرات، واسـتمر هـذا الوضـع خـلال

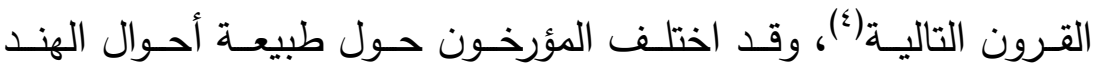

البرتغالية قبل بدء النزاع بين الهند والبرتغال عام 90 (م، فهنالك من يرى أن سكان الهند البرتغالية قد نعموا بحياة مستقرة، وحرصت البرتغال على صبغهم بالصبغة البرتغالية، وأن البرتغاليين نظروا إلى "جوا" على أنها مقاطعة خارج البلد الأم، ومُثِلت في البرلمـان البرتغالي، كمـا أن بعض الجوين عملوا كموظفين في الحكومة البرتغالية ()، في حين يرى آخرون أن سكان المستعمرات البرتغالية في الهند لاقوا نفس المعاملة التي يعامل

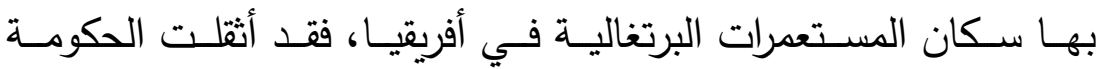
الاســعماريـة كـاهلهم بالضــرائب، وصــادرت فـي كثيـر مـن الأحيـان ممتلكـاتهم، وحـرمتهم مـن حقهم في إدارة شـئون بلادهـم، كمـا مارســ

- Chinkin, Christine, "The East Timor Case (Portugal v. Australia)", The International and Comparative Law Quarterly, Vol. 45, No. 3 (Jul. 1996), p. 715.

(1) انظر : خريطة رقم (1) التي توضح موقع المستعمرات البرتغالية في الهند.

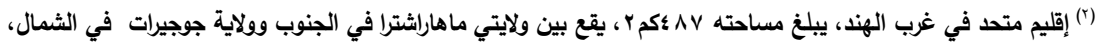

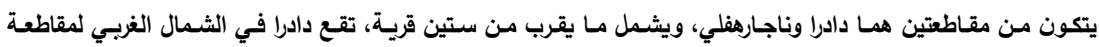

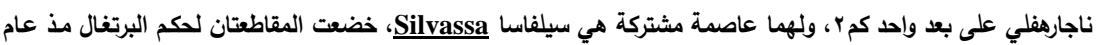

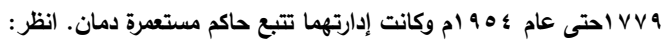
- Wanmali, Sudhir Vyankatesh, "Dadra and Nagar Haveli", Encyclopædia Britannica, www.britannica.com, (21 July 2015).

(r) وثائق وزارة الخارجية، الأرشيف السري الجديد، محفظة . . ץ، ملف ا، بحث في النزاع البرتغالي الهندي حول الممتلكات البرتغالية في الهند.

(\$) لمزيد من التفاصيل حول الاستعمار الرسمي وغير الرسمي البرتغالي انظر:

-Newitt, Malyn, "Formal and Informal Empire in the History of Portuguese Expansion", Portuguese Studies, Vol. 17, (2001), pp. 1-7.

${ }^{(5)}$ B. E. H. F., "Goa and the Indian Union: Background of the Recent Dispute", The World Today, Vol. 10, No. 12 (Dec., 1954), pp. 543-545. 
سياسة دينية متعصبة؛ فقد غالوا في التبشير بالمسيحية، واتخذوا إجراءات متشددة لتحويل الهندوس إلى الكاثوليكية'('). ويمكن ترجيح الرأي الثاني والدليل على ذلك؛ الثوليه الثورات المتعددة

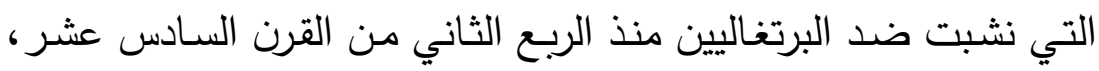

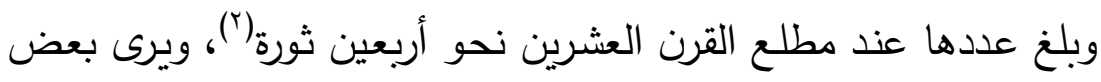

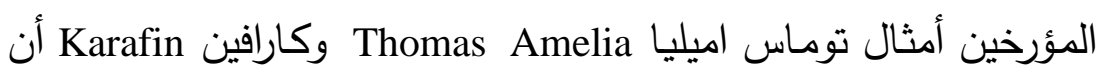
هذه الثورات لم تتمكن من إحداث تغيير ذي معنى؛ لعدم وجود قاعدة

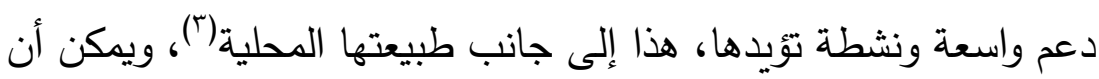

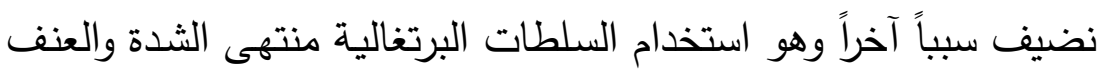
في إخمـاد تلك الثورات، وهـو مـا عبر عنـه بعض الكتاب البرتغاليين أنفسهم مثل كونها ريفيرا

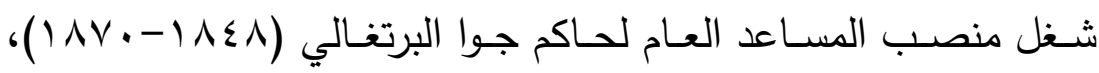

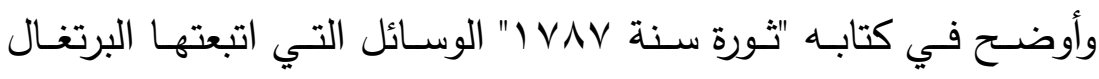

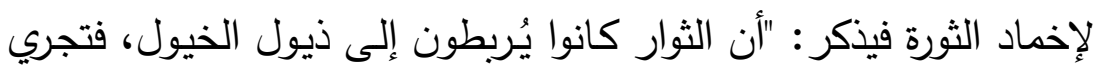

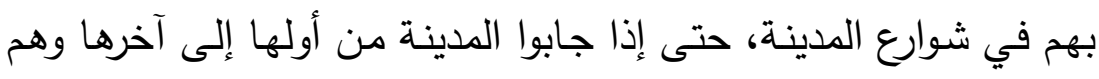

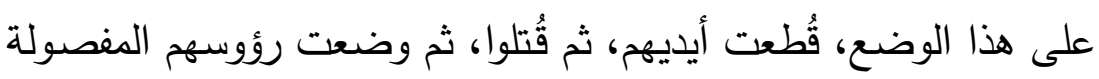
عن أجسادهم على أعمدة مقامة في الأماكن العامة..." (؛).

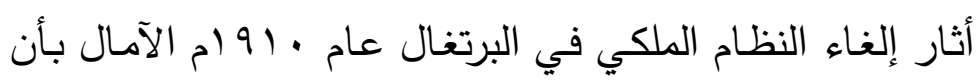

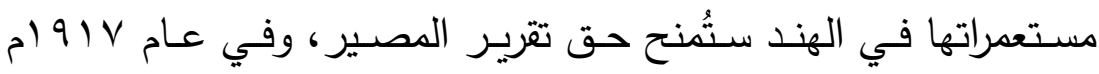

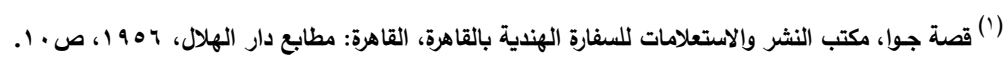

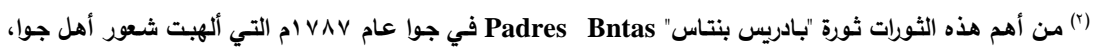

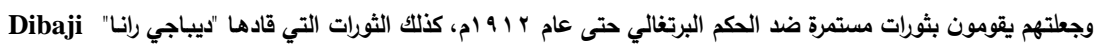
Rana

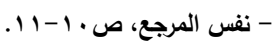
${ }^{(3)}$ Amelia, Thomas and Amy, Karafin, Goa and Mumbai, New York: Lonely Planet Publication, 2009, p. 45. 
مُنِحت المستعرات الحكم الذاتي، وعلى إثر ذلك تكون في "جوا" المجلس الاستشاري الذي عرف بـ Conselho do Governo، وعينت الحكومـة البرتغالية جزءاً من أعضائه إلى جانب عشرة ممثلين منتخبين من سكان

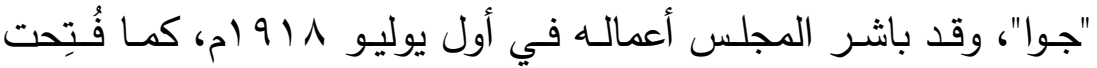

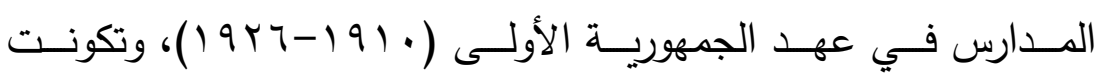
الجمعيات الأهلية، وأُصدِرت الصحف، وفُتِّت المكتبات، مما أثر بشكل

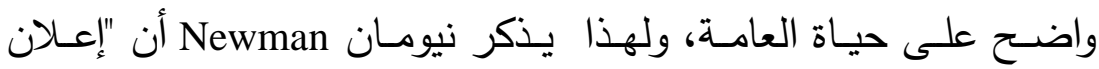

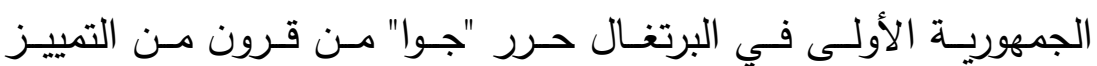

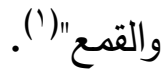

لكن اضطراب الأوضاع في ظل الجمهورية الأولى (r) أثر بشكل واضـح على الوضـع السياسي في المستعمرات البرتغالية في الهند؛ فقد

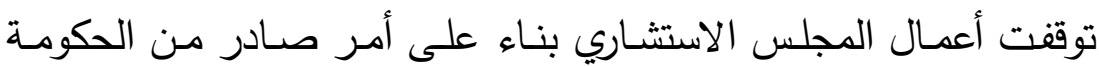

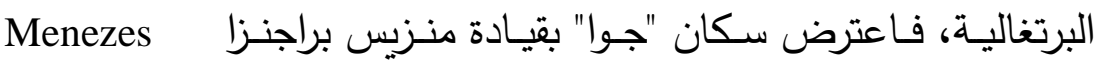

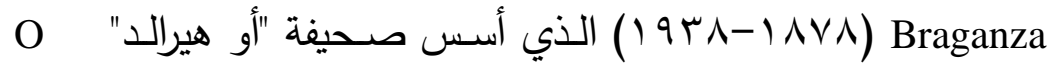
كأول صحيفة تصدر باللغة البرتغالية في "جوا" تتتقد الاستعمار البرتغالي، وفي ردود فعل عنيفة على المعارضـة المتزايدة نفذت الحكومة لئه البرتغاليـة مجموعـة مـن السياسـات تهدف إلى تقليص الحريـات المدنيـة

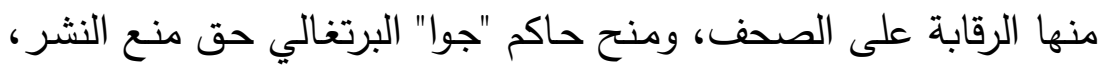
وإغلاق المطابع، وفرضت غرامات باهظة على الصحف التي رفضت الامتثال لهذه السياسة، ولهذا نظم منزيس براجنزا في مدينة "مارجاو "(")

(1) Newman, Robert S., "Goa: The Transformation of an Indian Region",_Pacific Affairs, Vol. 57, No. 3 (Autumn, 1984), p. 340.

(r) خلال السنوات الست عشرة كانت هناكت ثمانية رؤسـاء للجمهوريـة، وشُكِلت أربعة وأربعين وزارة، لـ تدم أول حكومـة جمهورية أكثر من عشرة أسابيع. لمزيد من التفاصيل انظر : -Derrick, Michael; Stove R.J., The Portugal of Salazar, (New York: 1938), pp. 38-44. 
Margao المعارضــة، وعجـز الحكومـة البرتغاليـة عـن كبح جماحهـا، اضـطرت الحكومة إلى منح سكان "جوا" بعض الحقوق التي يتمتع بها البرتغاليون الأصـليون (r)، فعـاود مجلس "جوا" أعماله عـام ، ب 9 (م، وأُعيد تســيته بالمجلس التشريعي Conselho legislativo وظل معمولاً به حتى سقوط الجمهورية الأولى في الثامن والعشرين من مايو جب 9 ("r).

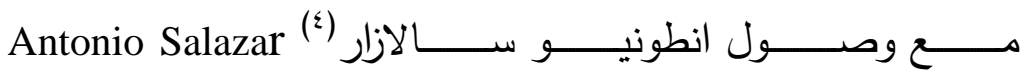

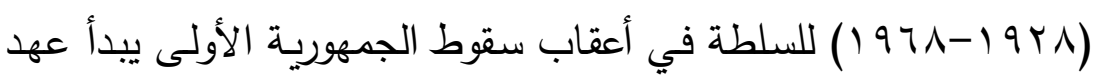
جديـد في علاقـة البرتغـال بمسـتعمراتها الخارجيـة، فقـد أصـدر "قـانون المسـتعرات" في الثـامن مسن يوليـو ، بو ام، الذي نس على: "بنـاء العلاقــة بـين البرتغــال ومسـتعمراتها علـى أســاس الوحــدة الكاملــة والتضامن" (ْ)، ثم أدخل هذا القانون في نص الدستور البرتغالي الذي أُقِرَ في التاسع عشر من مارس سبو (م (")، كما أصدرت الحكومة البرتغالية

(1) Janaka Perera, "Goa's liberation and Sri Lanka's crisis", Asian Tribune, www.asiantribune.com, (18 December 2006).

${ }^{(2)}$ Sakshena, R.n., Goa: into the Mainstream, New Delhi: Abhinav Publications, 2003, p. 28. (3) Prabhakar, Peter Wilson, op.cit., p. 36.

(ई) عمل سالازار أستاذاً لعلم الاقتصاد في جامعة كومبيرا Comibera ، وخبيرا في الثئون المالية، اهتم بالواقع المحيط به فئ

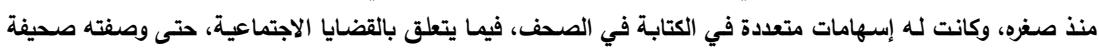
Local Press

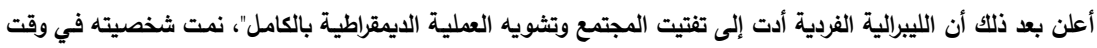

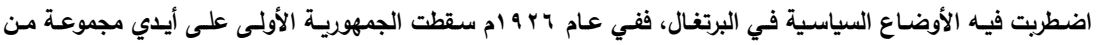

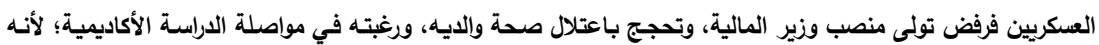

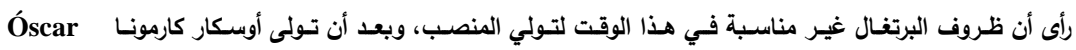

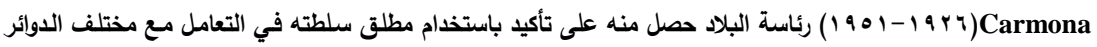

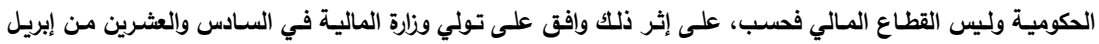

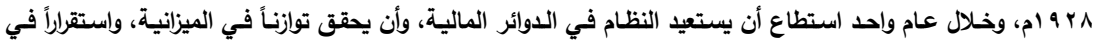

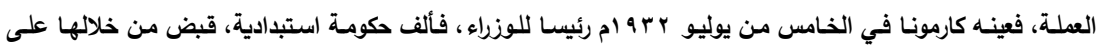

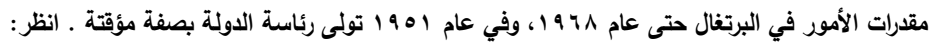
- Kay, Hugh, Salazar and Modern Portugal, (New York: Hawthorn Books, 1970), pp.22-32; Wiarda, Howard J., Corporatism and Development: The Portuguese Experience, (University of Massachusetts Press: 1977), p. 94.

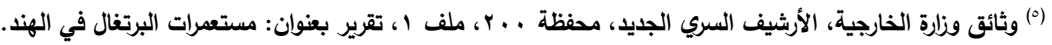


في العام نفسه قراراً بعدم اعتبار أملاكها الخارجية مستعمرات بل "أقاليم"

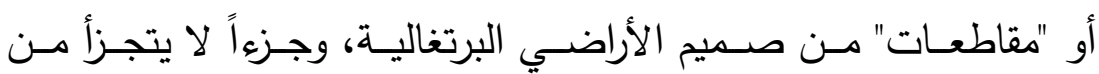
أراضيها مثلها في ذلك مثل الجزه الذي تقوم فيه البرتغال في شبة جزيرة أيبيريا، وأطلقت عليها اسم "أقاليم ما وراء البحار "(')، وأوضح سالازار في أكثر من مناسبة أن القومية البرتغالية لا تعتمد على البرتغاليين فقط، وأن القانون البرتغـالي "لن يسـح بـأي تمييز على أسـاس العرق"؛ لذا أحكم قبضـته على الهنـد البرتغاليـة، فنفـذ سياسـة التجنيـد الإجبـاري، ومنـع المظـاهرات، وقيـد الاجتماعـات السياسـية(؟)، فقـد كـان اسـتقرار نظــام سـالازار - على حد قـول بعض المـؤرخين - قائمـا على قــع الحقوق الإنسـانية، وكبت الحريـات(َ)، ممـا سـاهم بشكل واضـح في زيـادة موجـة الاستياء ضد الحكومة البرتغالية. ونظـرا لأن حركات التحرر مـن الاستعمار اكتسبت زخمـا في الإمبراطوريات الأوروبية بعد الحرب العالمية الثانية؛ فقد طالب حزب

في عام بr 9 ام طرح سالازار دستورا جليدا، وافق عليه البرتغاليون في استفتاء شكلي، أقر في البلاد حكومة غير برلمانية

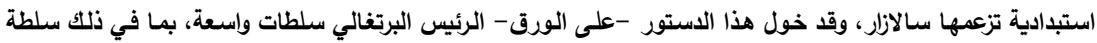

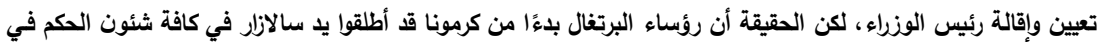
- Kay, op.cit., p. 49.

${ }^{(3)}$ Kay, op.cit., p. 55. 
المؤتمر الـوطني الهندي .Indian National Congress (') بإنهاء

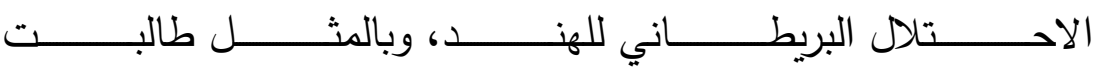

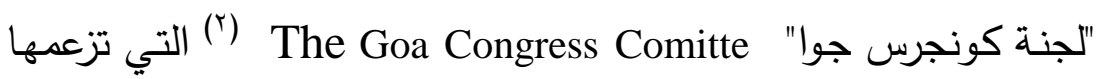
Tristao de Braganza Cunha تريسـتاو براجنـزا كونهـ (901-1991 (901) بنفس المطلب بالنسبة للاستعمار البرتغالي، ونظمت

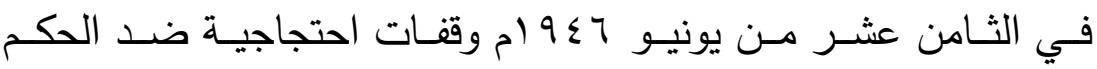

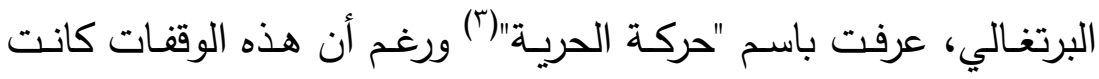

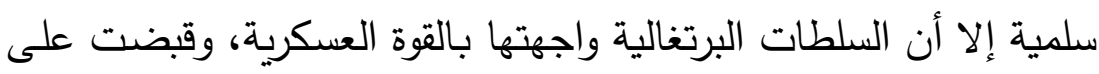

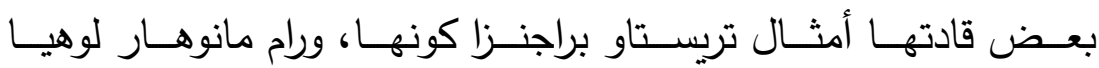
Ram Manohar Lohia

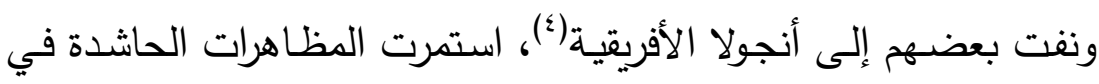

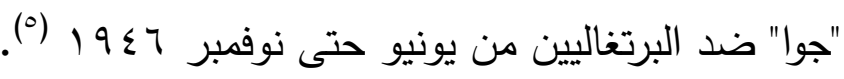

(1) يسمى غالبا باسم الكونجرس Congress، وهو أحد أقدم الأحزاب السياسية، تأسس عام ه1 ام أثناء الاستعمار

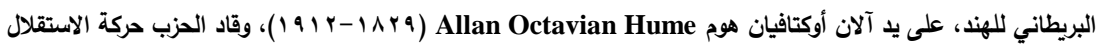

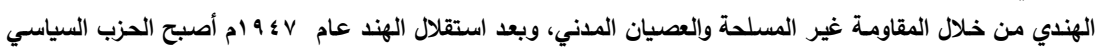

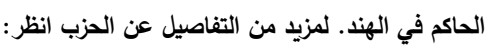
- Bevir, Mark, "Theosophy and the Origins of the Indian National Congress", International Journal of Hindu Studies, Vol. 7, (January 2003), pp.13-17.

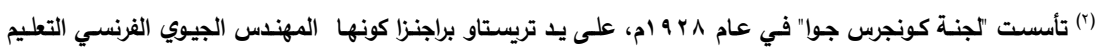

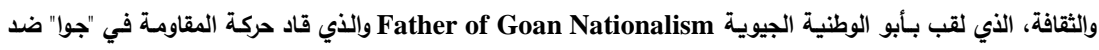

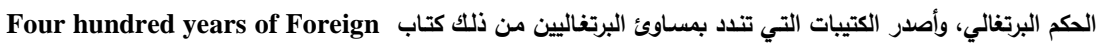
Rule

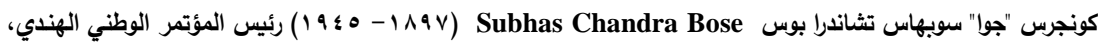

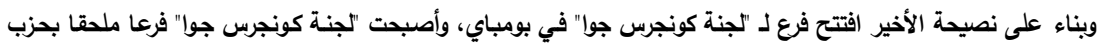
المؤتمر الوطني الهندي. انظر: - Prof. Frank D'Souza, "FRANKLY SPEAKING, The Collected Writings of Prof. Frank D'Souza, published by the Prof. Frank D'Souza Memorial Committee, Bombay 1987, www.goacom.com, (15 November 2014).

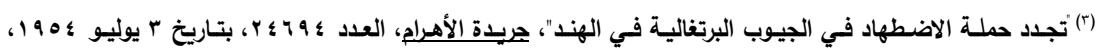

(4) Prabhakar, Peter Wilson, op.cit., p. 37.

${ }^{(5)}$ On Rammanohar Lohia's 99 th Birth anniversary, mainstream weekly, Vol XLVII, No 14, www.mainstreamweekly.net, (21 March, 2009). 
حصلت الهند على استقلالكا من بريطانيا في الخامس عشر من

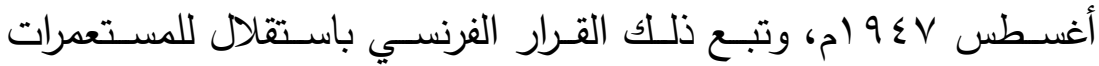
الفرنسية في الهند (')، ممـا هيأ ضنغوطا على البرتغال أن تتتهج نفس وله السياسة، وفي عام 9 9 (م افتتحت حكومة الهند مفوضيتها في لشبونة؛ حتى يســل عليها إجراء مفاوضـات مـع البرتغـال تتتهي بتسـوية عاجلة لمسألة المستعمرات البرتغالية في الهند، وبعثت بأولى مذكراتها في هذا

Paulo Cunha الموضـوع إلـى وزيـر خارجيـة البرتغـال بـاولو كونهـا

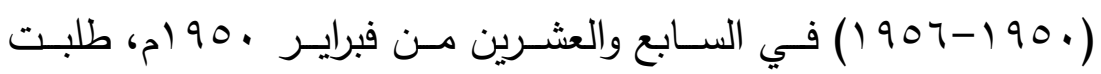
الحكومة الهندية فيها من الحكومة البرتغالية فتح باب المفاوضـات حول مستقبل هذه المستعدرات()، ولكن سـالازار رفض المبدأ ذاته، وأكد أن أراضي البرتغال في شبة القارة الهندية "ليست مستعمرات ولكنها جزء من الأراضـي البرتغالية لا يمكن التتازل عنها بحال من الأحوال، فمواطنو الهند البرتغالية، مثلهم مثل البرتغاليين يتحدثون نفس اللغة ويدينون بنفس الديانة، ويجري في عروقهم نفس الدم، وهم على قدم المساواة مع سكان

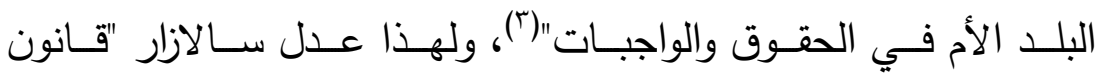
المسـتعمرات" عـام 901 (م بحيـث جعـل "أقـاليم مـا وراء البحسار أقاليم برتغالية تتمتع بالاستقلال الذاتي والإداري طبقا لموقعها الجغرافي وحالتها

(1) فسر الساسة الفرنسيون أن سبب تنازل فرنسا عن مستعمراتها في الهند هو "انتشار الوعي القومي في الهند وخصوصا

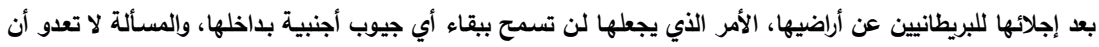

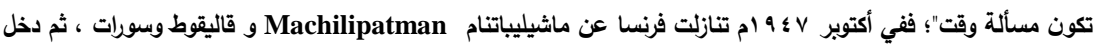

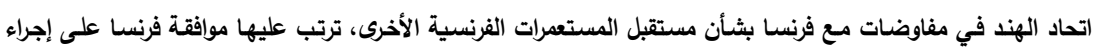

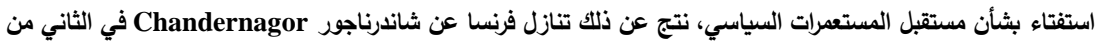

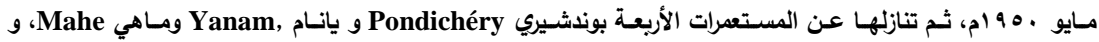

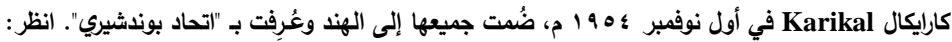
-V. Sankaran, "Freedom struggle in Pondicherry", Government of India, www.pib.nic.in , (15 April 2015).

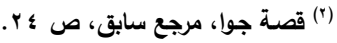

(3) Luthera, Ved Prakash, "Goa and the Portuguese Republic", The Indian Journal of Political Science, Vol. 17, No. 3 (July-September 1956), p. 262. 
الاجتماعية"(')، ويمكن القول بأن تمسك البرتغال بمستعمراتها في الهند كان في نظر سالازار السبيل الأول للحفاظ على مستعمراتها في أفريقيا وبخاصة في أنجولا وموزمبيق.

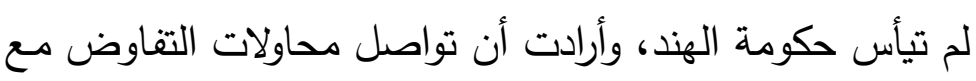

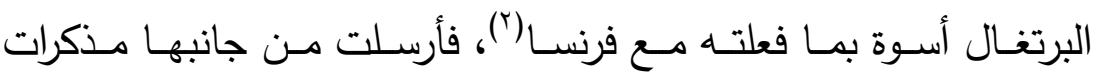

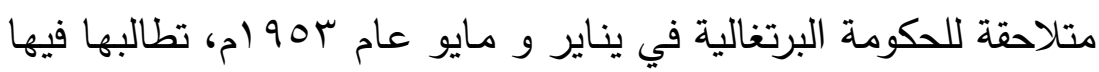
من جديد بعودة المستعمرات البرتغالية إلى اتحاد الهند، فرفضت البـائ البرتغال

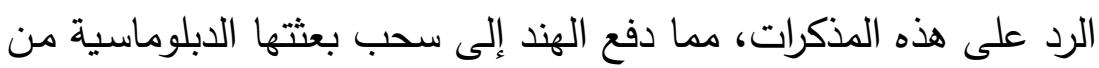

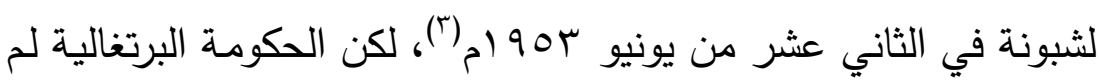

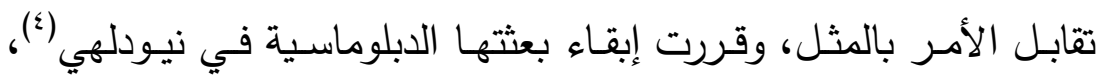

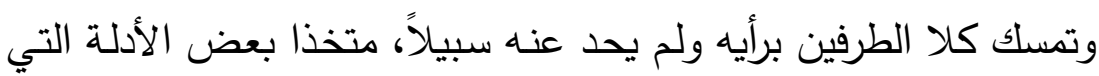

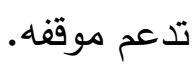

يتضح من مطالعة التصريحات التي أدلي بها ساسـة الهند وزعماؤها

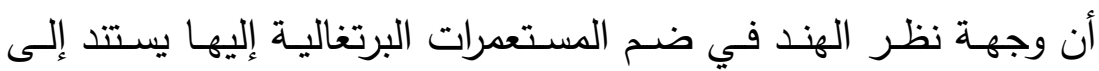
الأسباب الآتية (0)

أولا: تُعد هذه المستعمرات من الناحية الجغرافية جزءاً لا يتجزأ من شبه القارة الهندية. ثانياً: أن وجود هذه المستعمرات داخل الأراضي الهندية تخلق للهند

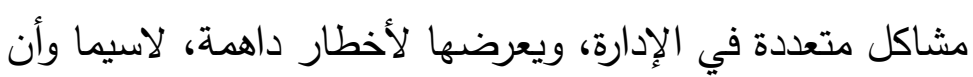

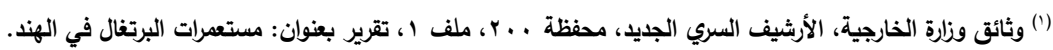

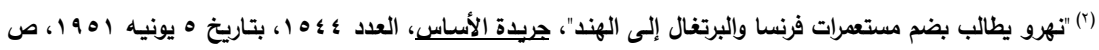
${ }^{(3)}$ E. B, "The Salazar Regime and Goa", The World Today, Vol. 10, No. 9 (Sep., 1954), p. 390.

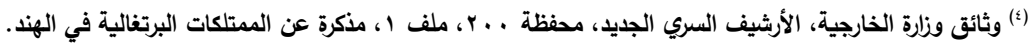

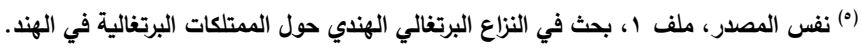


البرتغال عضو في منظمة حلف شمال الأطلنطي Nato، التي قد تتخذ من هذه المستعمرات قواعد حربية.

ثالثا: صعوبة الدفاع عن الهند مي وجود هذه المستعمرات، وتبعيتها إلى سيادة أجنبية.

ويرد البرتغاليون على هذه الأسباب الثلاثة بلسان سالازار رئيس

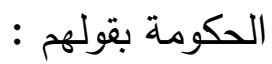

أولاً: أن "الممتلكات البرتغالية" من الوجهة الجغرافية موجودة في شبه

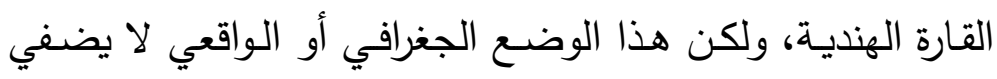

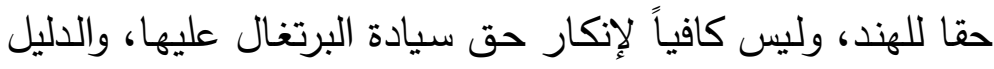
على ذلك الدويلات المتداخلة في أراضي الدول الأوروبية كدوقية لإنية لكسمبرج. ثانيا: فيما يتعلق بصعوبات الإدارة فإن البرتغال مستعدة للتفاوض مع الحكومة الهندية للبحث في تذليلها وإزالتها. ثالثا: من غير المعقول أن تخشى الهند من هذه المقاطعات الصغيرة، لتهات والتهات

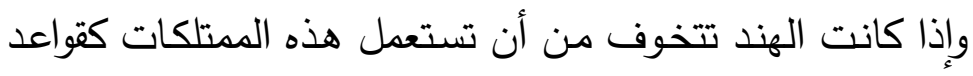
عسكرية لقوات أجنبية، وهو ما يخالف سياسة الحياد التي تقفها الهند بين الكتلتين الشرقية والغربية، فإن البرتغال على استعداد

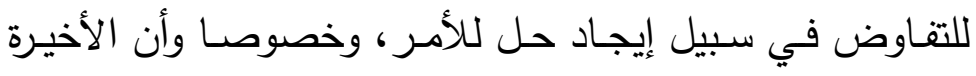

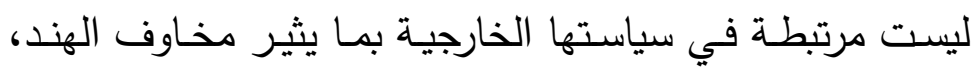

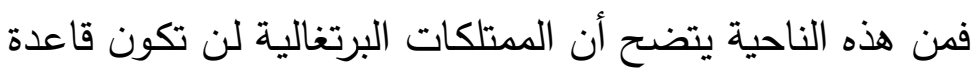
أعمال عدائية ضد الهند ('). لابعاً: يشير البرتغاليون أن اتحاد الهند لا يرمي إلى منح الحكم الذاتي

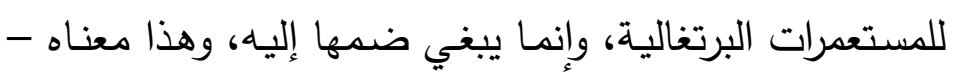


من وجهة نظرهم - أن تحكم دولة أجنبية شعبا برتغالياً له تقاليد في الحياة ترجع إلى أربعة قرون، بحجة الجوار وكبر الإقليم، وهذا كاف لإظهار الأساس الواهي لموقف الهند، وأن الحديث عن التحرر من الاستعمار لا محل له في هذه الحالة('). وقد حرصت البرتغال على نشر هذه المبررات التي تستند إليها في أحقيتها لملكية تلك المستعمرات، كما أكدت في أكثر من مناسبة أن العالم المسيحي على رأسه الفاتيكان يقف بجانبه؛؛ لأن "جوا" تعد مركز الإشـعاع الأول لنشر التعاليم الكاثوليكية في الشـرق الأقصسى، وأن شـارة البابا مكونة من مشعلين على كل منهما حجر كريم، أحدهما كبير يمثل

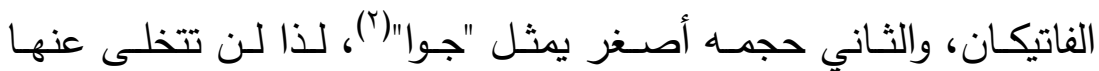
البرتغال بأي حال، وقامت الإدارة العامـة للممتلكات البرتغالية فيما وراء البحار بإصـدار نشـرات وكتيبات تصـور فيها أحوال هذه الأقاليم، ومـا تبذله حكومة البرتغال من جهد للنهوض بمستواها، والمعاملة التي يتلقاهـا مواطنوها على أيدي رجال الإدارة البرتغالية، ومـا إلى ذلك من تفاصيل الغرض منها تبرير موقف البرتغال من حكومة الهند، وتمسكها

بهذه المستعمرات(ّ)، وأمام إصرار كل طرف على رأيه، أصبح النزاع بين

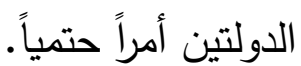

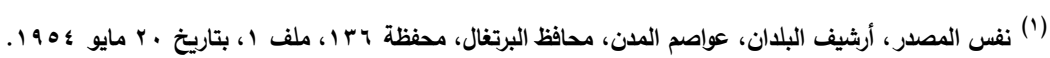

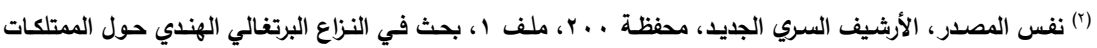

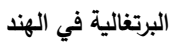
(") من هذه الإصدارات: الكتيب الأول بعنوان "قضية جوا"، الذي يحوي مقتطفات من خطاب سـالازار الذي ألقاه في العاشر الثر

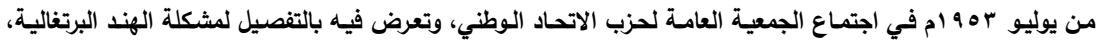

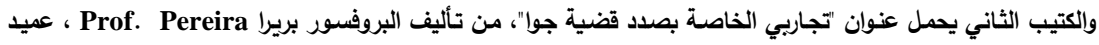

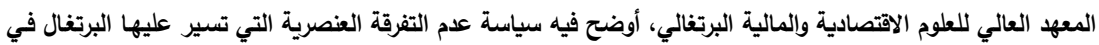

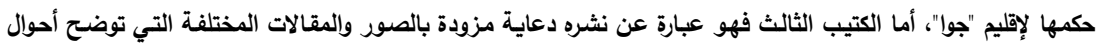

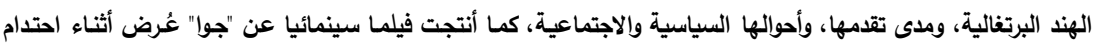

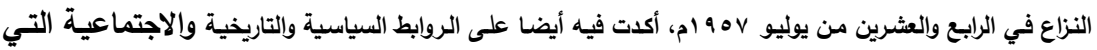


r ـ مراحل النزاع الهندي البرتغالي حول المستعمرات:

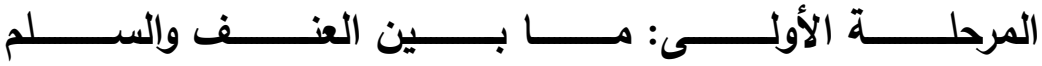

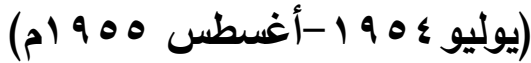

في هذه المرحلة من مراحل النزاع يظهر نوعان من المقاومـة، كل

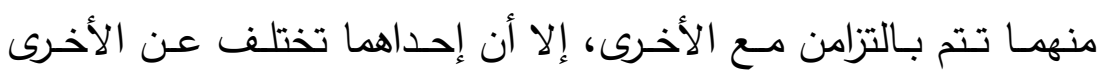

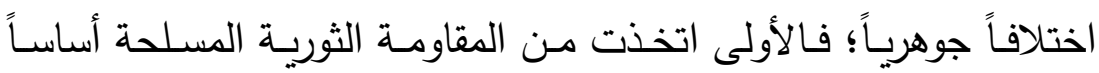

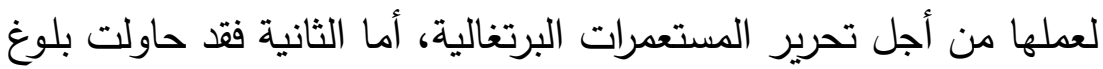

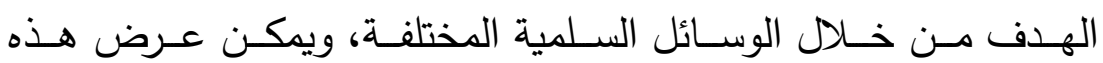

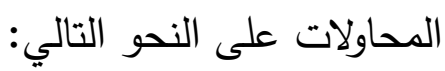
أ. محاولات الاسترداد المسلحة (إسقاط إقليم دادرا وناجارهفلي) حرصـت المنظمـات الهنديـة المسـلحة المعاديـة للاسـتعمار على إنى التكاتف من أجل إسقاط السيادة البرتغالية على بعض الأراضي الهندية،

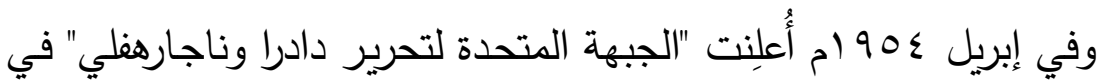

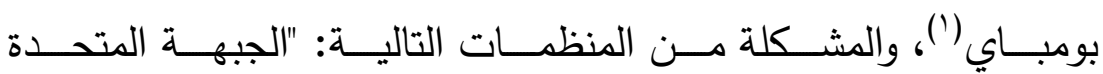
للجويين"(†) (U) United Front of Goans) ، "منظمة حركة التحرير ، الوطني" (NMLO) National Movement Liberation Organization "راشتريا سوايا مسيفاك سانغ"(") Rashtriya Swayamsevak Sangh"

تربط البرتغال بأرضيها فيمـا وراء البحار، ودعت وزارة الخارجية البرتغالية السلك السياسي الأجنبي

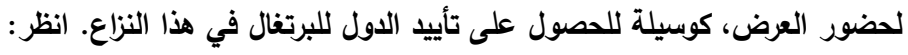

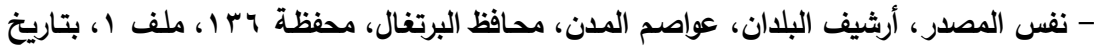

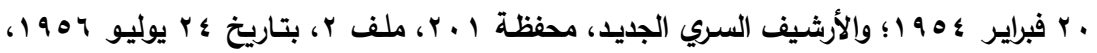

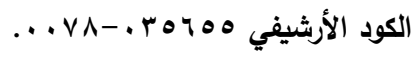

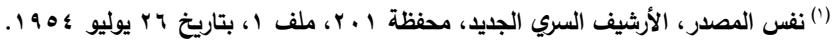

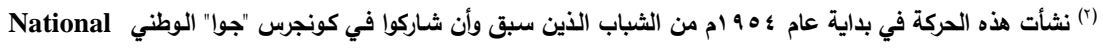
Congress of Goa -Prabhakar, Peter Wilson, op.cit., p. 37.

(م) راشتريا سوايا مسيفاك سانغ: تسمى ايضا Rashtriya Seva Sangh راشتريا سيفا سانغ وتغني بالهندية منظمة

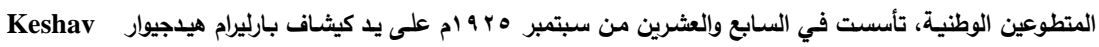
Baliram Hedgewar 


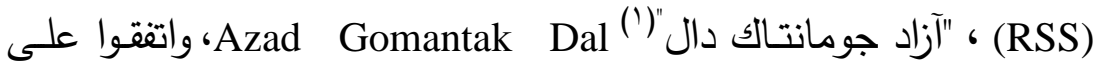
العمل المشترك، وأرسلوا من جانبهم بعض المتطوعين لزيـارة إقليم "دادرا وناجارهفلي" ، للتعرف على طبيعة أراضيه، وتحقيق أفضل سبل التواصل مع العمال والقادة المحليين في الإقليم المنادين بالتخلص من الاستعمار

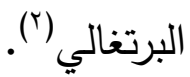

بادر خمسة وثلاثون متطوعاً من متطوعي "الجبهة المتحدة للجويين" في مساء الثاني والعشرين من يوليو 90 ام بالهجوم على مركز شرطة مقاطعـة دادرا، فحدث اشتبالك بينهم وبين البرتغـاليين، أسفر عنـه مقتل اثثين من قوات الشرطة البرتغالية، وأصيب ثلاثة منهم بجراح بالغة (ّ)، ونظراً لمـا كان عليه المتطوعون مسن الحماسـة والقوة، انهارت المقاومـة البرتغاليـة سريعا، وسقطت المقاطعة في أيديهم خـلال سـاعات معدودة، وفي صباح اليوم التالي رُفََ العلم الهندي على المقاطعة، وأعلنت "الجبهة المتحدة لتحرير دادرا وناجارهفلي" تحرير مقاطعة دادرا (؛)، ومن جانبها أصدرت الحكومة البرتغالية في اليوم نفسه بياناً رسمياً أوضحت فيه أن

الثغب بين الهندوس والمسلمين، وكان من أهم المبادئ التي قامت عليها الكفاح ضد الاستعمار بكل أنواعه، وشـارك

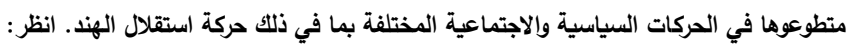
- Encyclopedia Britannica, www.britannica.com, (7 June 2015).

(1) مجموعة ثورية حملت على عاتقها مناهضة الحكم البرتغالي في الهند، من خلال ما يسمى باستراتيجية "العمل المباشر"

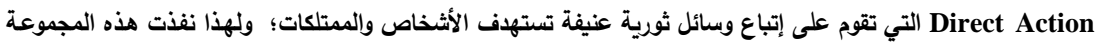

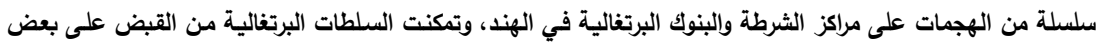

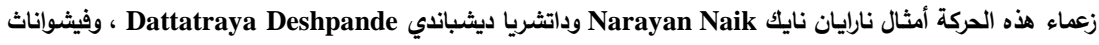

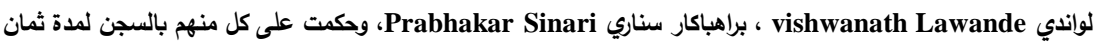

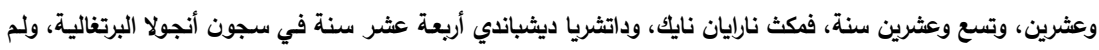

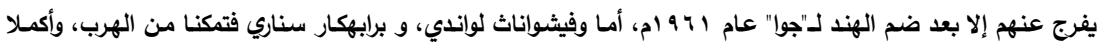

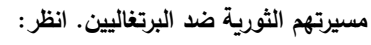

-Prabhakar, Peter Wilson, op.cit., p. 38.

${ }^{(2)}$ Sinari, Prabhakar," A Liberation From Lies", Indian Express, 6 November, 2003, www.countercurrents.org, (7 June 2015).

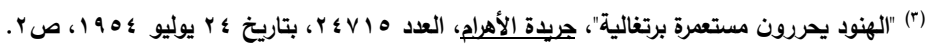
(4) Lele, P S, Dadra and Nagar Haveli: past and present, Published by Usha P. Lele, 1987, p.46. 
إسقاط المقاطعة جاء بسبب ضعف تحصينها؛ إذ كانت تحرسها قوة قليلة من قوات الشرطة، واتهمت الحكومـة الهندية بتأييد هؤلاء "المهاجمين"، ومدهم بالأسلحة التي مكنتهم من إسقاط المقاطعة(') ويمكن القول بأن الحكومة البرتغالية كانت محقة في سبب تفسيرها لسقوط دادرا، إلا أنها لم يثبت أن الحكومـة الهنديـة دعمت المهاجمين للمقاطعـة بالأسلحة؛ لكنها غضت الطرف عما تقوم بـه "الجبهـة المتحدة لتحرير دادرا وناجارهفلي" من أعمال لإسقاط الإقليم.

ولمـا كان إقليم "دادرا وناجـارهفلي" يتكون مـن مستعمرتين غير

سـاحليتين محساطتين بأراضـي الاتحساد الهندي، والتواصـل بينهمـا وبين مستعمرة دمان الساحلية يتم من خلال المرور لمسافة عشرين كم داخل الأراضي الهندية، تقدمت حكومة لشبونة إلى الحكومة الهندية بطلب في مسـاء يـوم الثالث والعشـرين مـن يوليو 90 ام؛ بثـأن السـماح للقوات البرتغالية المسلحة الموجودة في مستعمرة دمان باجتياز الأراضي الهندية والوصول إلى دادرا ()، لكن الحكومة الهندية رفضت ذلك على اعتبار أن هذه المقاطعـة لا تتبـع الاتحـاد الهندي، فاتهمتهـا البرتغـال بأنهـا تمسـك العصا من الوسط لتظهر أمام العالم أنها محبة للسـلام في الوقت الذي الذي سهلت فيه السبيل للمسلحين الهنود من أجل إسقاط المقاطعة(؟).

(1) وثائق وزارة الخارجية، الأرشيف السري الجديد، محفظة . . r، ملف ا ، مذكرة عن الممتلكات البرتغالية في الهند، بتاريخ 10 أغسطس ؛ 190.

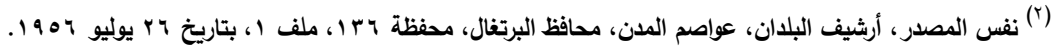

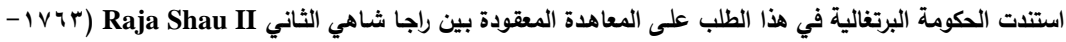

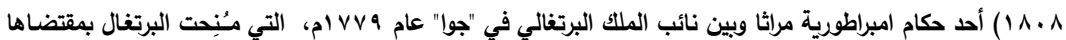

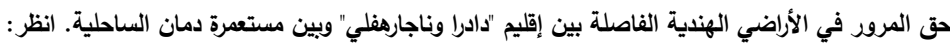

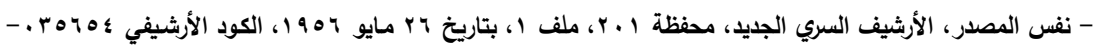
..v 1

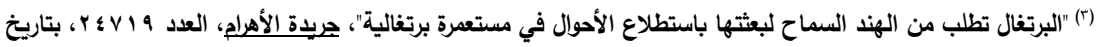

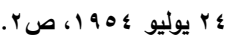
وبعد انضمام البرتغال لهيئة الأمم المتحدة في الرابع عشر من ديسمبر و 900 ام، أسرعت برفع قضية أمسام محكمة العدل

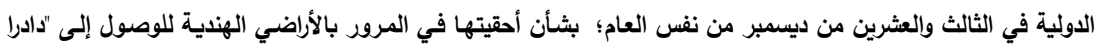


وفي الثامن والعشـرين مسن يوليو 90 ام قـام خمسـة وعشرون

متطوعـاً مـن "راشـتريا سـوايا مسيفاك سـانغ"، وعشرة متطوعون مـن "آزاد جومانتـاك دال" بــالهجوم علـى قريــة نـارولي Naroli فــي مقاطعـة ناجـارهفلي، وأجبروا قوات الثـرطة البرتغاليـة على الاستسـلام، وتسـموا المدينة دون خسائر في الأرواح من الطرفين (')، وفي اليوم التالي أعلنوا تحريرهـا مـن البرتغـاليين (r)، وبعد إسـقاط نـارولي تركزت قوات الشـرطة البرتغاليـة -وعـددهم مـائتي شـرطي - تحــت قيـادة فيرجيليـو فيـدالجو Silvassa في سيلفاسا Virgílio Fidalgo مكن الهنـود مـن إسـاط القرى الخاضـعة للحكم البرتغـالي والخاليـة مـن Piparia المقاومسة، فستطت في أيديهم قريـة لوهـاري Lahory بيباريـا دون مقاومـة تـكر ()؛ لـذا ركز الهنـود هـدفهم على إسـقاط العاصـمة سيلفاسـا؛ فوجهت الحكومـة البرتغالية تعليمات مشددة إلى قوات الشرطة المدافعة عنها بمواجهة الهنود بمنتهى القوة والحزم، والدفاع عن المدينة لآخر رمق (ع).

وناجارهفلي"، واستندت الحكومة البرتغالية في هذا الطلب على المعاهدة سـالفة الذكر، وأن من حقها الحصول على كافة

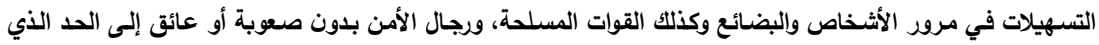
يتطلب مزاولتها الفعلية لسيادتها على هذه الأراضي.

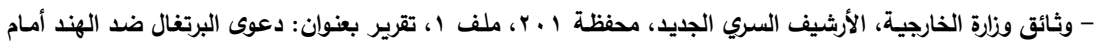

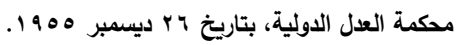

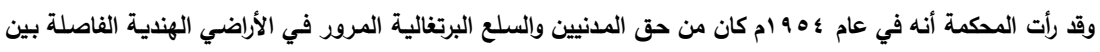

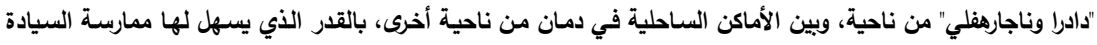

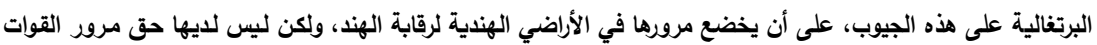

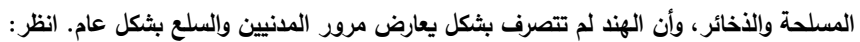
- International Court of Justice, Reports of Judgments, Advisory opinions and orders, "Case Concerning Right of Passage over Indian Territory" (Portugal v. India), Judgment of 12 April 1960, pp. 43-44.

(1) Prabhakar, Peter Wilson, op.cit., p. 39.

(2) Lele, P S, op.cit., p. 57.

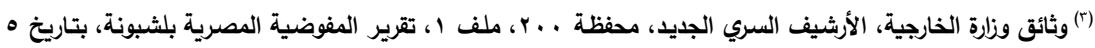


ونظرا لأهمية إسقاط سيلفاسا فقد شارك المتطوعون من "منظمـة

حركة التحرير الوطني"، و "راشتريا سوايامسيفاك سانغ" ، و "آزاد جومانتاك دال" في الهجوم على المدينـة تحت قيادة كارملكار قائد "منظمـة حركـة التحريـر الـوطني"، وطلبـوا مـن فيرجيليو فيدالجو تسـليم المدينة دون قتال، ولمـا لم يبد أيـه استجابة، هـاجموا المدينة من ثلاث جهات في وقت واحد، فلم يكن بوسـع فيرجيليو فيدالجو إلا الهرب مـع مائة وخمسين من قوات الثرطة البرتغالية إلى خانوفيل Khanvel جنوب ناجارهفلي، وفي الثاني من أغسطس ؟0 90 ام سقطت سيلفاسا في أيدي الهنود، دون إراقة للدماء ('). رفـح هــذا النصـر روح الهنـود المعنويـة، ولـــ يكتفـوا بإسـقاط Sinari العاصمة فحسب، بـل تعقب عشرة منهم بقيادة برابهكار سـاري Prabhakar بصعوبة بالغـة عبور نهر "دمـان جانـا" Daman Gana الفاصـل بينين ناجارهفلي وبين خانوفيل، والتقوا بثمانين من قوات الثـرطة البرتغالية، الذي وصفهم سـناري بـأنهم كانوا "سـكارى، محبطين، مـذعورين بشكل مميـت"، فسـطت خانوفيـل في أيـيههم في الثاني عشـر مـن أغسطس ـ 90 ام(؟)، وسـلم الضـباط البرتغـاليون وفي مقدمتهم فيرجيليو فيدالجو أنفسهم إلى قوات التحرير (r)، وهكذا تحرر إقليم "دادرا وناجارهفلي" بكامله من البرتغاليين، واختارت الجبهة المتحدة للتحرير كارملكار حاكما للإقليم

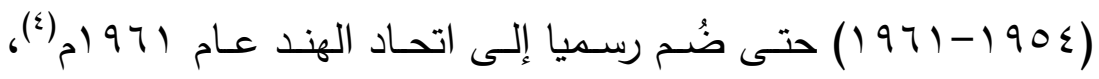
وحينمـا طلبـت الحكومـة البرتغاليـة من الحكومـة الهنديـة إرسـال وفد من

${ }^{(1)}$ Lele, P S, op.cit., p. 58-59. www.countercurrents.org, (7 June 2015).

${ }^{(4)}$ Lele, P S, op.cit., p. 59. 
ثلاثة من البرتغاليين للتحري عن الحالـة في المناطق المحرة، أكدت

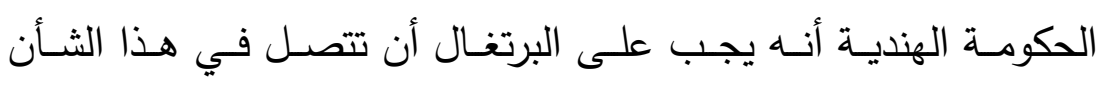

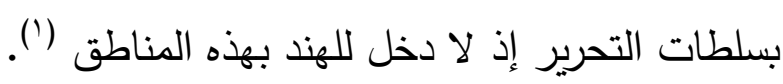
ب. محاولات الاسترداد السلمية

تولى تريستاو براجنزا كونها رئيس "لجنة كونجرس جوا" توحيد جهود

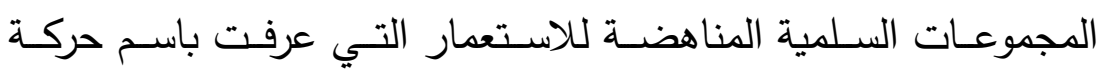

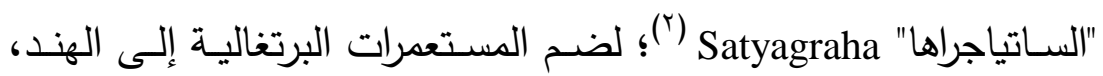
وقد انطلقت هذه الحركة في الأساس من أفكار المهاتما غاندي الذي دعا إلى استرداد المناطق الخاضعة للاستعمار في الهند دون إراقة للدماء، فقد أكد غاندي أن "جوا" لا يمكن أن تظل كيانا منفصلا عن اتحاد الهند،

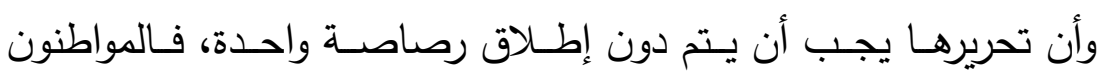

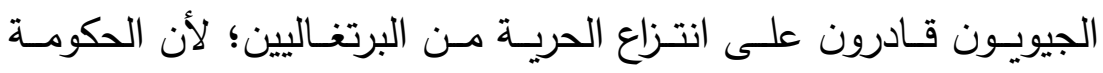

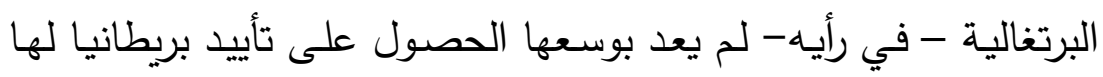

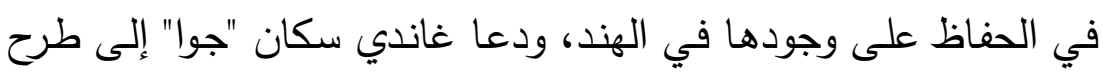

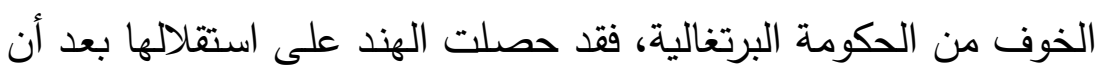

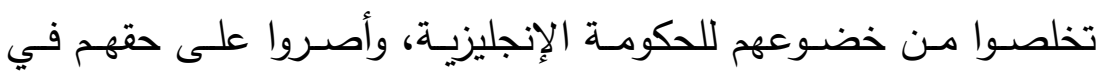
الحرية المدنية(")، ويمكن القول بأن تركيز غاندي في خطابه على أهالي

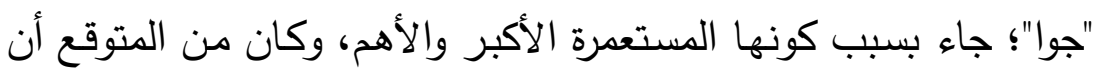
يحمل مواطنوها لواء الثورة ضد البرتغاليين.

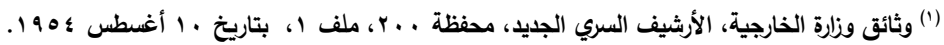

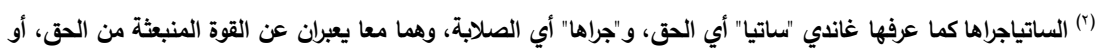

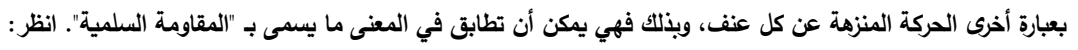

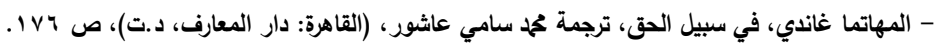
(3) Prabhu, R. K.and Rao, U. R., The Mind of Mahatma Gandhi, Encyclopedia of Gandhi's

Thoughts (Ahmadabad: Jitendra T Desai, 1960), p. 316-317. 
على أية حال حددت جماعات "الساتياجراها" يوم الخامس عشر من أغسطس ع 90 ام (العيد الوطني لتحرير الهند) موعدا للزحف السلمي

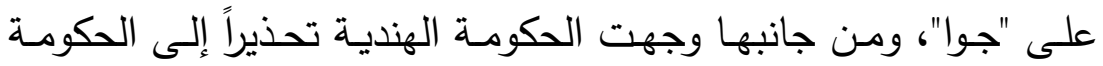
البرتغالية، بأن استعمال القوة في مواجهة الهنود الذين يهدفون إلى تحرير

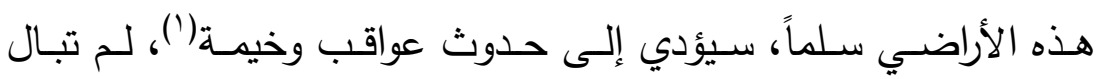

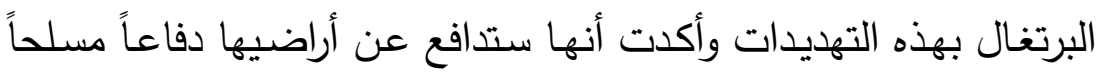
في مواجهة هذا الزحف، وأرسلت إلى مستعمراتها في الهند قوات إضافية

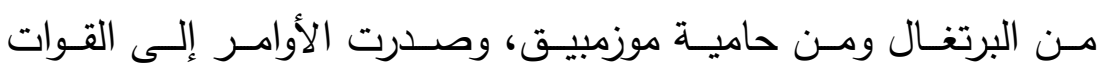

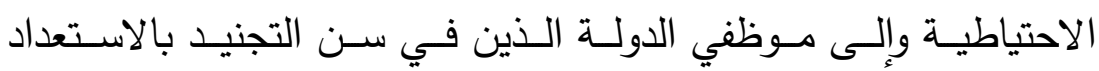

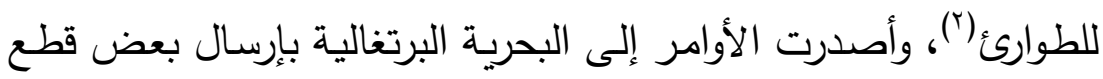

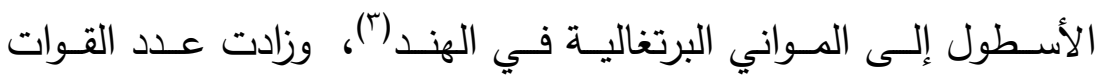

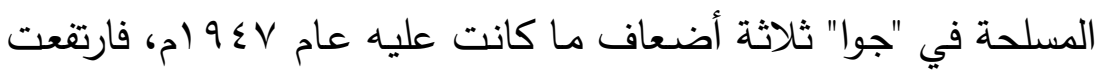
من ألف وخمسمائة إلى خمسة آلاف جندي، كما زيدت قوات الشرطة من

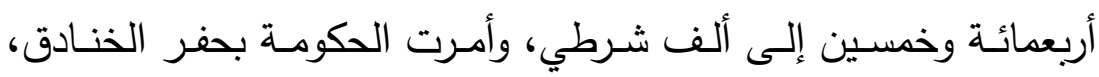

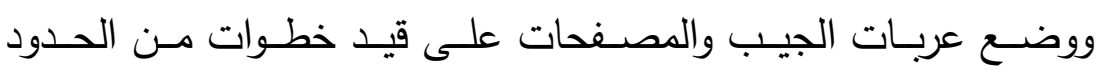

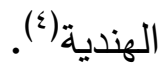

كـذللك فـرض حساكم "جــوا" البرتغــالي بـاولو بينـارد جيـديس (901-190r Paulo Bénard Guedes

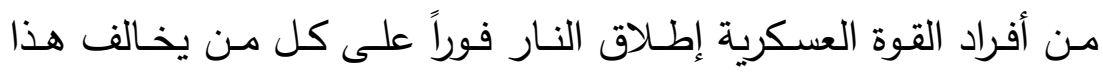

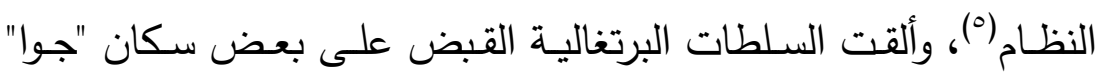

(') وثائق وزارة الخارجية، الأرشيف السري الجديد، محفظة . . ץ، ملف ا ، تقرير المفوضية المصرية بلشبونة، بتاريخ •

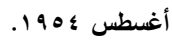

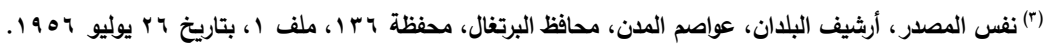

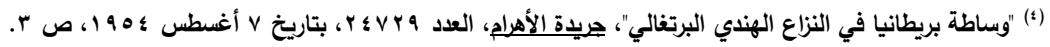




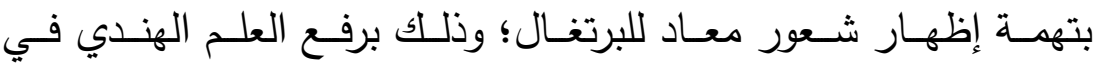

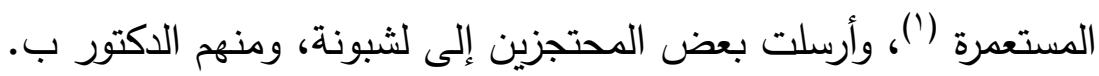

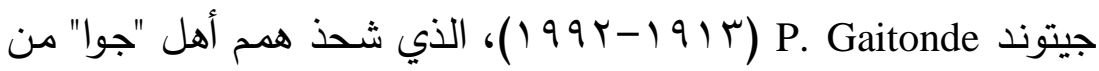

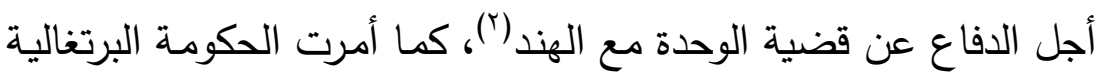

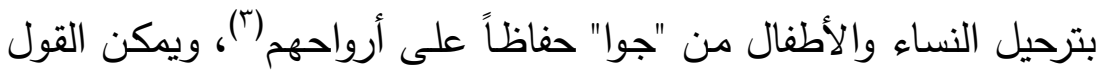

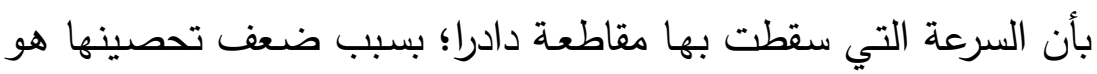
الذي دفع السلطات البرتغالية لتدعيم تحصين "جوا" بهذه الكيفية، فقد كان الحفاظ على هذه المستعمرة الكبرى يعني الحفاظ على الوجود البرتغالي

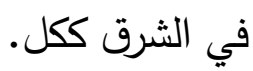

وعلى الرغم مـن الإجـراءات السـابقة للـدفاع عـن "جـوا" إلا أن التقارير الدبلوماسية أوضحت توتر الأحوال في لشبونة بشكل كبير ، وأن الأن

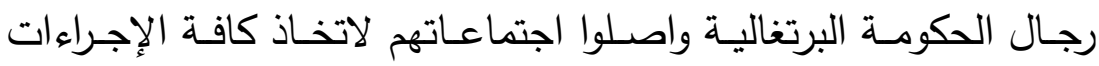

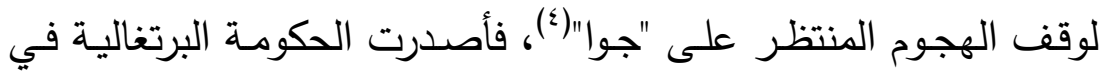
الثلاثين من يوليو عام 90 ام قرارين: الأول: ينص على سحب رجال السلك القنصلي الهندي من "جوا"؛ مشيرة

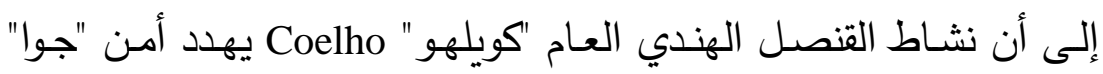

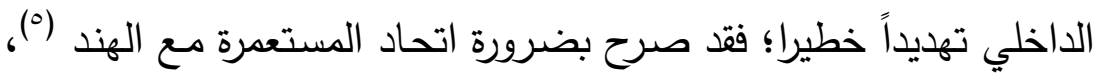
فردت الخارجية الهندية بأن ما أثارته البرتغال بشأن القنصل الهندي العام

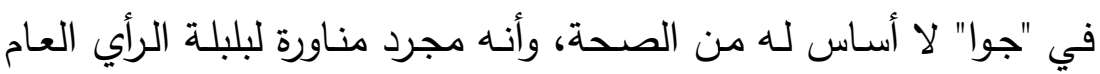

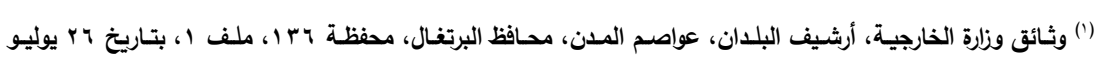


العالمي فيما يتصل بمشكلة المستعمرات البرتغالية في الهند(')، وبالمثل طلبت الهند من القنصل البرتغالي العام اميليو باتريشيو Emilio Patricio ونائبه أنطونيو كارفالهو Antônio Carvalho في بومباي مغادرة الإقليم (؟). الثاني: إلزام السلطات البرتغالية كل هندي يدخل "جوا" اعتبارا من الأول

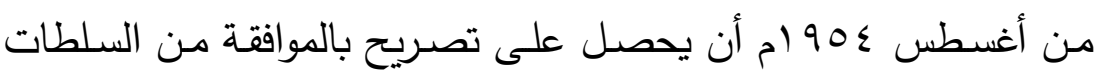
القنصلية البرتغالية (َ).

ومع اقتراب الموعد المحدد لزحف "الساتياجراها"، أمرت السلطات

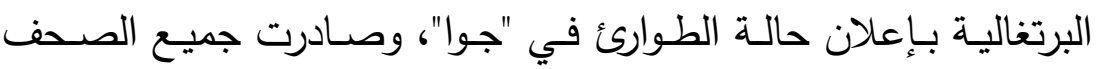
الهندية والأجنبية من المستعمرة، وأمرت بوقف سير القطارات بين "جوا" جهات وهات

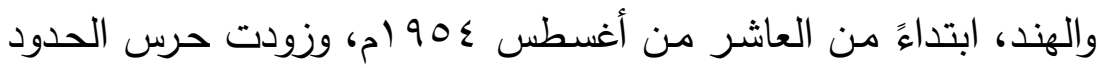
بتعليمات تقضي بإطلاق النـار على كل مـن يحاول عبورها بعد هذا الموعد())، وفي الرابع عشر من أغسطس أحاطت السلطات البرتغالية

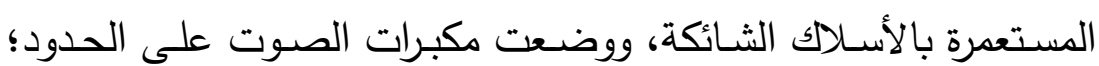
لتحذير المتطوعين من عواقب اقتحام الحدود عنوة(').

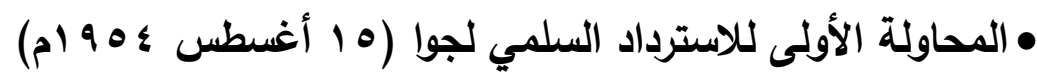

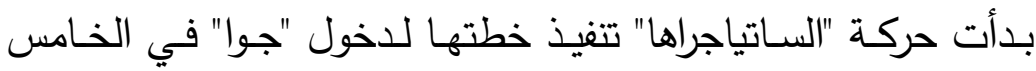

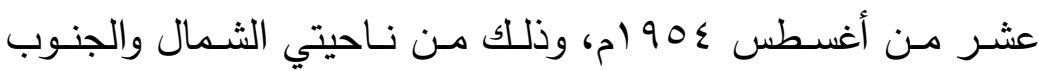

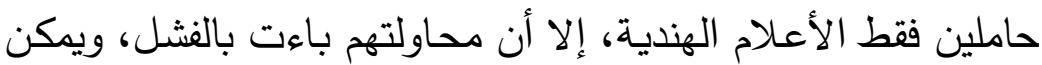
تفسير ذلك في ضوء العوامل الآتية:

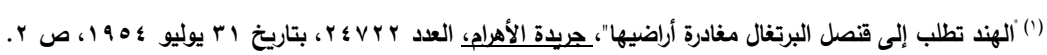

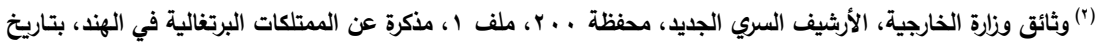

10 190 1 أغسطس 190

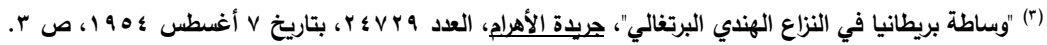

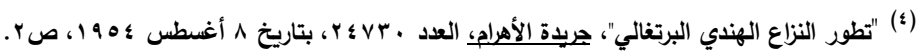

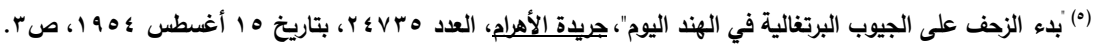


1. قلة عدد المتطوعين وتمسكهم بالغزو السلمي: فقد عبر تسعة عشر متطوعاً الحدود الجنوبية لمستعمرة "جوا" عند "بولم" Polem وقطعوا خمسة أميال في قلب "جوا"، كما عبر اثنا عشر متطوعا المستعمرة عند "تورسل" Torsel في الثمال، فتصدى لهم البوليس البرتغالي،

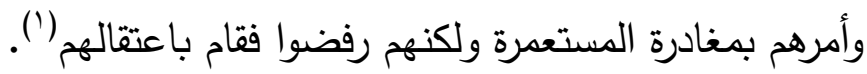

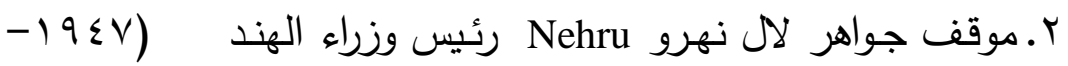
ع 9 ( ))، وأمره للبوليس الهندي بعدم السماح لغير الجويين بدخول

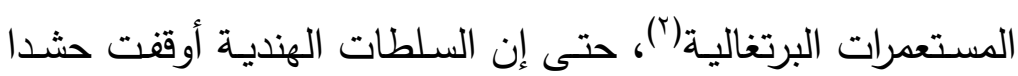

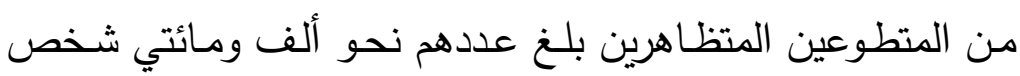

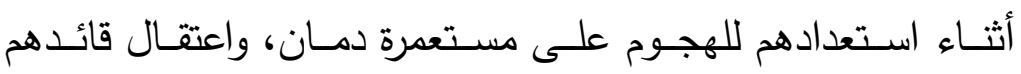
الاشتراكي الهندي لال ديساي Desai (")، وأمام ذلك طالب بعض ده

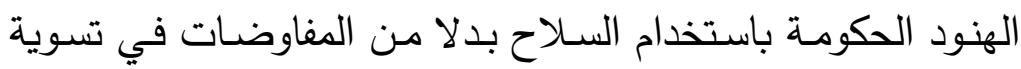

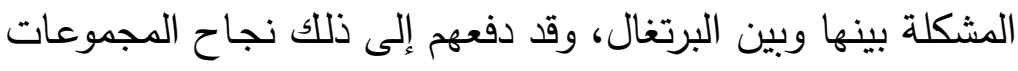

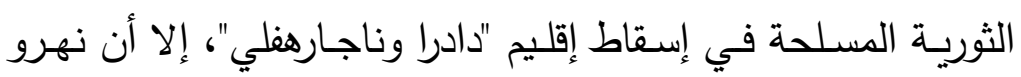

فضل الحلول السلمية، والتحكيم الدولي (๕). • عرض النزاع على التحكيم الدولي

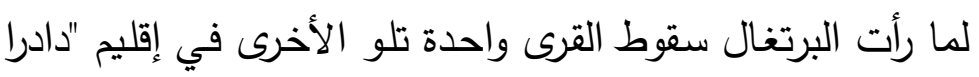
وناجارهفلي"، وبعد سقوط سيلفاسـا عاصمة الإقليم، بادرت البرتغال في

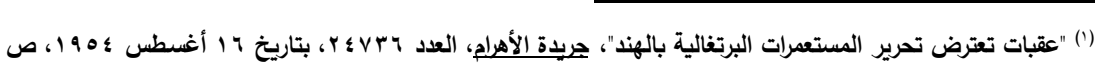

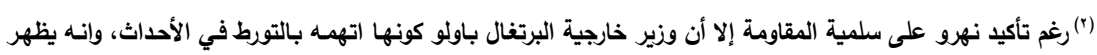

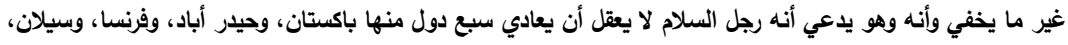

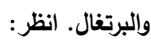

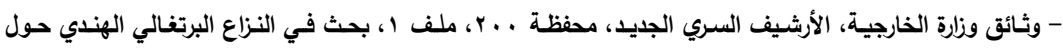
الممتلكات البرتغالية في الهند.

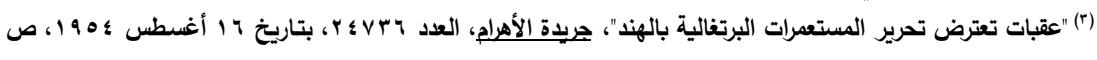

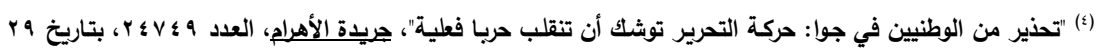


الثامن من أغسطس ؟0 9 ام باقتراح عرض النزاع بينها وبين الهند على التى

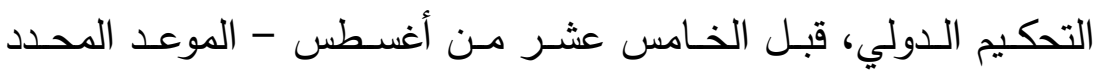
للزحف على "جوا"- على أن تتكون لجنة للتحقيق المحايد من ست دول،

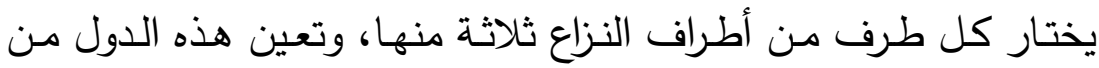

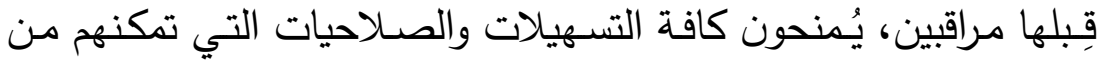
إجراء تحقيق شامل في النزاع القائم، ودراسة الحالة القائمة في المناطق

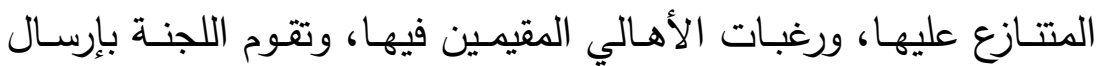
تقارير عاجلة؛ تنشر عن نتائج ملاحظاتهم ودراستهم للنزاع المذكور (')

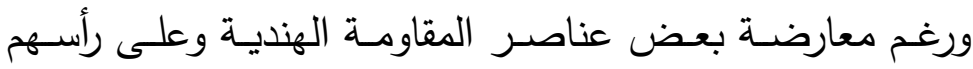

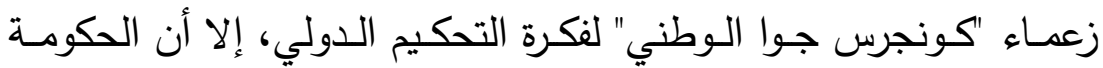
الهندية وافقت على إجراء تحقيق محايد في النزاع، لكنها طالبت البرتغال

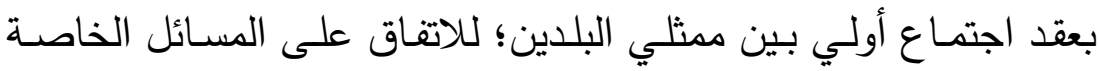

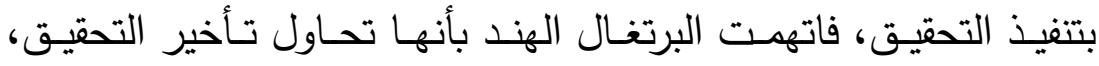

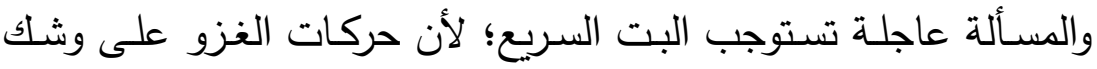
التنفيذ(ب)

لكـن سـرعان مــا تغيـر موقـف البرتغــال بعـــــــــل محاولــة

"الساتياجراها" في اقتحام "جوا" في الخامس عشر من أغسطس عـ 90 (م،

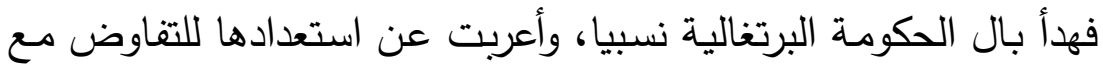

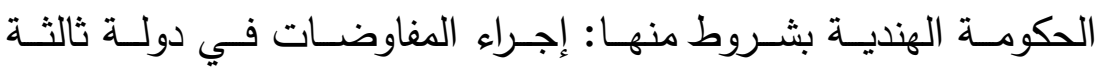

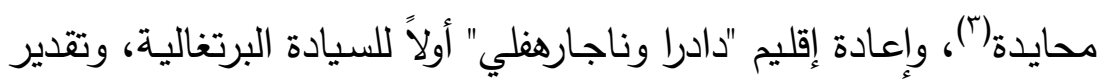
حسن الجـوار ، ومــا يتطلبـه ذلــك مـن إعـادة فـتح الحسدود، وتسـهيل

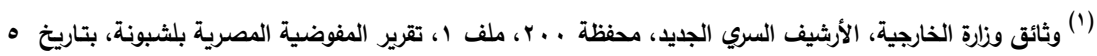
أغسطس 190 أغ 190

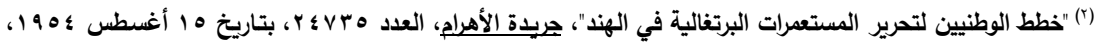


المواصـلات ورفـع الحصـار الذي فرضـته الهند على هذا الإقليم، كمـا

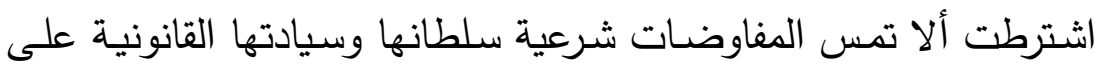
المستعمرات موضـع النزاع، ورفض إجراء أي استفتاء؛ لأن قبولها مبدأ

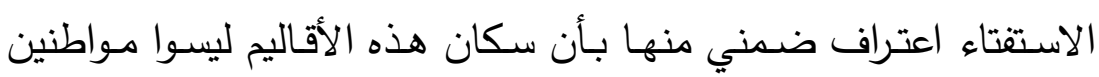

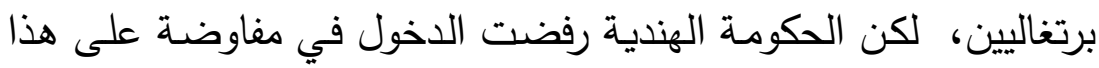
الأسـاس(')، ولعل تغير موقف البرتغال جاء من منطلق شعورها بالقوة، وقدرتها على كبح جماح حركة الاسترداد السلمي.

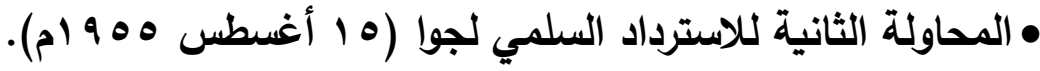

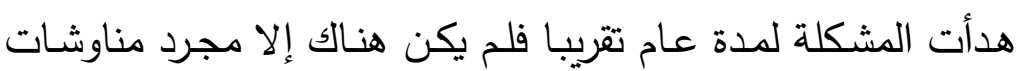

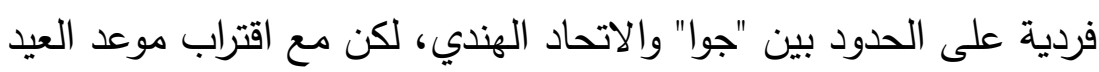
الوطني لتحرير الهند طالب الحزب الثـيوعي الهندي الحكومـة باتخـاذ إجراء حاسم لضم المستعمرات البرتغالية، ولو كان هذا الإجراء مشوباً

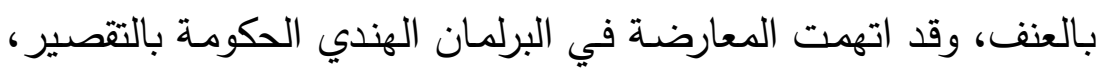
وأمام تلك الضغوط أكد نهرو أنه لا يميل إلى العنف، ولا يشجع الأعمال

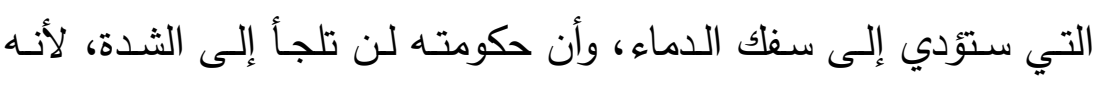

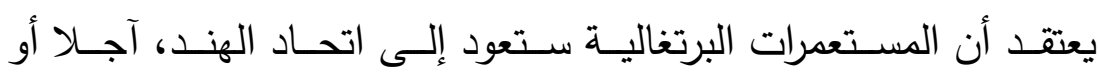

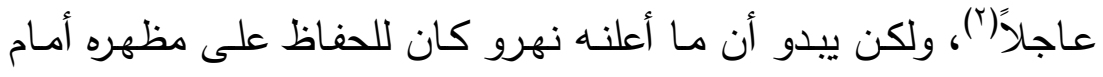

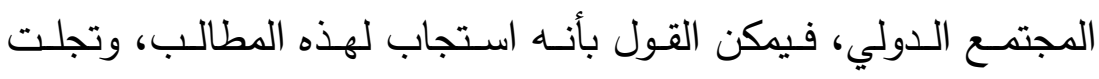

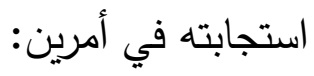

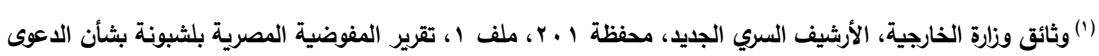


الأول: طلب الحكومـة الهنديـة في السـادس والعشرين من يوليو 1900

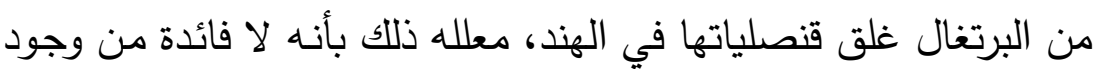
هذه الجهة التمثيلية والخلاف بلغ أشده بين الدولتين ('). الثاني: دعوة أعضاء حزب الكونجرس الحاكم جميع الهنود وتحرضيهم على غزو "جوا" غزوا سلميا، فاستجابت كافة الأحزاب والهيئات الهندية

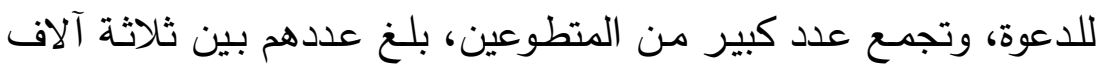

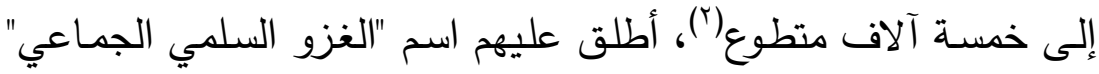
Mass Satyagraha

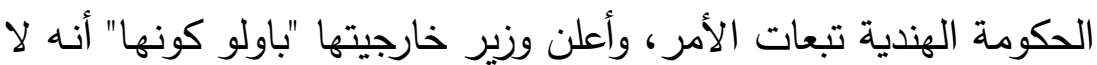
يوجد في القانون الدولي مـا يسـى بـالاحتلال السلمي، وأن الهنود إذا لها

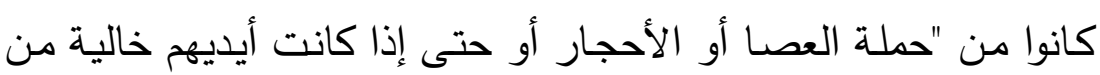
كل ما يؤذي أو يضر ، فإن مجرد اختراقهم الحدود هو اعتداء صارخ" (").

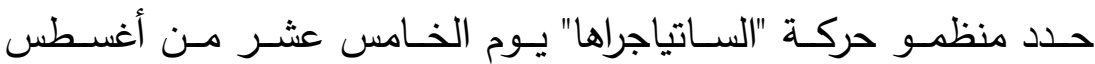

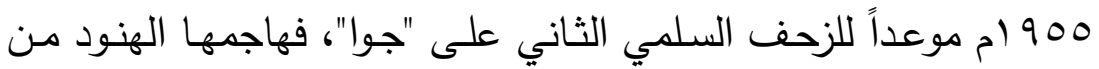
ستة مواقع، وكانت تصطحبهم بعض السيدات المتطوعات، وقاموا برفع الأعـلام الهنديـة على الأراضـي البرتغاليـة، فأنـذرتهم الشـرطة البرتغاليـة

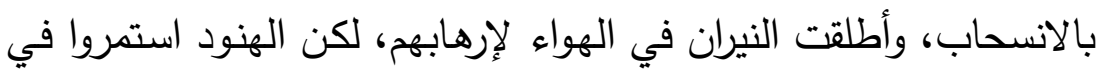

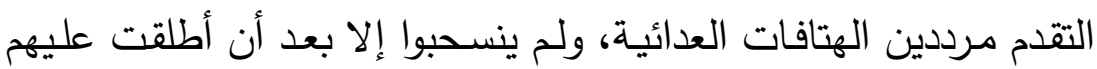

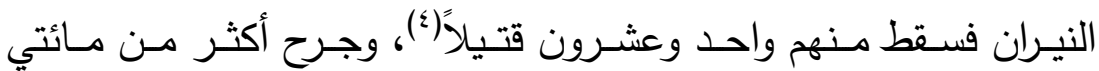

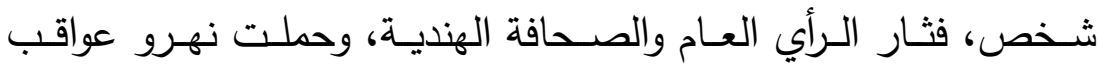

(1) وثائق وزارة الخارجية، الأرشيف السري الجديد، محفظة ... r، ملف 1، ،ترير سفارة مصر بالهند عن التطورات الأخيرة

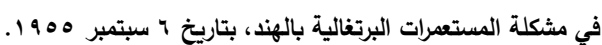

${ }^{(2)}$ Ghose, Sankar, Jawaharlal Nehru: A biography. Mumbai: Allied. Published, 1993, p.282.

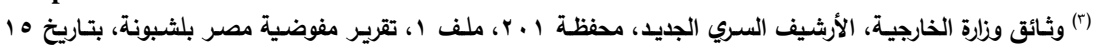

4 "Indian Volunteers Invade Goa; 21 Die; Unarmed Indians March into Goa", Times, 15 August 1955. 
الموقف وأنه رغم تشجيعه للساتياجراها على التقدم بشكل غير مباشر إلا

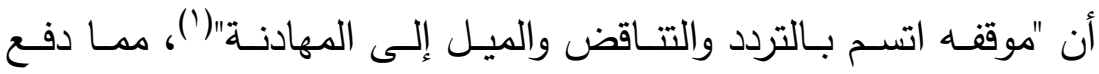

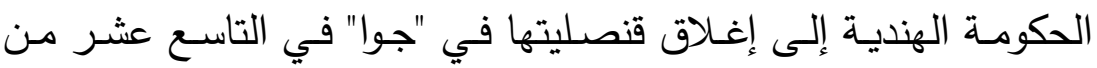
أغسطس 900 (م، كمـا أغلقت قنصليات البرتغال في بومباي وكلاكتا

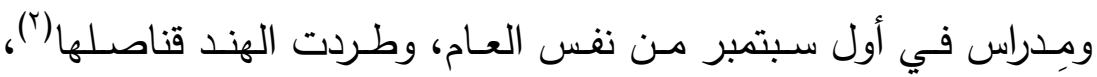
وهكذا قطعت العلاقات القنصلية كما قطعت العلاقات الدبلوماسية من قبل عام سه 90 (")، وبادر نهرو بفرض سياسة الحصار الاقتصادي. فرض الحصار الاقتصادي على المستعمرات البرتغالية في الهند

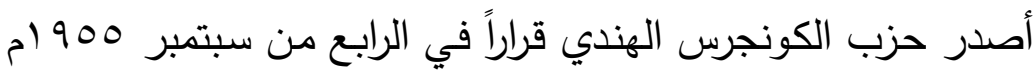

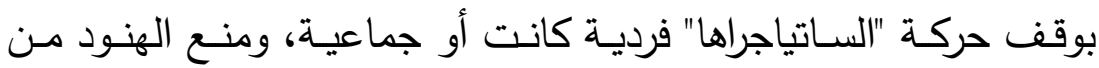
اقتحام حدود المستعمرات البرتغالية، وإقامـة حراسـة شديدة عليها، وترك

1 "India Force and Soul Force", Times of India, 29 August 1955.

(†) وثائق وزارة الخارجية، الأرشيف السري الجديد، محفظة . . †، ملف ا ، تقرير سفارة مصر بالهند عن التطورات الأخيرة

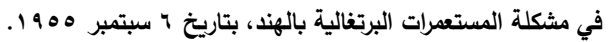

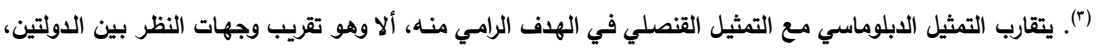

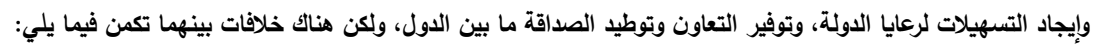

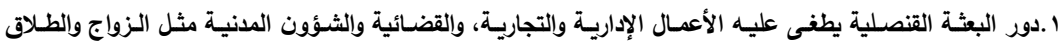

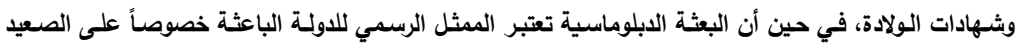
السياسي والخارجي.

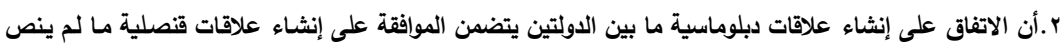

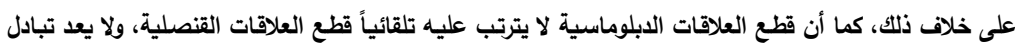

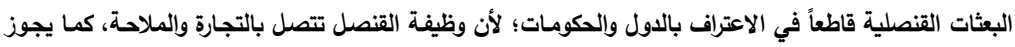

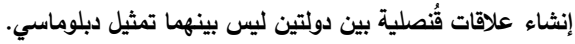

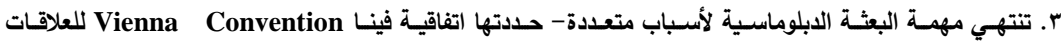

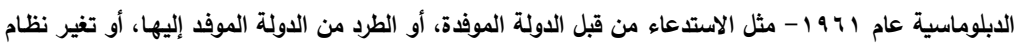

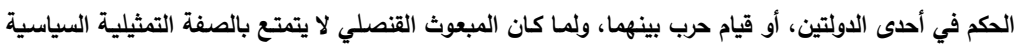

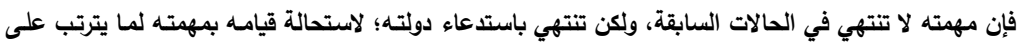

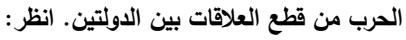
-Vienna Convention on Diplomatic Relations 1961, United Nations Treaty Collection, www.treaties.un.org, (28 November 2015). 
أمـر تحريـر المسـتعمرات البرتغاليـة لأهلهـا، واسـتبدال سياسـة الحصــار

الاقتصادي بسياسة الغزو السلمي لإنهاك قوة المستعمرات (').

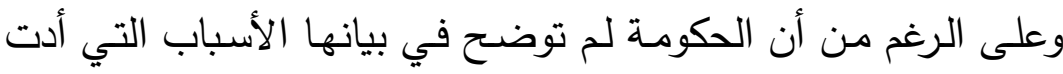

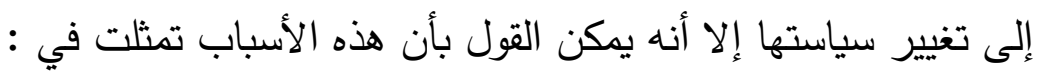

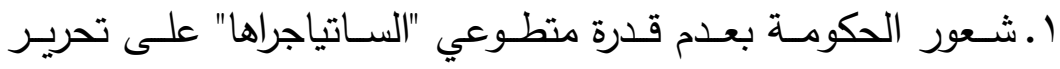
المستعدرات البرتغالية وحدهم، وخصوصـا مـع استخدام البرتغاليين منتهى الثدة والعنف في مواجهتهم.

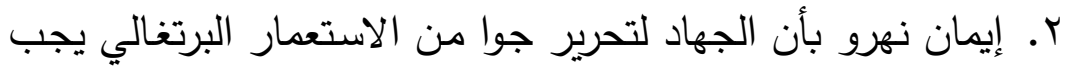

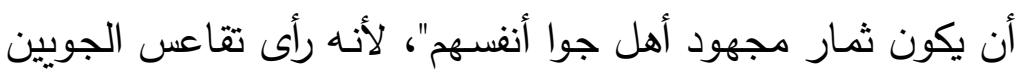

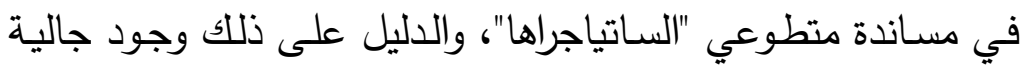

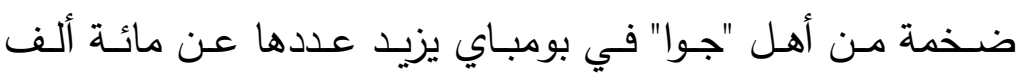
شخص - وفق تقرير السفارة المصرية في الهند- - ولو كانوا يرغبون الانضمام إلى الهند لتطوع هؤلاء لغزو المستعمرة دون أي مساعدة

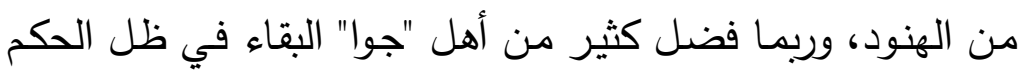
البرتغـالي، لـرواج الحالـة الاقتصـادية في المستعمرة، وعدم وجـود ولهي رسوم جمركية على الواردات وإباحـة استيراد كافة البضـائع، على عكس الحال بالهند، التي قيدت استيراد البضائع، وفرضت رسوما

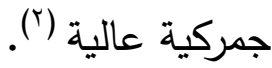
على أيه حال فقد تسبب تراجع حزب الكونجرس الحاكم عن سياسة الغزو السلمي مستبدلين به الحصـار الاقتصادي، في عاصفة من النقد

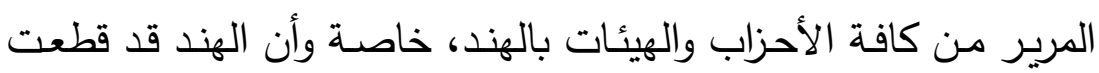
شوطا بعيدا في السياسة الأولى، وذهب كثيرون ضحيتها، ومن ثم اعتبر

(1) وثائق وزارة الخارجية، الأرشيف السري الجديد، محفظة ... r، ملف 1، بتقرير سفارة مصر بالهند عن التطورات الأخيرة

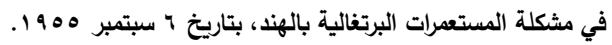


تراجـع الحزب - على حــ تعبيـر الـبعض - "أسـوأ قـرار في تاريخـهـ السياسي، وأمر هزيمة سياسية للرئيس نهرو، الذي بات موقفه حرجا تجاه الشعب الهندي بسبب هذه المشكلة"(')

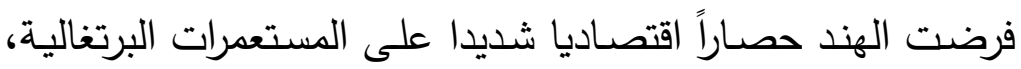
وخصوصـا "جوا"، وأوقفت خطوط السكة الحديد التي كانت تمر بينها وبين شبة القارة الهندية، فصارت بذلك معزولة تماما عن بقية الهند، كما حذرت شركات الملاحة من التعامل مـ تلك المستعررات، وكان عقاب الشركات التي خالفت ذلك إضراب عمال الثحن في ميناء بومباي عن شحن أو تفريغ بواخرهـا، وطلب نهرو من كافة الدول المجاورة التعاون

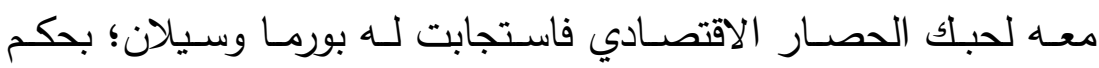
صـلاتهما القوية بالهند، ولكن نداءه لم يجد صدى لدى باكستان، التي لـي

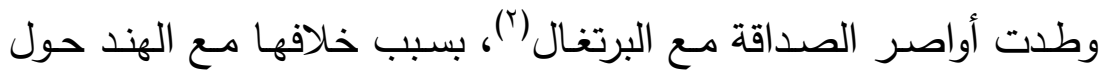

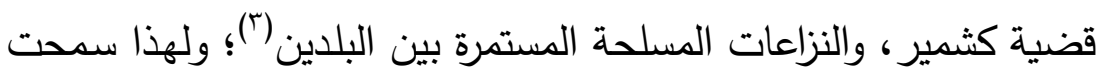

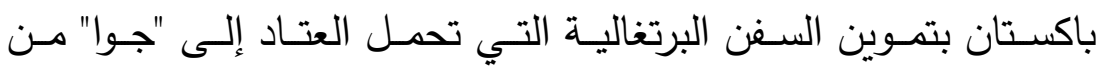

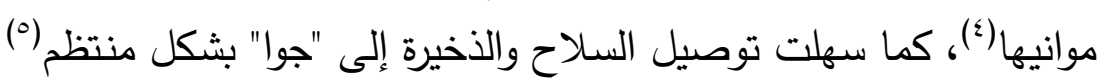
(r) توطلت العلاقات البرتغالية الباكستانية إثر مشكلة "جوا"، فقد أظهر الباكستانيون عطفهم على تمسك البرتغال بحقها في

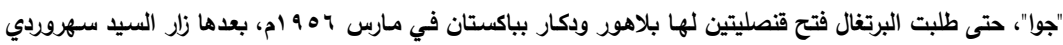
Suhrawardy

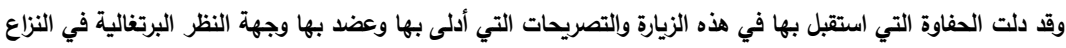

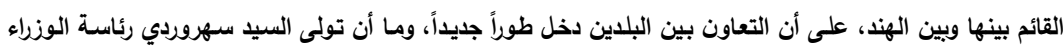

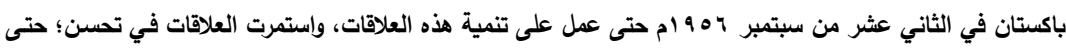

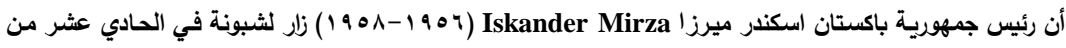

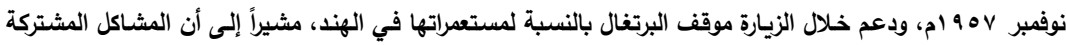

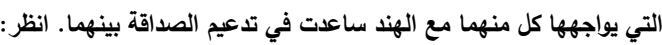

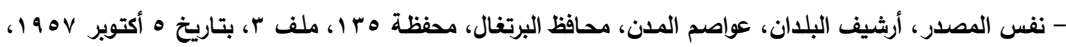

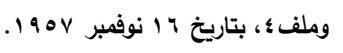

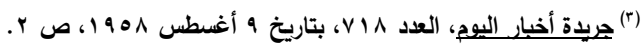

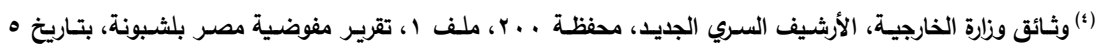

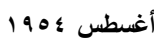

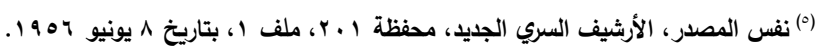


ومدت خطوطها المدنية الجوية إلى مستعمرة "جوا"، كما مدت الاتصال

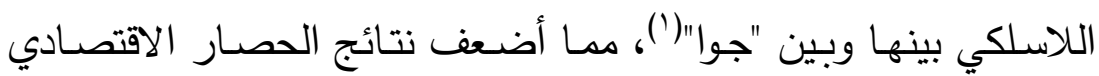

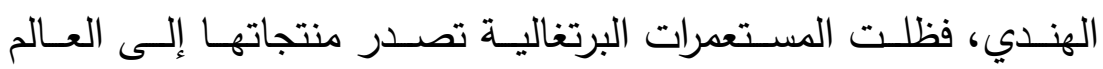
الخارجي، بل زاد معدل الصـادر من خام الحديد من "جوا" إلى اليابان

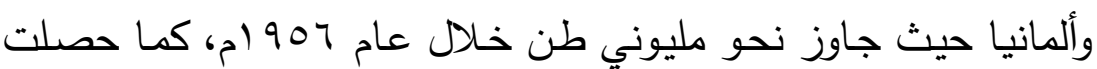
المستعمرات البرتغالية على كل ما تحتاجه من العالم الخارجي (؟).

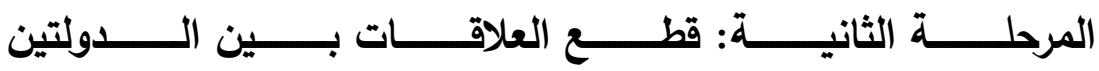

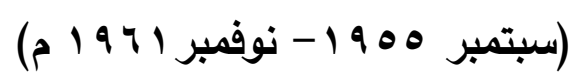

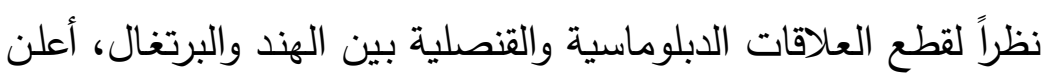

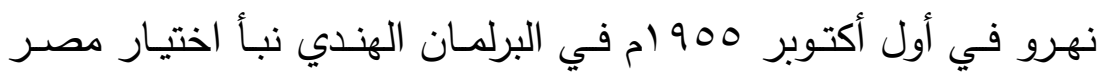
لتمثيل مصالح الهند في البرتغال، كما أعلنت البرتغال اختيارها للبرازيل

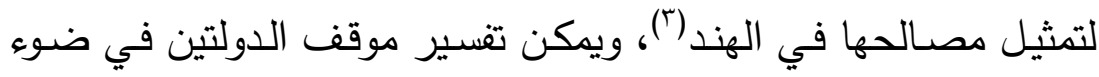
العوامل التالية: أولاً: بالنسبة لاختيار الهند لمصر يرجع ذللك إلى العلاقة الوطيدة التي ربطت مصر بالهند، وارتباطهما

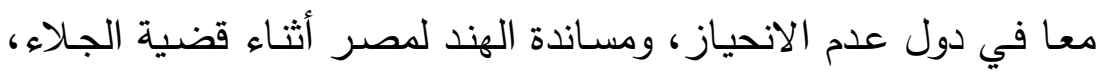

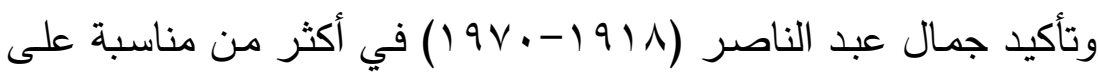

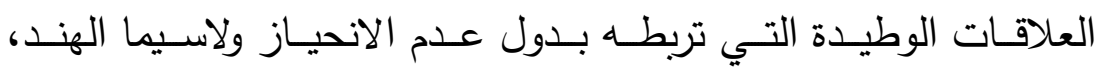

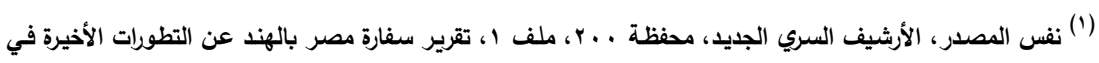

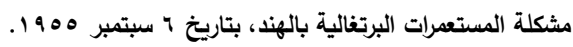

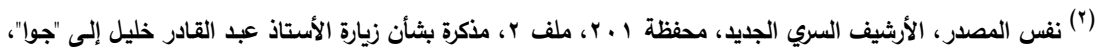

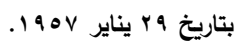

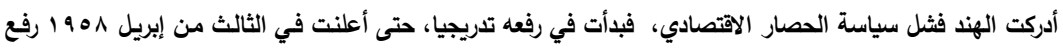

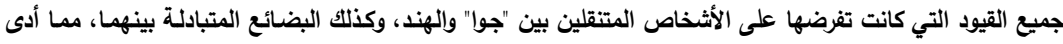

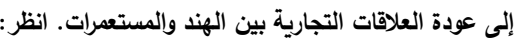

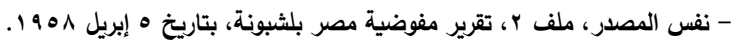

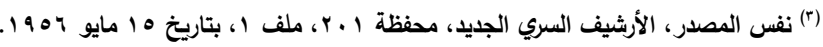


واستتكاره للاستعمار بكل صسوره ففي تصريح لعبد الناصـر في مدينة

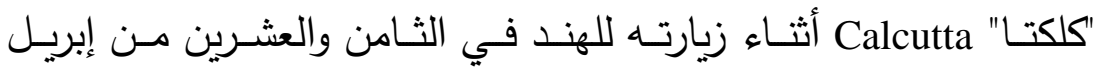

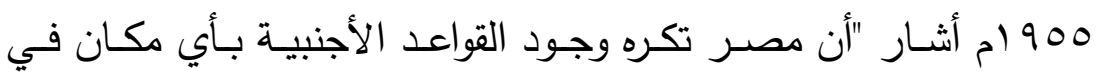
الشرق الأوسط، وأنه لا ينتظر من مصر أن تخدم قضايا الدول الكبرى

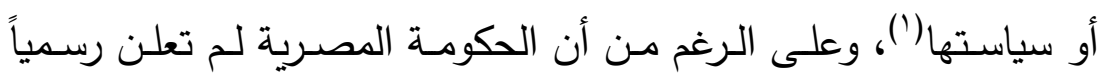

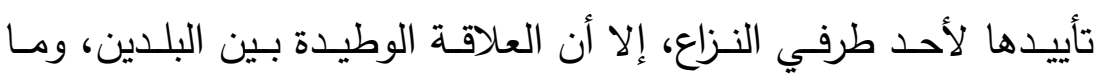

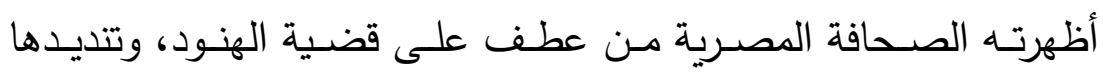

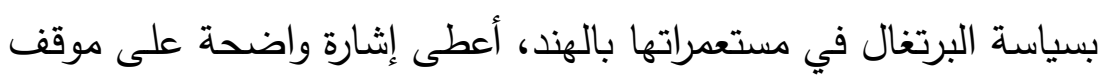
مصر المحابي للهند. فقد امتنعت الصحف المصرية عن نشر البلاغ الرسمي الذي أذاعه

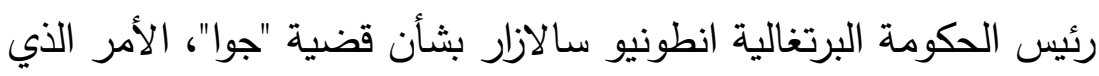

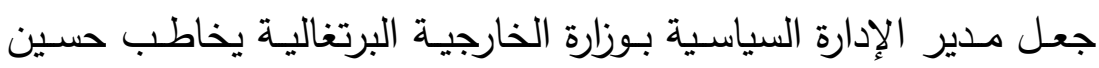

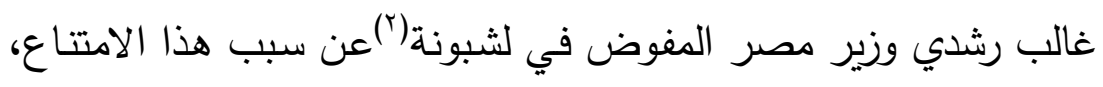

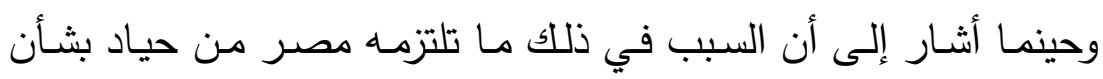

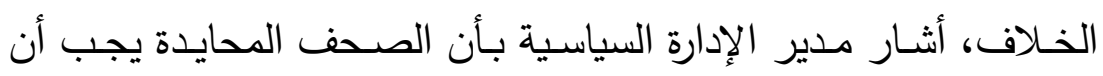

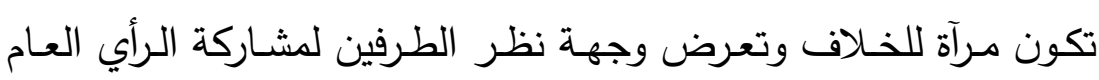

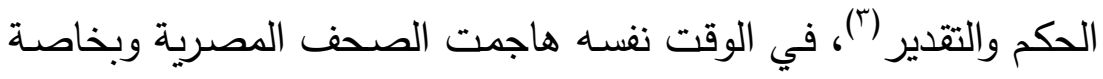
جريدة الجمهورية مسلك البرتغاليين في "جوا"، ففي السادس والعشرين من فن يونيو 907 ام نشرت مقال بعنوان "فظائع الاستعمار البرتغالي في جوا"، فئهين

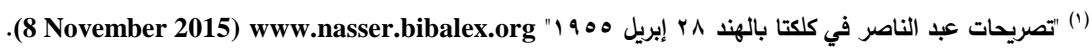

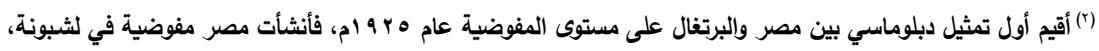

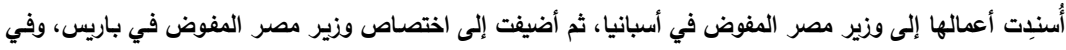

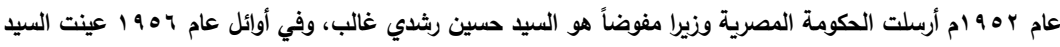

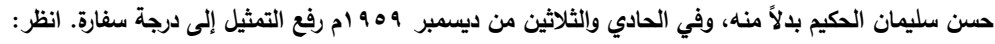

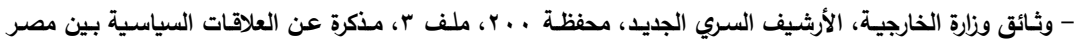

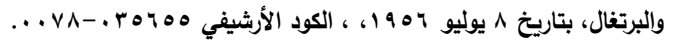

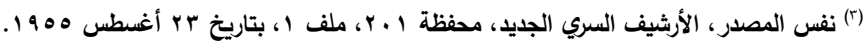


أوضحت فيه التعذيب الذي تمارسـه السلطات البرتغالية ضد سكان "جوا" المناهضين للاستعمار البرتغالي (')، مما دفع مفوضية البرتغال بالقاهرة إلى تقديم مذكرة استتكرت فيها هذه التصريحات، فردت إدارة الصحافة على خطاب المفوضية البرتغالية بأن مـا نشرته جريدة الجمهوريـة تلقته من وكالة أنباء رويترز Reuters وليس من مراسلها في بومباي، وأن ما أوردته الجريدة يتفق مـع سياسـة مصـر في الدفاع عن حقوق الثـوب كرب المغلوبة على أمرها، ويتفق مع مبدأ حقوق الإنسان، وحريـة الصحافة في

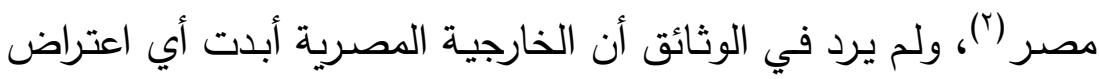
على مـا ذكرته إدارة الصـافة بشـأن مـا نشرته جريدة الجمهوريـة، وهذا يعطي دلالة واضحة على موقف مصر المؤيد للهند في هذا النزاع. ثانياً: بالنسبة لاختيار البرتغال للبرازيل يرجع إلى العلاقة الوطيدة والتاريخ القديم الذي ربط بين الدولتين، فقد كانت البرازيل أكبر المستعمرات البرتغالية، وأكثرها أهمية حتى أعلنت

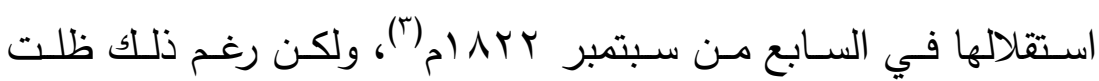

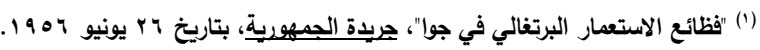

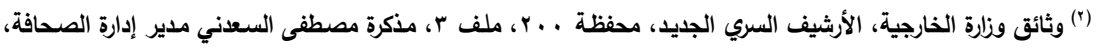

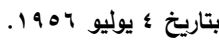

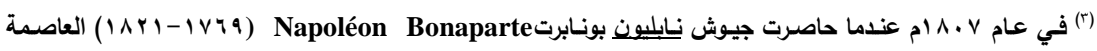
البرتغالية لثبونة، فر الأمير الحاكم والوصي على العرش البرتغالي ويدعى الأمير جواو Joao إلى البرازيل، وذلتك تحت

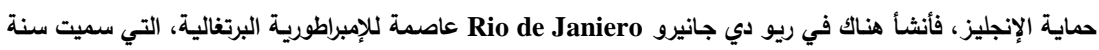

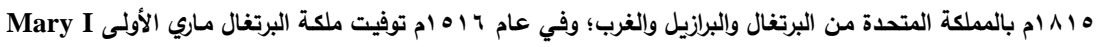

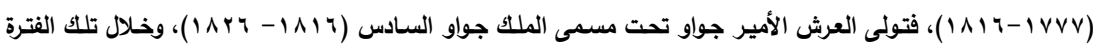

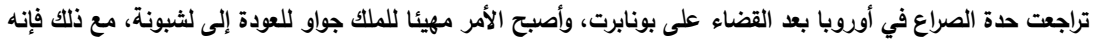

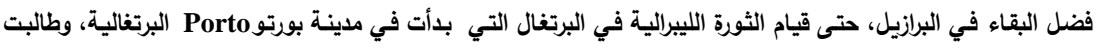

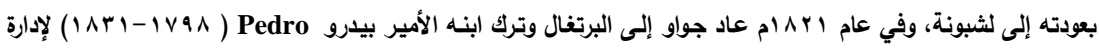

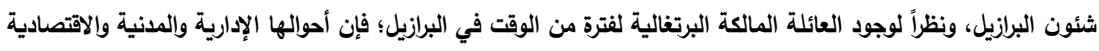

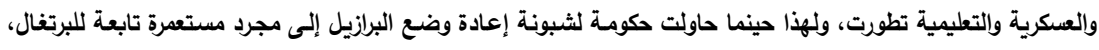

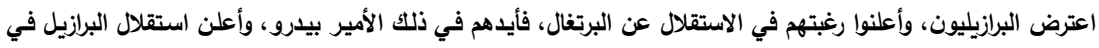

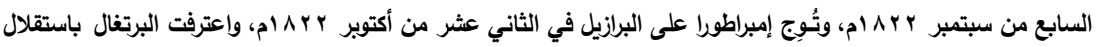

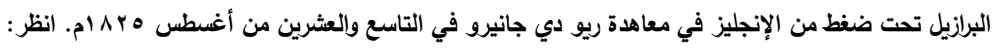


أواصر العلاقة بين البلدين قوية، بحكم اشتراكهما في اللغة والدين، وذلك على المستويين الرسمي وغير الرسمي، حتى أن بعض الكتاب البرازيليين

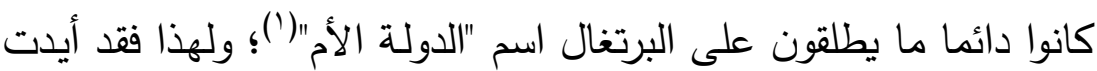

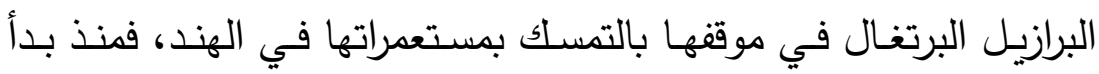
النزاع أعلن سلفيو ريبيرو دي كارفالهو Ribeiro de Carvalho القائم بأعمال السفارة البرازيلية في الهند، رفض دولتئه ضـ الهم الهند لمستعمرات

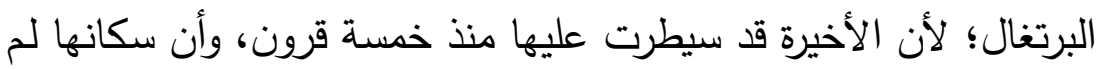

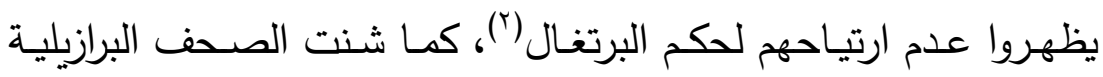
حملة قوية ضد عزم الهند على استرداد ما وصفته بـ"الممتلكات البرتغالية"

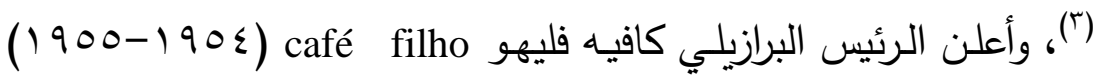

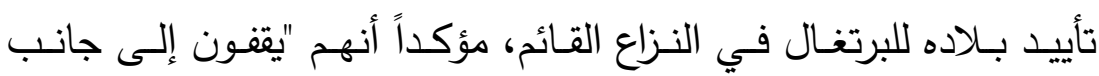

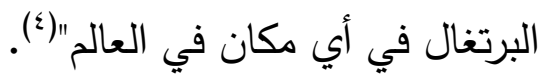

وفي الثلاثين من يوليو 90 ام استدعى سكرتير عام وزارة الخارجية البرازيلية السفير الهندي وأبلغه مشاركة الشعب البرازيلي شعور الشعب البرتغالي فيما يتعلق بالتطورات الأخيرة بين الهند والبرتغال؛ نظرا لئها لوحدة الأصل واللغة التي تربط بينهما، فأظهر السفير الهندي استنكاره

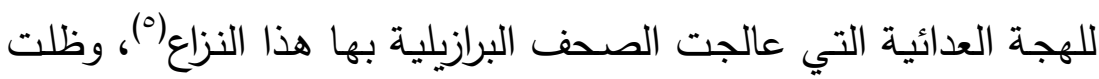

-Mosher, Jeffrey C, Political Struggle, Ideology, and State Building: Pernambuco and the Construction of Brazil, 1817-1850, University of Nebraska Press, 2008, pp. 7-9.

${ }^{(1)}$ Fitzpatrick, John, Brazil and Portugal - The Samba and the Fado, 18 August, 2003, www.gringoes.com, (19 November 2015).

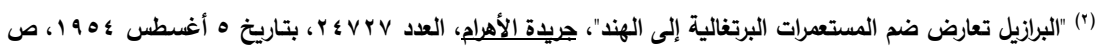

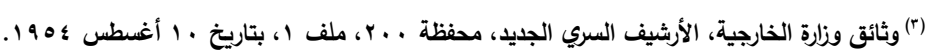

(4) Davila, Jerry: Brazil and the Challenge of African Decolonization 1950-1980, London: Duke University Press, 2010, p. 27.

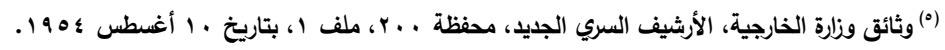


البرازيل حكومة وشعبا تظهر هذا التائيد، مشيدة بالخدمات التي أدتها البرتغال - على حد قولهم- لثـبة القـارة الهنديـة، وأنها حملت إليها

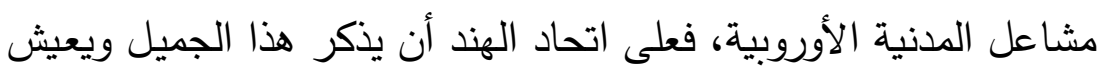
مع جارته البرتغال في سلام (') مئل بدأت مصر والبرازيل عملهما في رعاية مصالح الهند، وقد طلبت

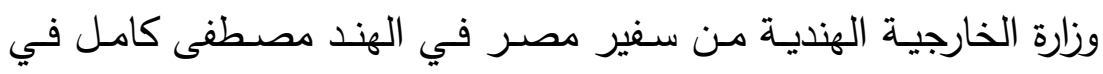
السادس والعشرين من نوفمبر 1900 1م تكليف أحد كبار موظفي السفارة

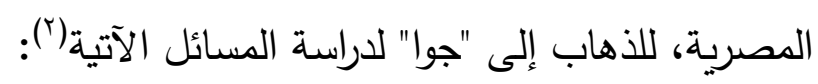
ا ا ـ حالة الهنود المعتقلين فيها.

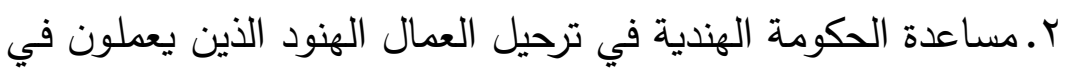
السكك الحديدية في "جوا".

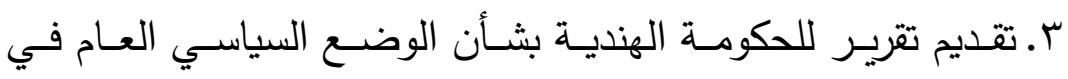
المستعمرة.

انتدبت السفارة لهذه المهمة عبد القادر خليل السكرتير الأول لسفارة مصر بنيودلهي، وفي الفترة من الثاني إلى التاسـع عشر من فئرياير

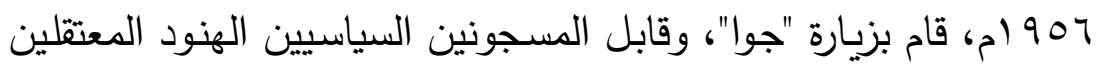

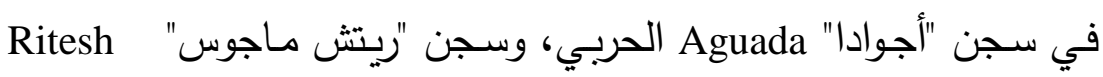

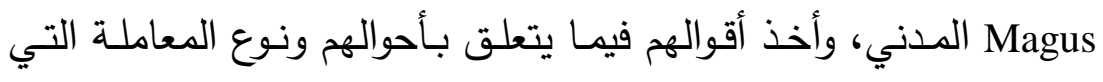

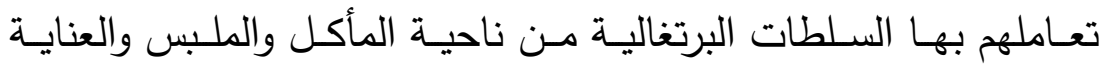

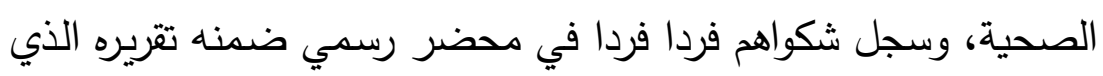
قدمه للحكومة الهندية، ثم تقدم بطلب إلى حاكم "جوا" العام باولو بينارد 
جيديس شرح فيه شكاوى المسجونين الهنود، وطلب منه العمل على إزالة

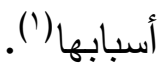

اسـتغلت الحكومـة الهنديـة التقريـر الذي أعده المنـدوب المصـري، وتقدمت في الثاني مـن مـارس 907 ام بمـكرة إلى السـفارة المصـرية بنيودلهي تتضـمن شكاوى المسـجونين السياسـيين الهنـود، وطلبت مـن الحكومة المصرية تقديمها إلى الحكومة البرتغالية حتى تتولي العمل على لئ لئي

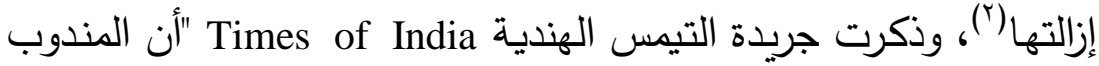
المصري عند زيارته لـ"جوا" لم يلق من السلطات البرتغالية المساعدات

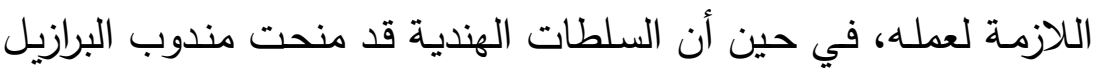
كافة المساعدات الممكنة أثناء زيارته لبومباي"(").

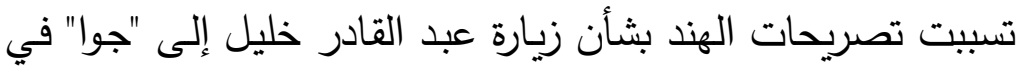
حدوث نوع من التوتر في العلاقات المصرية البرتغالية، وعلى إثر ذللك

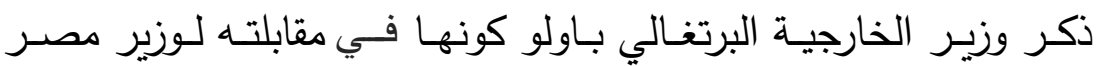

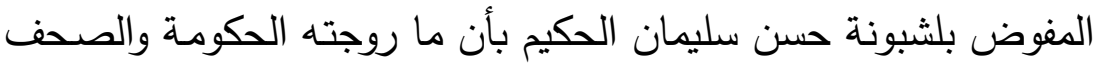
الهندية من أقاويل بشأن زيارة المندوب المصري لـ لـ "جوا" يحتمل أمرين:

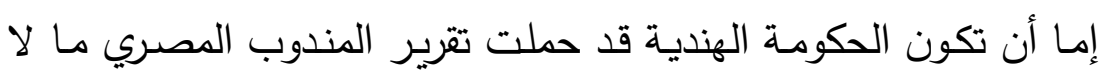

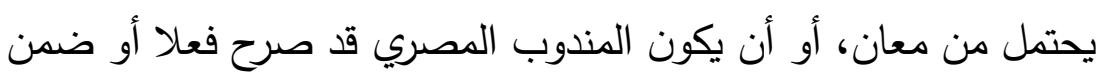

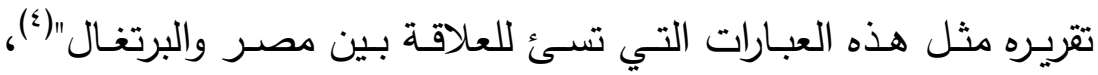
والـراجح أن الحكومـة الهنديـة أرادت أن تتخـذ مـن هـذا التقريـر وسيلة للضغط على البرتغال، فاستخدمت بعض عبارات المبالغة الشديدة التي لم يستخدمها المندوب المصري في تقريره، والذي نفى بنفسـه مـا ذكرته 
جريدة التيمس الهنديـة، وأكد أن السـلطات البرتغاليـة قد عاملتهه معاملـة طيبة، وأنه لـ يصدر تصريحا للصحف عن زيارته لـ"جوا" من قريب أو من بعيد(')، كما حرصت الخارجية المصرية على معالجة هذا الأمر بأن أرسلت نسخة من التقرير الذي أعده المندوب المصري فيما يتعلق برصده لشكاوى المسجونين السياسيين إلى الحكومة البرتغالية، مؤكدة أن مصر تقوم بعملهـا في رعايـة مصـالح الهند بالممتلكات البرتغاليـة في القـارة الهندية بكل حيدة طبقا للأوضـاع الدولية مـع مراعاة الصداقة التي تربط

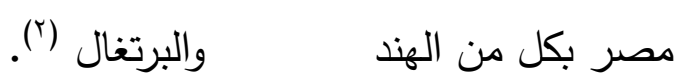
والـراجح أن البرتغـال تفهــت الموقـف بـدليل سـماحها للمنـدوبين المصرين بتكرار زيـارتهم إلى "جوا"؛ ففي الرابع والعشـرين من ديسمبر 907 ام وافقـت الحكومـة البرتغاليـة على سـفر عبد القـادر خليـل للمـرة الثانية إلى المستعمرات البرتغالية في الهند(َ)، وقد سافر في السادس من ينـاير 90 (م، ومكـث في"جـوا" مـدة ثلاثتة عشر يومـا، نـاقش خلالكها الإجـراءات التـي اتخـذتها السـلطات البرتغاليـة لتســيل مسـألة اشـتراك المسـونين السياسيين الهنود في الانتخابـات العامـة في الهند، ومسألة الترتيبـات النهائيـة لقيـام الهنـد بمـنح معاشـات لمسـتحقيها مـن الهنـود الموجودين في "جوا"، كما استمع إلى شكاوى المسجونين السياسيين في المستعمرة، وكتب تقريـرا مفصسلا عن الحالة الاقتصـادية والسياسية في المستعمرات البرتغالية(؛)، كذلك سمحت السلطات البرتغالية في ديسمبر

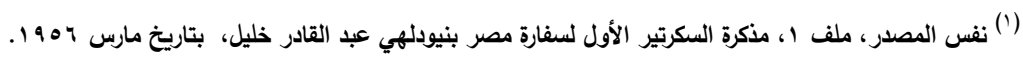

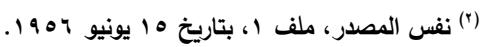

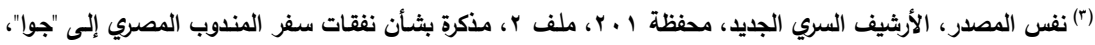


1901 ام بسفر السيد صـلاح العبد مستشـار سفارة مصر بنيودلهي إلى

"جوا"؛ لتفقد أحوال المسجونين، والمعتقلين السياسيين فيها (') ويتضـح مـن تقـارير منـدوبي السـفارة المصـرية إلى المسـتعمرات

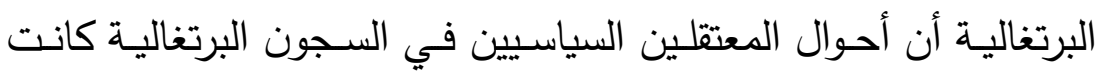

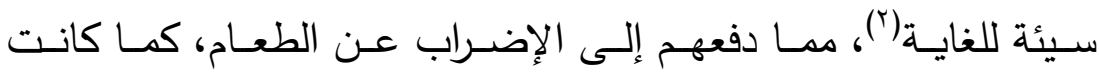

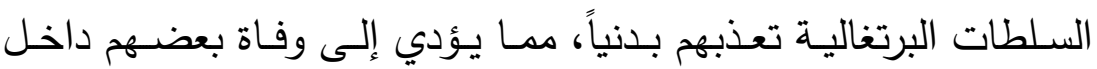

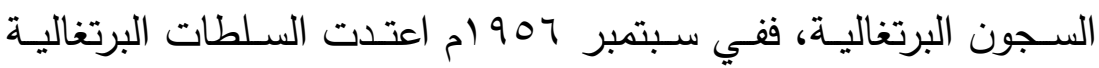
في"جوا" على معبد "بارتاجال" Partagal الهندوكي، وقبضت على ثلاثتة وعشرين من رجاله الدينيين وعلى رأسهم مدير المعبد ثري بارثورام اشاريا Three Barzram Acharya الأخير ، فرفضت السلطات البرتغالية التحقيق في حادثة وفاته، وأحرقت

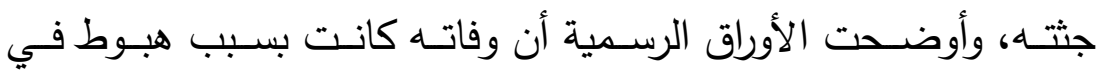

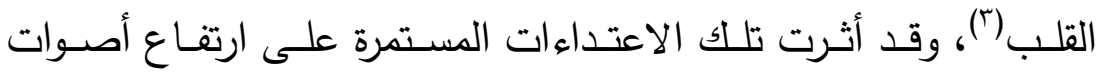

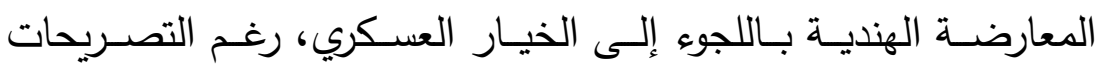

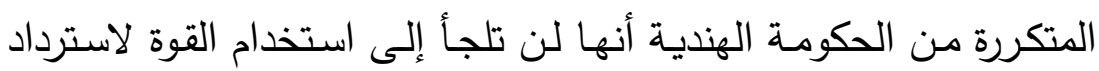

$$
\text { المستعمرات البرتغالية(أ). }
$$

المرحلة الثالثة: التدخل العسكري الهندي وضم المستعمرات البرتغالية

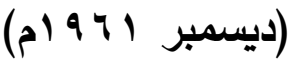

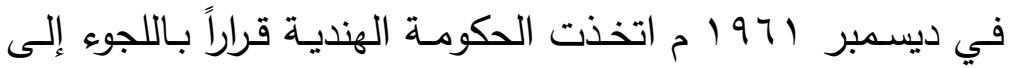
الخيار العسكري، وضم المستعمرات البرتغالية بالقوة، بعد فترة من النزاع

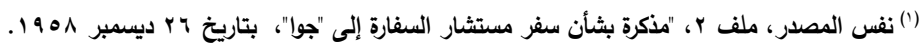

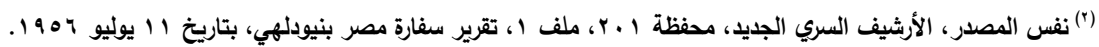

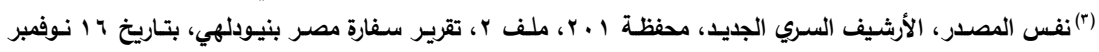

(4) Rotter, Andrew J., Comrades at Odds: The United States and India, 1947-1964, Cornell University Press, 2000, p. 185. 
السلمي استمرت لمدة سبع سنوات، تعالت خلالها صيحات المعارضـة الهندية من أجل اتخاذ قرار حاسم ضد الاعتداءات البرتغالية المتكررة، ويمكن القول بأنه إلى جانب السبب المباشر الذي دفع الهند إلى اتخاذ

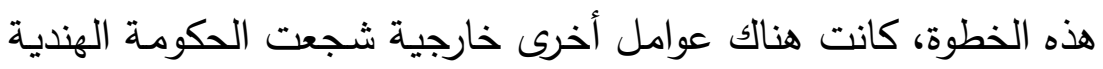
على اتخاذ هذا القرار، ويمكن عرض هذه العوامل على النحو التالي:

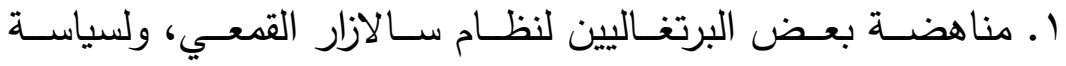

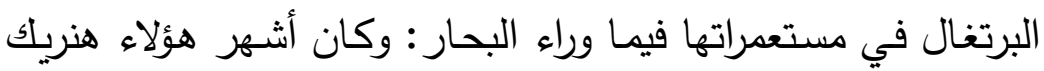

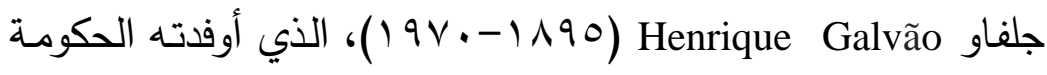
البرتغالية في عام 9 ام إلى مستعمرات البرتغال الإفريقية؛ ليضع

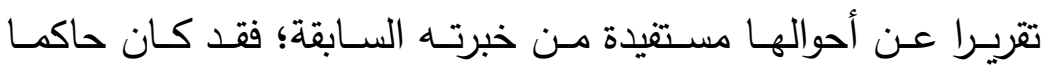

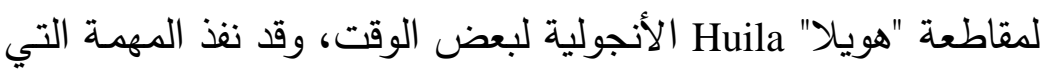

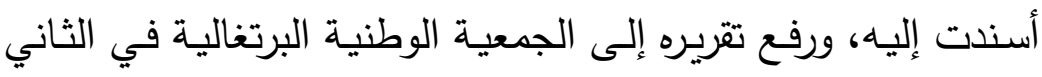

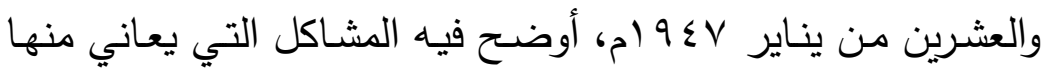

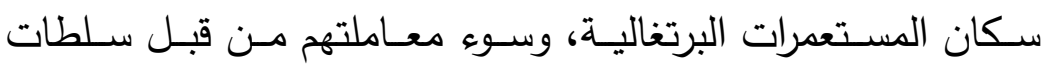

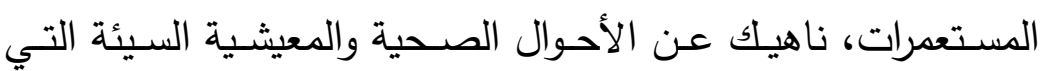
تؤدي إلى وفاتهم، وفي التقرير نفسـه اتهم السلطات البرتغالية بأنها تهدف إلى القضـاء على العمالـة الوطنية في مستعمراتها فيما وراء البحار ولاسيما في أنجولا، فأخفت حكومة سالازار التقرير ، واعتقلت

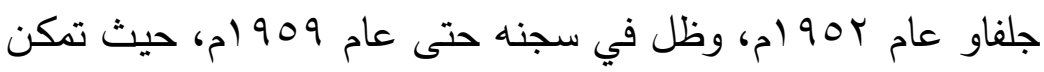

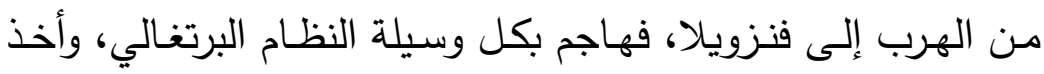

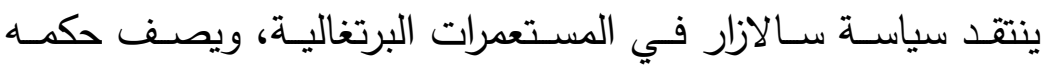

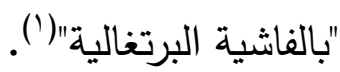

(1) Peres, Luis Miguel Solla De Andrade, Henrique Galvão, 1895-1970: Aspects of A EuroAfrican Crusade, Master of Arts, University of South Africa, 2009 , pp. 48-57. 
وفي بr يناير الو9 ام استولى هو ومجموعة من المغامرين على السـفينة البرتغاليـة سـانتا ماريـا Santa Maria وكـان هدفـه الوصول بها إلى أنجولا، لكن السفن الأمريكية المتعقبة لجلفاو أجبرته على التوجه إلى البرازيل، حفاظاً على أرواح الأمريكيين الذين كانوا على متن السفينة المخطوفة، الذي تسبب سيطرته عليها في حدوث زخم سياسي وإعلامي كبير ، ومن البرازيل أرسل جلفاو تقريره السـابق عن وضـع المستعمرات البرتغاليـة في أفريقيـا إلى جريدة الأوبزيرفر Observer فكـان تقريـره خيـر دليل على مـا تعلنـه الحكومــة الهنديـة مـن سـوء الاستعمار البرتغالي، وتأكيداً لشكواها المتكررة من سوء معاملة الهنود المحتجزين في سجون البرتغال في "جوا"، في الوقت الذي أكدت فيه الحكومـة البرتغالية مراراً أنهم يلاقون أحسن المعاملة، وقد تعرضت السياسـة الخارجيـة البرتغاليـة خـلال تلك الفترة لنقد ومعارضـة على نطاق واسع كما عبر عن ذلك الجنرال البرتغالي خوسيه لوبيز ألفيس

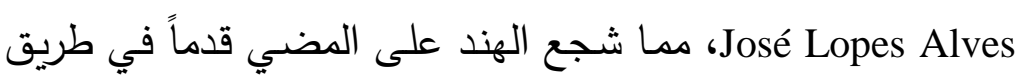

$$
\text { تحرير المستعمرات (r). }
$$

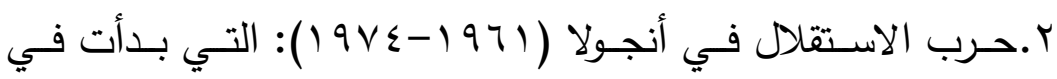

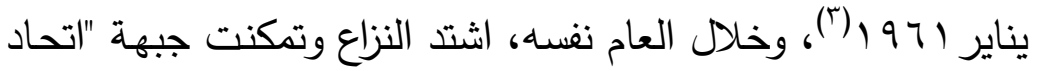
(') محمح هنائي عبد الهادي، نهاية الاستعمار البرتغالي، تقديم عز الدين فوده، (القاهرة: الدار القومية للطباعة والنشر،

(2) Lopes, José Alves, Estado Português da Índia, Lisboa: Revista Militar. 2007, p.6.

(م) بدأت أحداث الحرب بامتناع بعض الفلاحين الأنجوليين في منطقتي بايكسا دي كاسانجي Baixa de Cassanje،

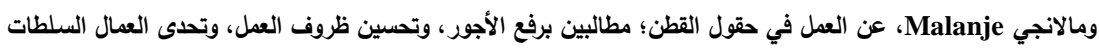

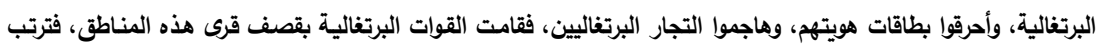

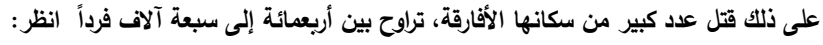
-Fearon, James, and Laitin, David, "Portugal", Stanford University, p.4, http://web.stanford.edu, (15 October 2015). 
شعب أنجولا" the Union of Peoples of Angola تحت قيادة هولدن

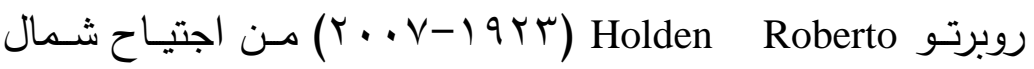

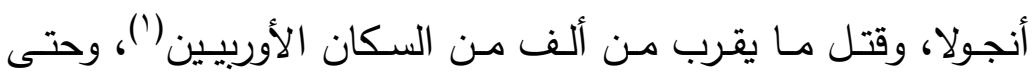

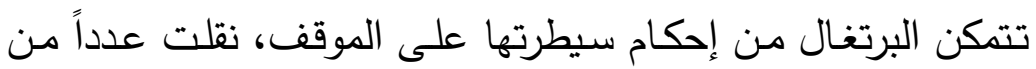

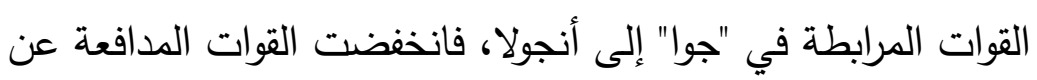

"جوا" من سبعة آلاف وخمسمائة إلى ثلاثة آلاف وثثلاثمائة فرداً (؟). أما عن السبب المباشر لاتخاذ الهند خطوات حاسمة ضد البرتغال

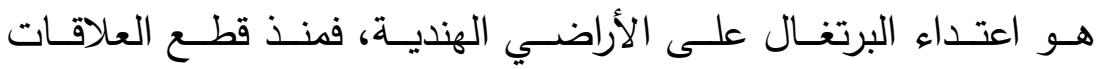

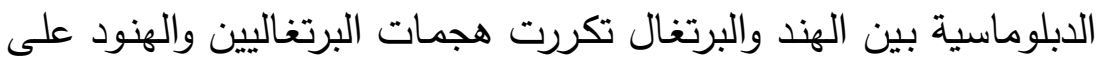
الحدود المشتركة بينهما، وكثيرا ما قدمت الهند شكاوى للحكومة المصرية لتحذير البرتغال من مغبة الهجوم على أراضيها، وازدادت الأوضاع سوءًا

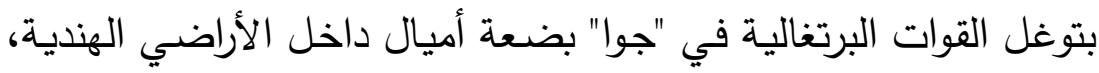

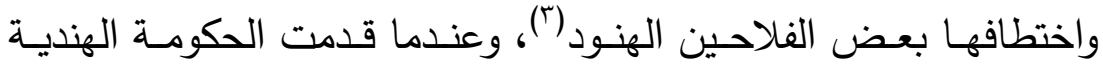
مذكرة اعترضت فيها على الحوادث المتكررة التي يرتكبها البرتغاليون في

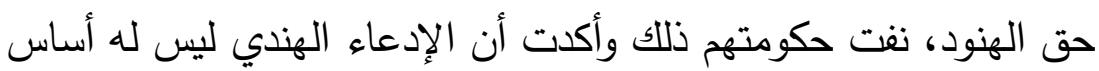

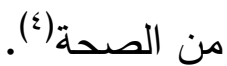

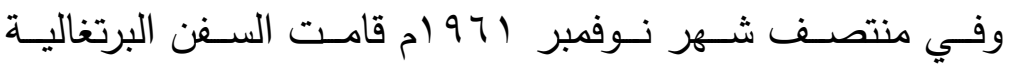

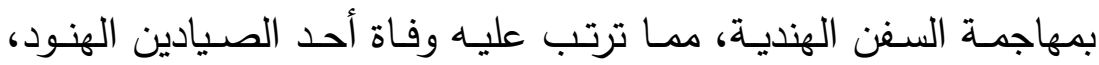

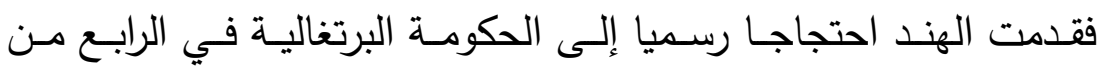

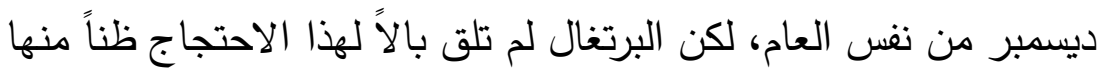

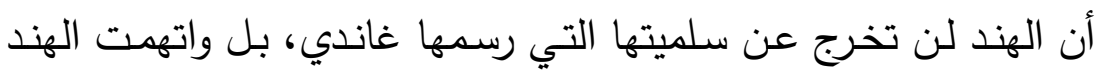

(1) George, Edward, The Cuban Intervention In Angola, 1965-1991: from Che Guevara to Cuito Cuanavale, First published, London: Frank Cass, 2005, p.9.

${ }^{(2)}$ Lopes, José Alves, Índia Portuguesa antes-do-assalto, Lisboa: Revista Militar. 2007, p.17.

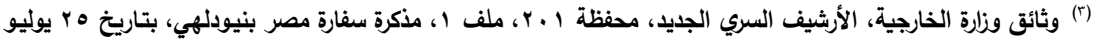


بالتآمر لغزو أراضيها(')، فأرسلت الهند بعض قواتها إلى منطقة الحدود

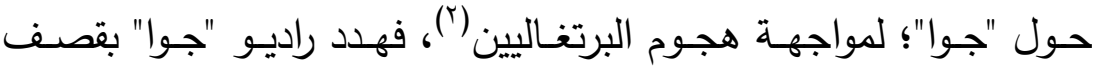
القوات البرتغالية للمدن الهندية، إذا واصلت القوات الهندية تعزيز قواتها على الحدود، فعدت موجة من السخط في البلاد، وتزايدت الصيحات

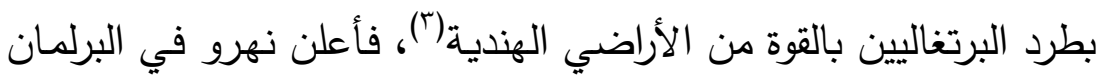

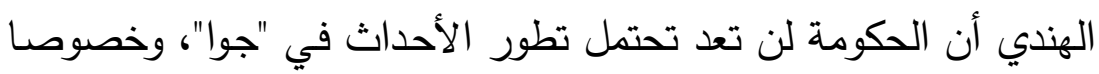

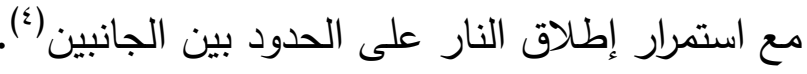

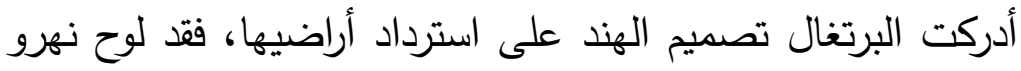
للمرة الأولى باستخدام القوة العسكرية؛ ولهذا اقترحت وضع مراقبين محايدين على الحدود بين الهند و"جوا"، لوقف الأعمال العسكرية،

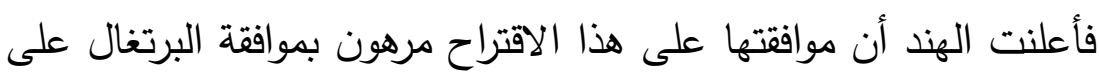
الانسحاب الفوري من المستعمرات لكن البرتغال رفضت ذللك(0)، ونظراً

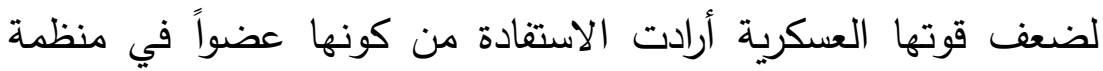
حلف شمال الأطلسي؛ في استخدام قواته العسكرية لرد الخطر الهندي عن مستعمراتها، وعلى الرغم من أن اتفاقية الحلف الموقعة في واشنطون Washington والسادسة لم تدرج الهند ضمن المناطق الأطلسية التي يشملها الدفاع، إلرئ لكن المادة الرابعة من الاتفاق تتص على: "أن يتثاور المتعاقدون معا إذا لإلها حدث تهديد للوحدة الإقليمية أو الاستقلال السياسي أو الأبعائ الأمن لأحد

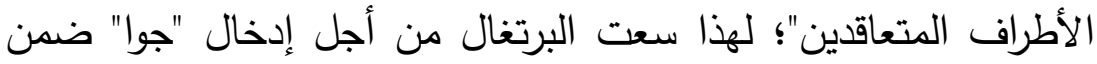

(1) Singhal, D.P., "Goa-End of an Epoch", The Australian Quarterly, Vol. 34, No. 1 (Mar., 1962), p. 77.

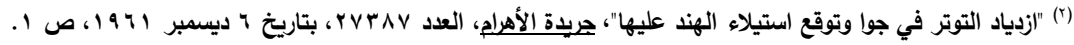

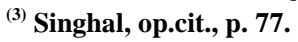

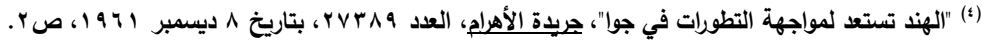
${ }^{(5)}$ Singhal, op.cit., p. 77. 
مناطق النفوذ التي تشملها اتفاقية الناتو للدفاع عنها ضد الهجوم

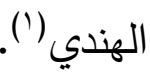

عارضت الولايات المتحدة مطلب البرتغال رغم المصالح المشتركة وعلاقة التحـالف بينهمـا؛ حتى لا تدفع الهند إلى الاتجـاه للتحـالف مـع روسـيا، التـي أيـدت مطلـب الهند بضـم المسـتعمرات البرتغاليـة إليهـا، وحاولت الولايـات المتحدة بكل الوسـائل التثـاهم مـع الهند، وحثها على عـرض القضـية على مجلس الأمسن، ومنعهـا مـن اللجـوء إلىى الخيـار العسكري، وبالتالي تكون قد استطاعت إمسـالك العصـا من المنتصف، وحافظت على علاقتها بطرفي النـزاع، لكن الهنـد لـم تسـتب للنصـح الأمريكي، وتوالت الهجمات الهندية منذ بداية شهر ديسمبر الج9 ام على الحدود البرتغاليـة؛ ولهذا قابـل السـير الأمريكي في الهند جون كينـث جالبريث $\quad$ John Kenneth Galbraith نهـرو وحثـه على حـل القضـية بـالطرق السـلمية عـن طريـق الوسـاطة والتوافـق بـدلاً مـن الخيـار العسـكري (؟)، لكـن الهنـد ضـربت بالنصــح الأمريكي عرض الحائط، واستمر تحرك الجيش الهندي نحو المناطق

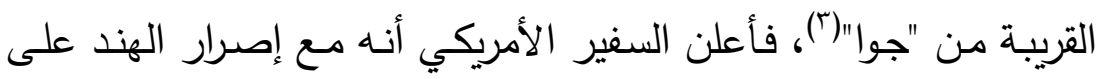
التصعيد العسكري فإن القضية ستعرض على مجلس الأمن ولن تتوقع الهند حصولها على تأييد الولايات المتحدة(؟).

(1) وثائق وزارة الخارجية، الأرشيف السري الجديد، محفظة . . ب، ملف ا، مذكرة عن الممتلكات البرتغالية في الهند، بتاريخ

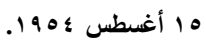

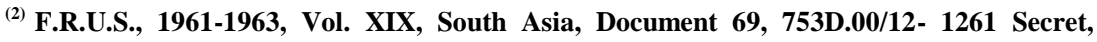
Memorandum From the Assistant Secretary of State for Near Eastern and South Asian Affairs (Talbot) to Acting Secretary of State Ball, Washington, 12 December 1961.

(•) وثائق وزارة الخارجية، الأرشيف السري الجديد، محفظة . . r، ملف ا، مذكرة عن الممتلكات البرتغالية في الهند، بتاريخ 10 أغسطس ؛ 1901

(4) F.R.U.S., 1961-1963, Vol. XIX, South Asia, Document 72, 753D.00/12-1461. Secret; Telegram From the Department of State to the Embassy in India, Washington, 14 December 1961. 


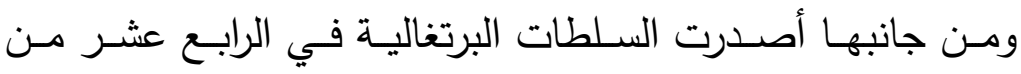

ديسمبر الا9 ام قراراً بترحيل الأطفال والنسـاء من "جوا"؛ لتوقعهم قيام

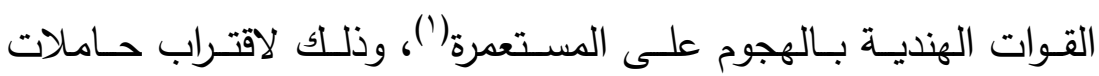

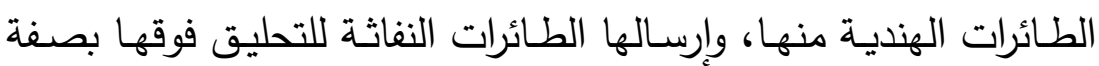
مستمرة، كما أن المصفحات الهندية اتخذت مواقع على الحدود البرتغالية، والهات مع وصول أربعة قطارات هندية محملة بالأسلحة الثقيلة إلى مدينة أونـا

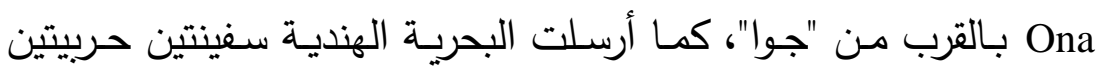

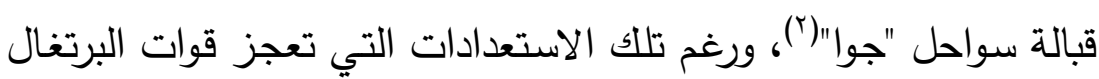

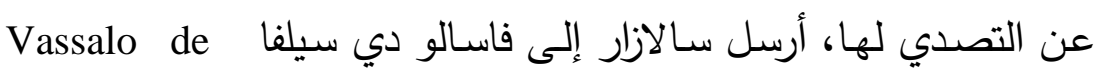

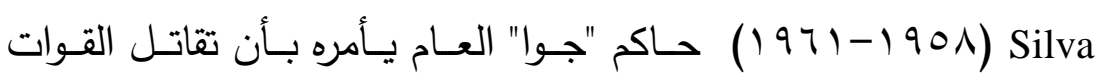
البرتغالية في "جوا" لآخر رجل، وأن يصمد حتى يتمكن من حشد التأييد

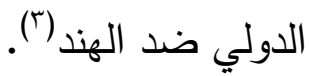

ذهبت آمال سالازار أدراج الرياح ؛ فقد رفض نهرو الضغط الثديد

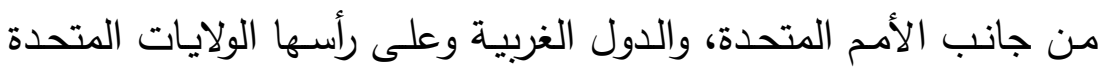

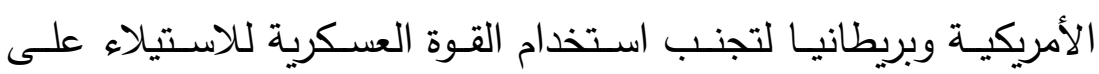

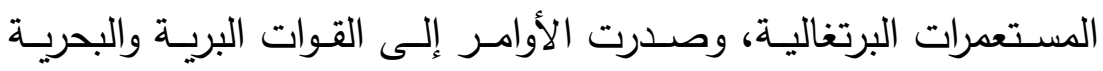

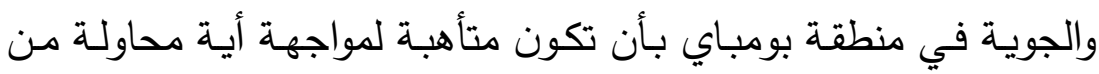

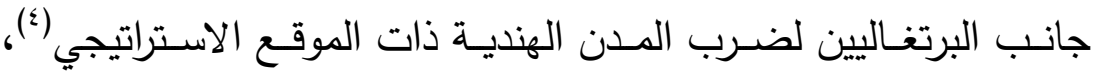

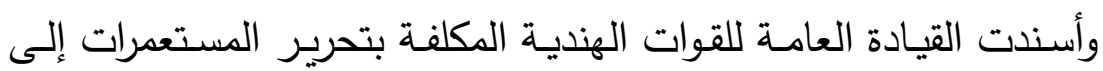

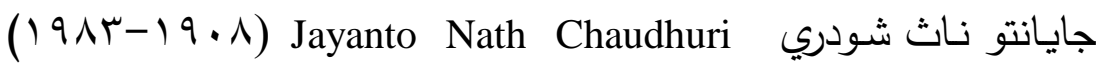

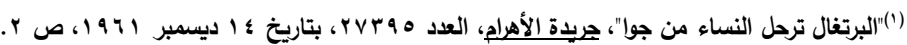

(2) Kore, V.S., "Liberation of Goa: Role of the Indian Navy", Bharat Rakshak Website, 1 October 2014.

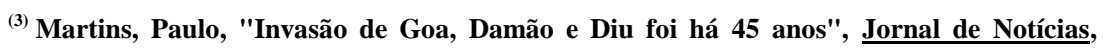
www.supergoa.com, (18 December 2006).

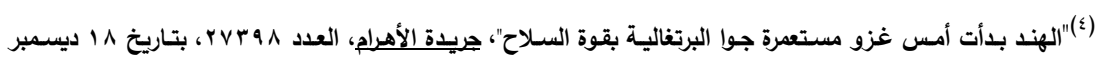


القائد العام السابق للجيش الهندي، ورئيس هيئة الأركان العامـة(') وفي السـابع عشر مـن ديسمبر الو9 ام صـدرت الأوامر إلىى القوات الهنديـة وسـلاح الطيران ببدء الهجوم، وقد أعلن نهرو أن الهند اضطرت لحمل السـلاح ضـد البرتغـاليين، بعد أن رفضـت البرتغال التخلي عن سياستها الاستعمارية (r) (ب)

\section{إسـقـاط مستعمرة "جـوا":}

بــدأت القــوات الهنديــة أعمالهــا بــالهجوم علـى بلــدة مـــولانجيم

شمال شرق "جوا"، مما أسفر عن مقتل اثنين من الجنود البرتغاليين، بعدها اتجهت إلى بلدة دوروماجوجو Doromagogo الواقعة شمال مولانجيم، ولم تستطع قوات الثرطة البرتغالية الصمود أمام القوات الهندية، فأرسلت القيادة البرتغالية في بانجيم إليهم بغرقة عسكرية، لكنها هزمت هي الأخرى وسيطر الهنود على المدينة، وفي الرابعة عصر يوم السـابع عشـر مـن ديسمبر بـدأ الهجوم الهندي مـع قصف مدفعي على المراكز البرتغالية جنوب مدينة مولانجيم بناء على معلومات استخباراتية خاطئة أشارت بتمركز الدبابات البرتغالية الثقيلة في هذه المنطقة، ولوقف مهولف تقدم الهنود قام البرتغاليون بتدمير الجسور في بيكولم Bicholim وكولفال Colvale وفي صـباح الثامن عشـر مـن ديسـمبر الو9 ام هاجمـت القـوات الهندية المستعمرة من ثلاث جهات(؛)؛

(1) Pillarisetti, Jagan, "The Liberation of Goa: 1961", Bharat Rakshak website, (1October 2014).

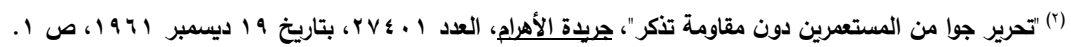
(3) "Invasão de goa", www.areamilitar.net, (8 May 2015).

(4) Chakravorty, B.C., "Operation Vijay", Bharat Rakshak website, www.bharatrakshak.com, (1 October 2015). 
ا ـالجزء الشـرقي: عبر منطقـة أوسـو Usgão مستهدفة مدينـة بوندا

$$
\text { Ponda }
$$

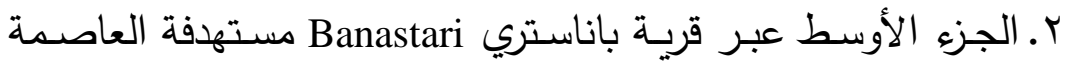

$$
\text { بانجيم. }
$$

r. الجزء الغربي استهدف منطقة تفيم Tivim شمال "جوا" .

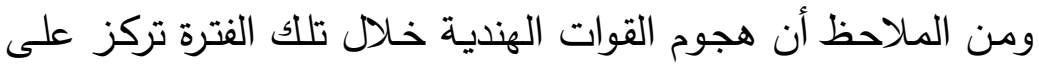

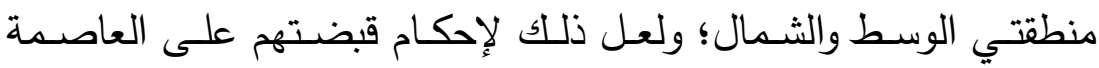
بانجيم التي سيكون لسقوطها أكبر الأثر في تحفيز الهنود للاستمرار،

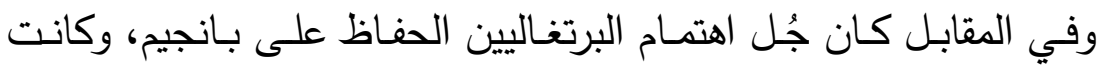
خطة دفاعهم -نظرا لضعف قدراتهم العسكرية- ترتكز على إعاقة تقدم الهنود إلى المدينة دن خـلال قطع كل الجسور المؤدية إليها، لكن هذه

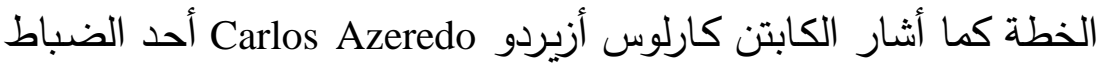

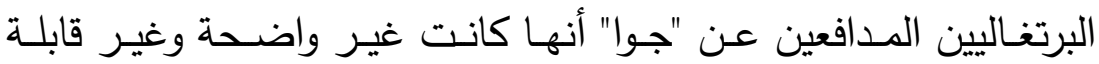
للتحقيق (').

وفي صـباح التاسـع عشـر مـن ديسـمبر الو ام تقـدمت القـوات الهندية إلى بانجيم، ودار قتال عنيف بين الطرفين، استمر لمدة ثمانية سـاعات، انتهى بسـيطرة الهنود على المدينة، وإطـلاق سـراح المعتقلين

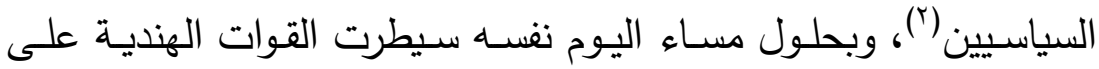
معظم مدن مستعمرة "جوا"، فتجمع ما يقرب من ألفين برتغالي في قاعدة

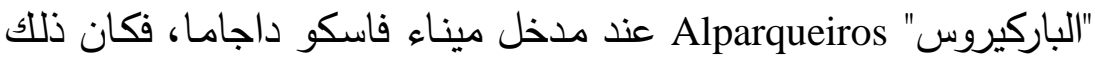

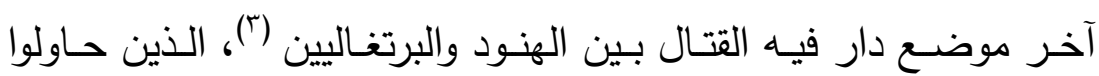

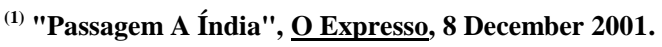

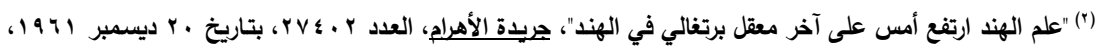


تأخير الاشتباك على أمل وصول تعزيزات من البحريـة البرتغالية، ولما عجزوا عن ذلك اضطروا إلى تسليم المدينة ولكن بعد تدميرها ('). • إسقـاط مستعمرتـي دمسان و ديـو:

ترأس الحامية البرتغالية المدافعة عن دمان انطونيو خوسيه دون دانيس كوستا بينتو António José da Costa Pinto ومعه ثلاثمائة وستون من جنود

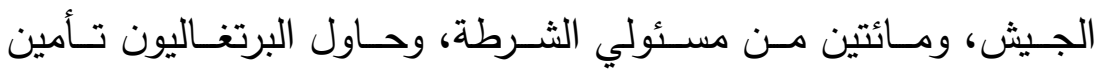

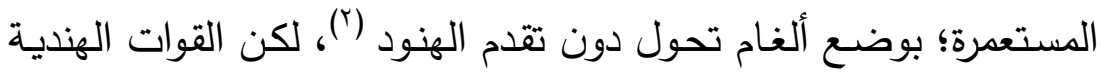
تحت قيادة الكولونيل بونسيل Colonel Bhonsle زحفت على المستعمرة في فجر الثامن عشر من ديسمبر (ا79 (م، وقامت بتصويب هجماتها على مطـار دمـان، فواجهتها القوات البرتغاليـة، ودار قتال عنيف بين الطرفين في أكثر من موضـع داخل المستعدرة، ولم يستسلم البرتغاليون

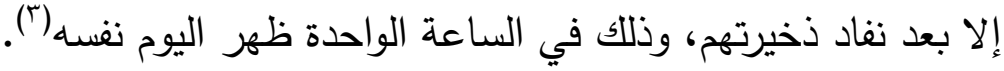

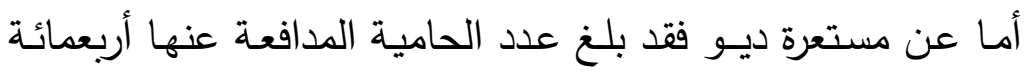

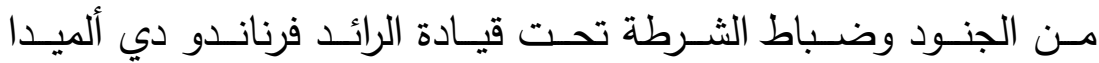
فاسكونسيلوس Fernando de Almeida e Vasconcelos، وكانت المستعمرة عبارة عن جزيرة يفصلها عن البر الرئيسي قناة ضيقة تشبه

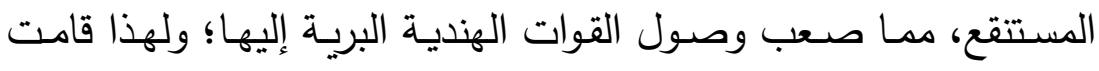
الطائرات الهندية بإطلاق النيران على قلعة ديو ، مما تسبب في اندلاع حريق في مركز الذخائر، فاضطر البرتغاليون إلى إخـاء القلعة، وأمام

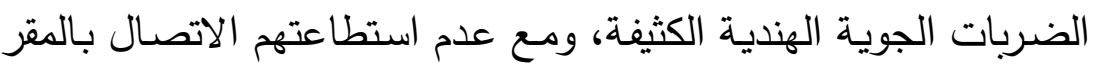
الرئيسي في "جوا" أو لشبونة أعلنوا استسلامهم في ظهر التاسع عشر من ون

\footnotetext{
${ }^{(1)}$ Martins, Paulo, "Invasão de Goa, Damão e Diu foi há 45 anos", Jornal de Notícias, www.supergoa.com, (18 December 2006).

(2) Ibid.

(3) Capt Kapil Bhargava, Operations at Diu: The One day war, www.bharat-rakshak.com, (1 October 2015).
} 
ديسمبر (ا79 (م، فأسر الهنود عددا من البرتغاليين، من ضمنهم حاكم ديو، وثمانية عشر ضابطا وثلاثة وأربعين جنديا('). هكذا سقطت المستعمرات الثلاثة في ثلاثة أيام، وكانـت الخسـئر البشـريـة قليلــة مــن الطــرفين الأمسـر الـذي جعـل كريشــنا مينــون (197r-190V) Krishna Menon العمل العسكري بأنه "عملية سريعة تمت دون إراقة دماء"(؟)، كما أشـار نهرو أن السرعة التي تمت بها العملية وقلة الخسائر خير دليل على أن الهند عرفت كيف تدبر الأهر (") مشيراً إلى ترحيب أهالي "جوا" بالقوات الهندية، وأنهم لو أرادوا البقاء في ظل الاستعمار البرتغالي لأقاموا مئات

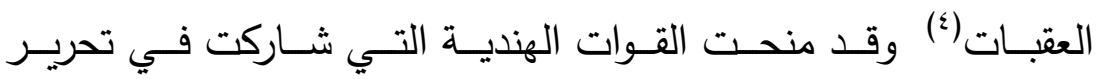
المسـتعمرات البرتغاليـة وســام الخدمــة العامــة وشــارة "جــوا" تكريمــا لجهودهم (0).

وعلى النقيض أعلنت البرتغال أنها لا تعترف بسقوط مستعمراتها في أيدي القوات الهندية، كما صرحت الحكومة البرتغالية أن المقاومة مازالت مستمرة في تلك المستعمرات، وأنـه لـ يحدث أن استسلم أحد بتفويض رسمي من الحكومة البرتغالية، وبناء عليه فلازال للبرتغال الحق في إدارة المستعمرات(؟)، كمـا أعلن سـالازار في خطاب لـه في الجمعية الوطنيـة

(1) Martins, Paulo, "Invasão de Goa, Damão e Diu foi há 45 anos", Jornal de Notícias, www.supergoa.com, (18 December 2006).

${ }^{(2)}$ Singhal, op.cit., p. 78.

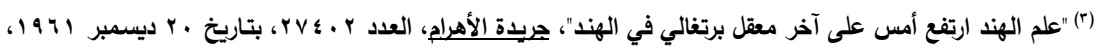

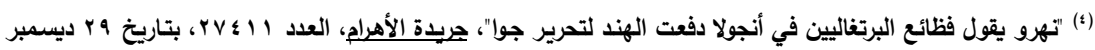

(5) "General Service Medal", www.prideofindia.net, (1 October 2015).

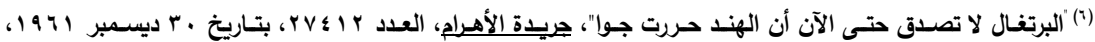




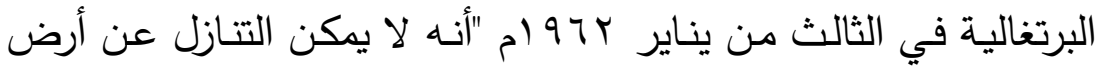

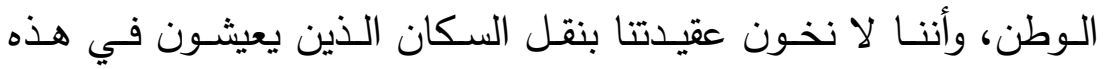
المناطق إلى مناطق خارجية"('). r. ردود الفعل الدولية على ضم الهند للمستعمرات البرتغالية

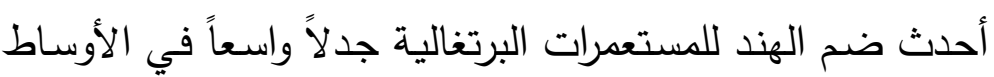
الدولية، وانقسمت الدول بين مؤيد ومعارض، وكان الاتحاد السوفيتي في مقدمة الدول التي أيدت الموقف الهندي وقد أظهر الزعيم السوفيتي ليونيد برجنيف Leonid Brezhnev (7 ـ 19-1919 1) الذي كان في زيارة للهند أثناء ضـمها للمستعمرات البرتغاليـة تأييد بـلاده التام لأي إجـراء تتخذهـ

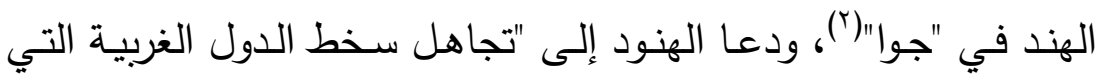
اعتادت قمع الشعوب ونهب خيراتها"، وحينما تقدمت البرتغال بطلب إلى

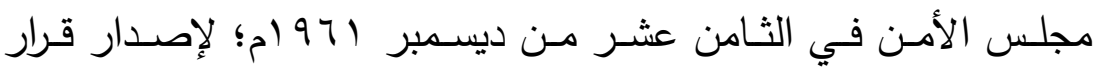

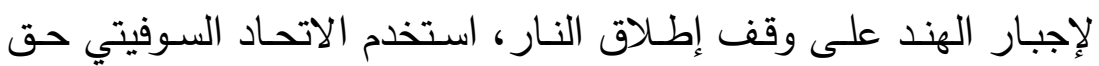
الفيتو لمنع تنفيذ القرار ("). وفي نفس السياق أعربت بعض الدول الأفريقيـة والأسـيوية عن بن

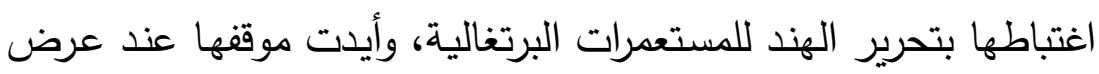

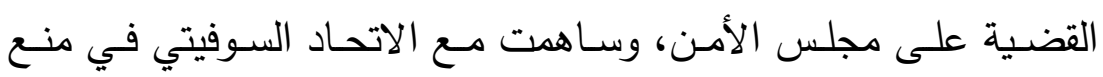

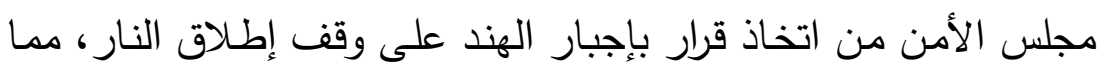
جعل سالازار يتهم الأمم المتحدة بالفشل في حل الموقف الفار، وأن السلطة

(1) "Records show colonizers were not done with Goa", The Times of India, 19 December 2011.

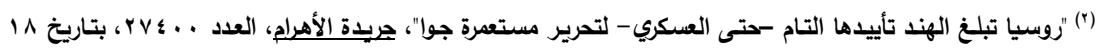

${ }^{(3)}$ Sharma, S.R., India-USSR Relations, 1947-1971: From Ambivalence to Steadfastness, New Delhi: Discovery Published House, 1999, p. 29. 
الفعلية فيها للدول الشيوعية والأفروآسيوية(')، وقد أشـار المؤرخ الهندي سـينجال Singhal بـأن كل صـحف البلدان الأسـيوية والأفريقيـة وأوروبـا الشرقية أشادت "بجهود الهند النبيلة في التصدي للاستعمار البرتغالي"(؟)، ويمكن القول بأن ما قاله صائب إلى حد كبير فقد تألمت هذه البلاد كما تألمت الهند من وطأة الاستعمار .

كانت مصر من أولى الدول الأفريقية التي أعربت عن تأييدها للهند

فـي جهودهــا لتحريـر "جــوا" منــذ الســاعات الأولـى لبـده العلميـات العسكرية(؟)، ورفضـت السماح بمرور أحدى السفن البرتغالية التي تتقل الجنـود والأسـلحة والذخائر إلى "جـوا"عبر قنـاة السـويس(ع)، مدـا جعل وله

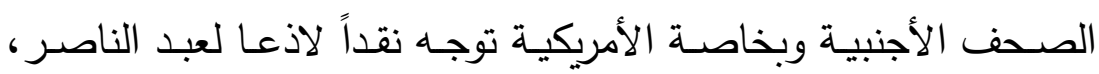

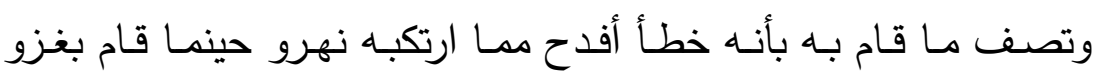
"جوا"(")، كما أعلن الدكتور الصسادق المقدم (ع (9 1-ب99 (9) المتحدث

(1) Keesing's Record of World Events, "International Reactions to Indian Attack on Goa: Soviet Veto of Western Cease-fire Resolution in Security Council", Volume 8, March, 1962 , p. 18659.

${ }^{(2)}$ Singhal, op.cit., p. 79.

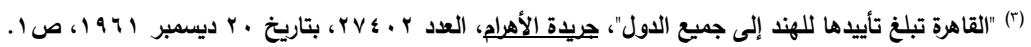

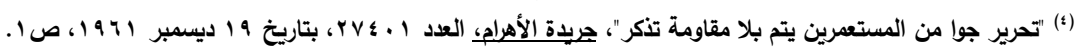

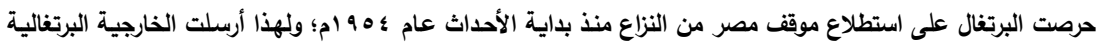

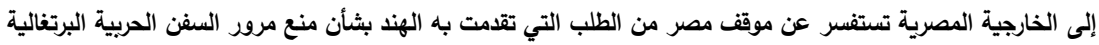

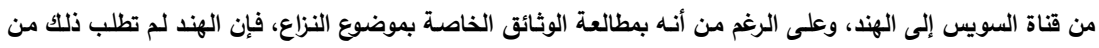

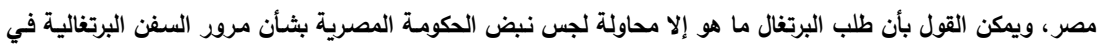

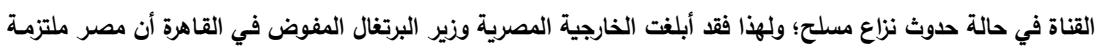

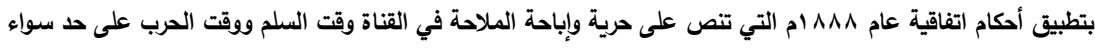

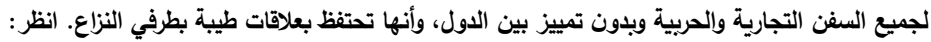

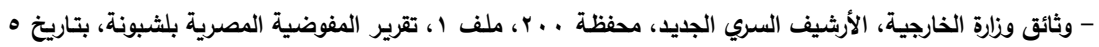
أغسطس § 190.

${ }^{(5)}$ David, Lawrence, "Nasser Violates Pledge on Suez Canal Passage", Spokane Daily Chronicle, 23 December 1991. p. 4. 
باسـم الخارجيـة التونسـية أن تحريـر "جـوا" سـيعجل بنهايـة الاسـتعمار

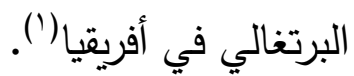

وعلى الجانب الآخر نددت بعض الدول بضم الهند للمستعمرات

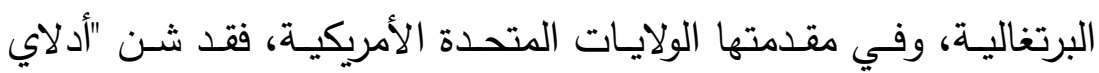

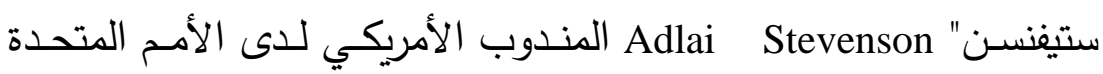

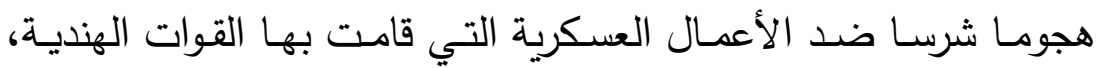

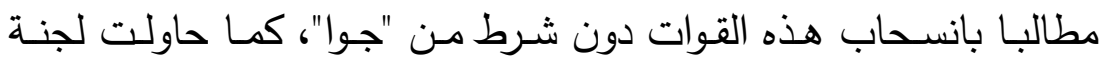

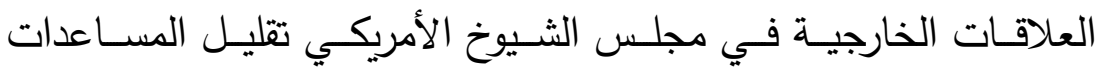
الأمريكية للهند بنسبة هץ\%(؟)، وأرسلت الولايات المتحدة مذكرة إلى الهند

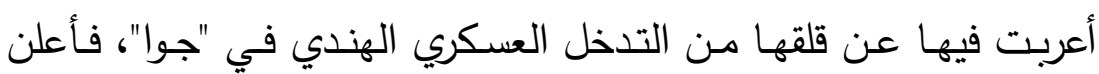

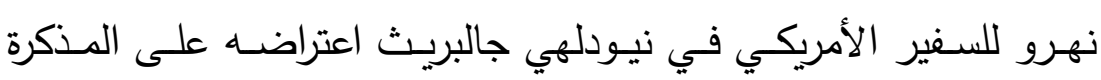
الأمريكية، وعلى الاحتجاج على ضم الهند قطعة من أراضيها، كما أرسل

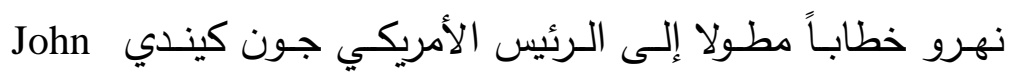
Kennedy قلقه من تأثير الموقف الأمريكي من ضم الهند للمستعمرات البرتغالية على العلاقات الأمريكية الهندية(").

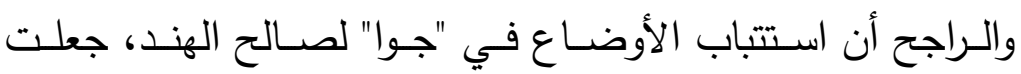

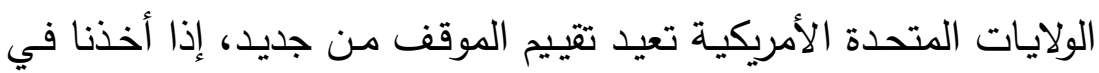
الاعتبار التأييد السوفيتي الواضح للموقف الهندي، وتصويره للقضية على أنها دفاع عن الشعوب المستعمرة في تقرير مصيرها، ولهذا لم تتخذ إدارة

\footnotetext{
${ }^{(1)}$ Keesing's Record of World Events, op.cit., p. 18659.
}

(2) F.R.U.S., 1961-1963, Vol. XIX, South Asia, Document 77, 753D.00/12-2361. Secret; Telegram From the Department of State to the Embassy in India, 23 December 1961.

(3) F.R.U.S., 1961-1963, Vol. XIX, South Asia, Document 78, 690D.91/12-2861. Secret, Telegram From the Embassy in India to the Department of State, New Delhi, 28 December 1961. 
كيندي إجراءاً حاسماً ضد الهند، ولكن اكتفت بإعلان استتكارها لضم الهند لتلك المستعمرات.

شاركت بريطانيا الولايات المتحدة في موقفها من ضم المستعمرات

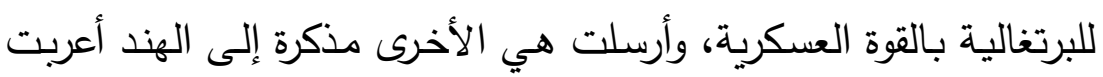

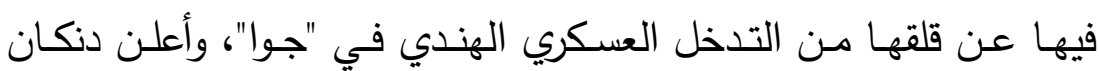
سـانديز Duncan Sandys مسئول العلاقات الخارجيـة في الكومنولث البريطـاني Commonwealth استيائه مـن قرار حكومـة الهند باسـتخدام القوة العسكرية لتحقيق أهدافها السياسية، كما أوضح باتريك دين Patrick

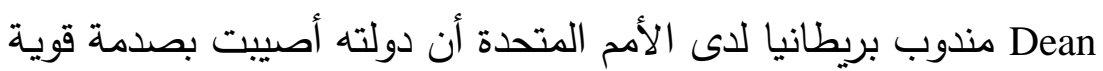

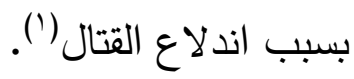

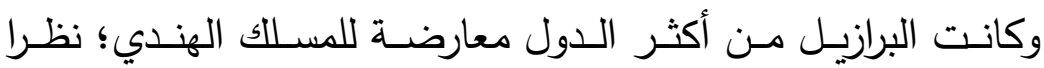

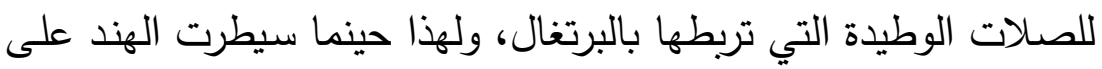

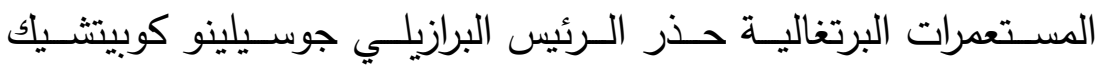

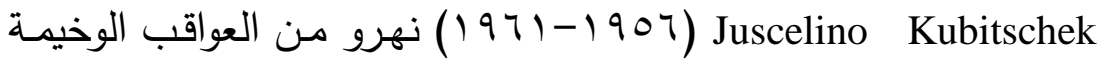

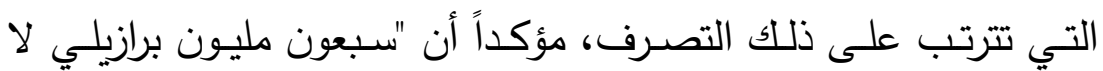

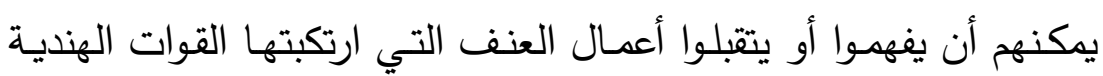

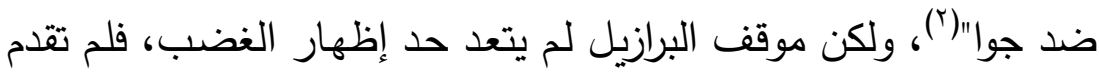

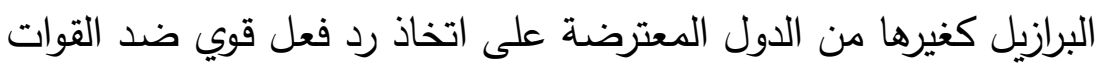
الهنديـة التي سيطرت بسـرعة على الموقف، واكتفت البرازيـل بإصـدار تصريحات توضح فيها مشاركتها للبرتغال في آلامها لفقد "جوا"(").

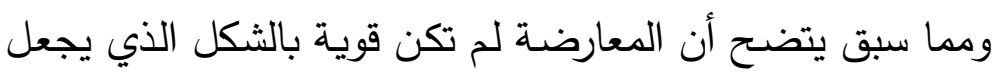

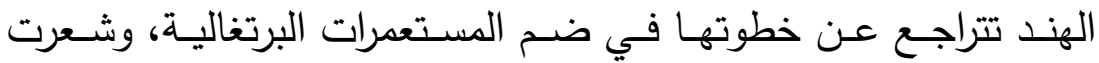

\footnotetext{
${ }^{(1)}$ Keesing's Record of World Events, op.cit., p. 18659.

(2) Davila, Jerry, op.cit., p. 27.

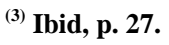


البرتغال بخيبة الأمل بسبب تخلي حلفائها عنها في هذا الموقف العسر؛

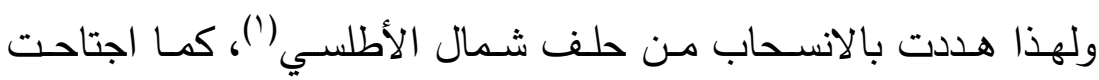
لثبونة مظـاهرات ضخمة معاديـة للولايـات المتحدة وبريطانيا احتجاجـا

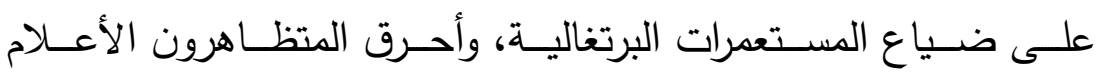

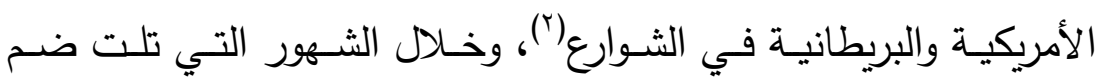

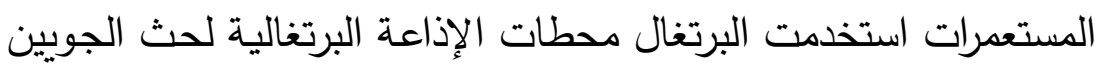
على معارضة الإدارة الهندية، وبذل الجهد لخلق حركات المقاومة السرية

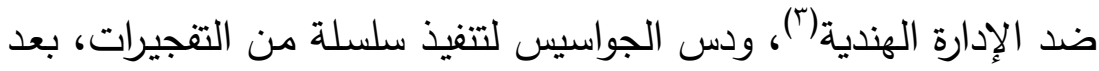
أن قاموا بتدمير المرافق الأساسية في المستعمرات قبل تسليمها للقوات

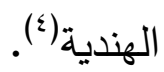

وبعد أن أطمأن نهرو لسيطرة الهنود على الوضـع في المستعمرات

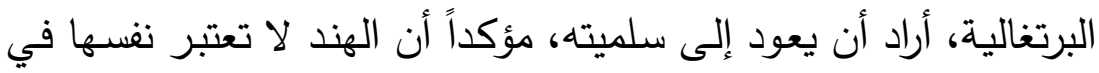

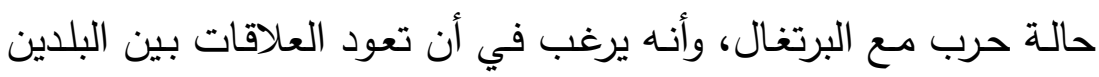

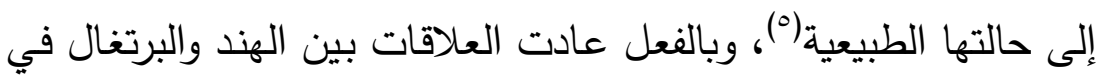
أعقاب الانقلاب العسكري الذي حدث في الخامس والعشرين من إبريل

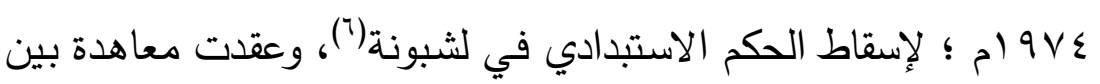

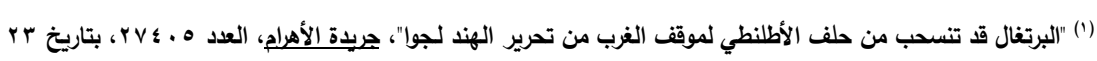

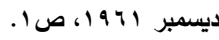

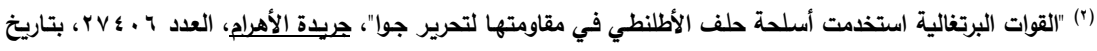
ع r r r

${ }^{(3)}$ Xavier, Constantino, "Lost in delusion", www.thegoan.net, (3 May 2014).

(4) Singhal, op.cit., p. 78.

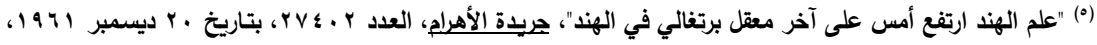

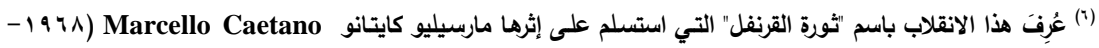

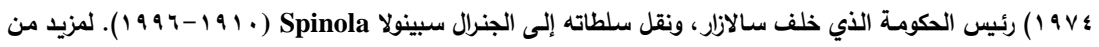

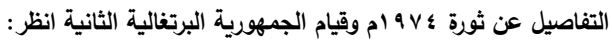
- Maxwell, Kenneth, "The Thorns of the Portuguese Revolution", Foreign Affairs, Vol. 54, No. 2 (Jan., 1976), pp. 250-270. 
الطـرفين في الرابـع والعشـرين مـن ديسـمبر ؟ \9 ام وقـع عليهـا وزيـر

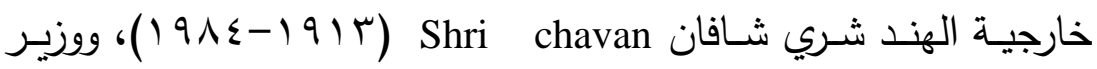

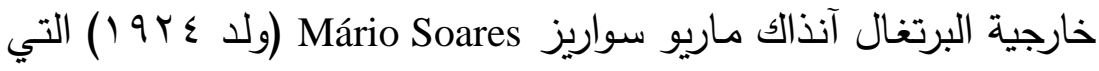
أكدت في المادة الأولى منها على اعتراف حكومة البرتغال بسيادة الهند

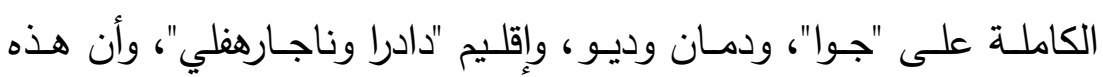

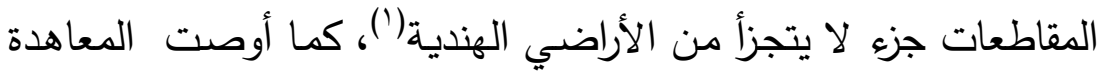
بضـرورة فتح آفاق جديدة للتعـاون بـين البلدين في مختلف المجالات ولاسيما المجالات الثقافية، واتخذت خطوات من جانب الدولتين لإعادة

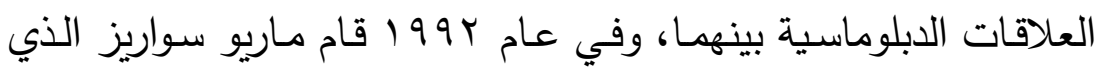

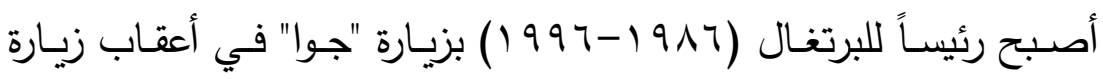
الرئيس الهندي فينكاتارمان Venkataraman (

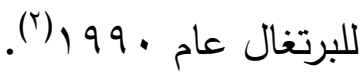
وهكذا عادت المستعمرات البرتغالية إلى الهند، بعد فترة من النزاع

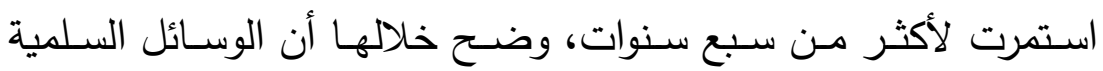
وحدها ليست قادرة على إعادة حقوق الهند التي سلبتها الحكومة البرتغالية

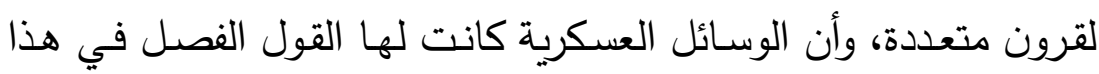

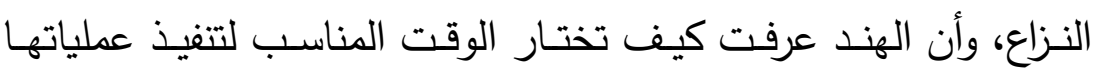
العسكرية لضم المستعمرات مستفيدة من حالة الضعف الداخلي والخارجي التي عانت منها البرتغال ولاسيما في عام (979 (م، ثم عادت العلاقات

${ }^{(1)}$ Ministry of External Affairs, India, "Treaty Between The Government of India and the Government of the Republic of Portugal on Recognition of India's Sovereignty over Goa, Daman, Diu, Dadra, Nagar Haveli and Related Matters", www.commonlii.org, (6 December 2015).

(2) "Portugal still in denial over goa", Deccan Herald, 20 March 2011, www.deccanherald.com, (2 October 2015). 
الوديـة بين البلدين بعد انقطساع دام مـا يقرب مـن ثلاثـة عشر عامـاً، وطويت بذلك صفحة النزاع لتبدأ مرحلة جديدة من العلاقات بين البلدين. 


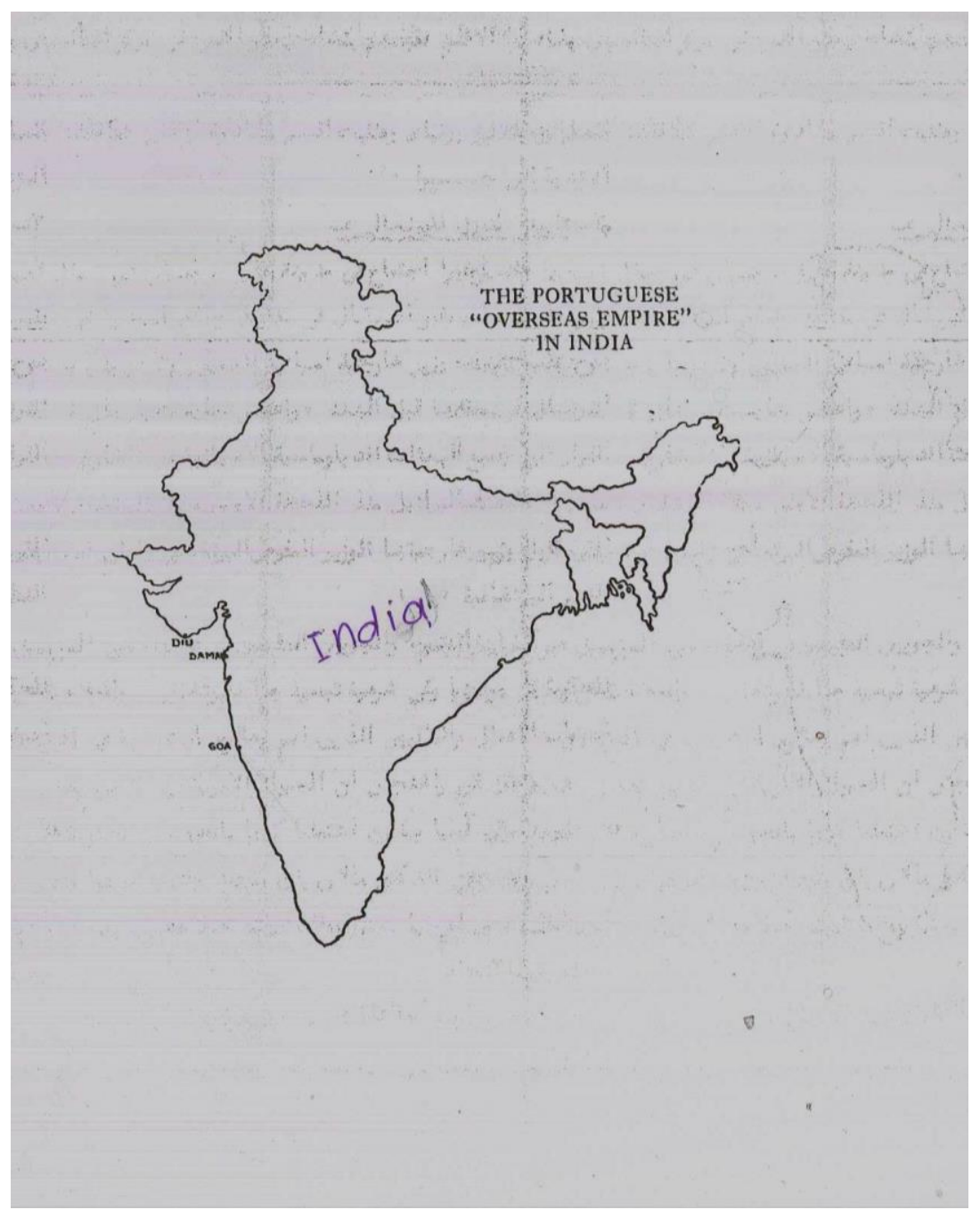

خريطة رقم ( ) التي توضح موقع المستعمرات البرتغالية في الهند"( ).

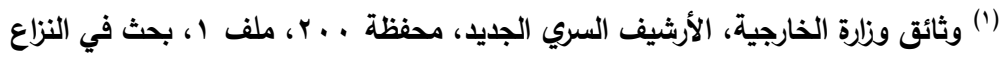
البرتغالي الهندي حول الممتلكات البرتغالية في الهند. 


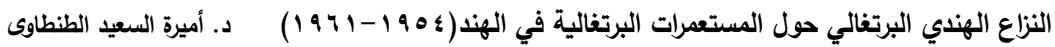

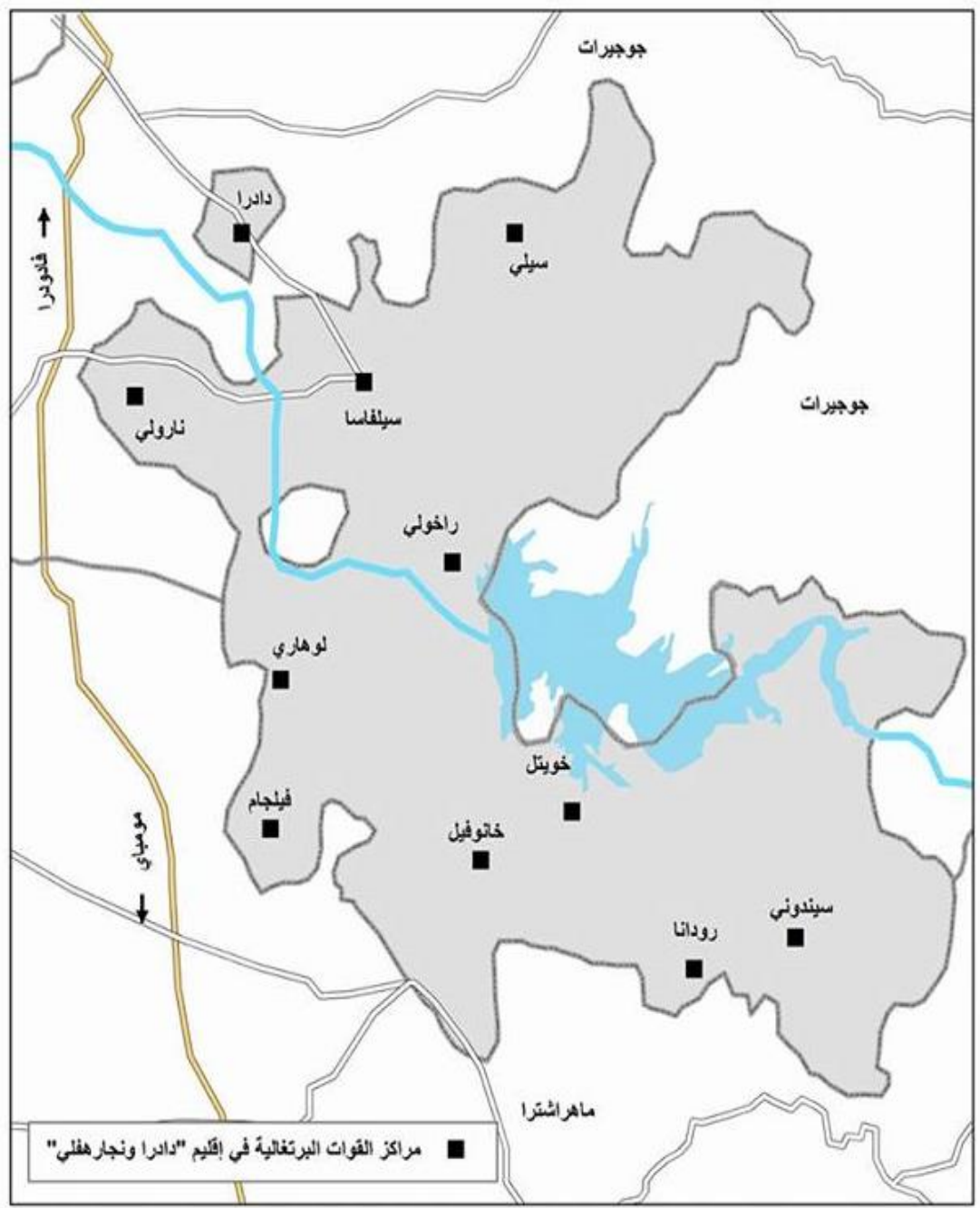

خريطة رقم (ץ) توضح مواقع القوات البرتغالية في إقليم "دادرا وناجارهفلي"(')

(1) - الخريطة من عمل الباحثة باستخدام برنامج GIS الجغرافي. 


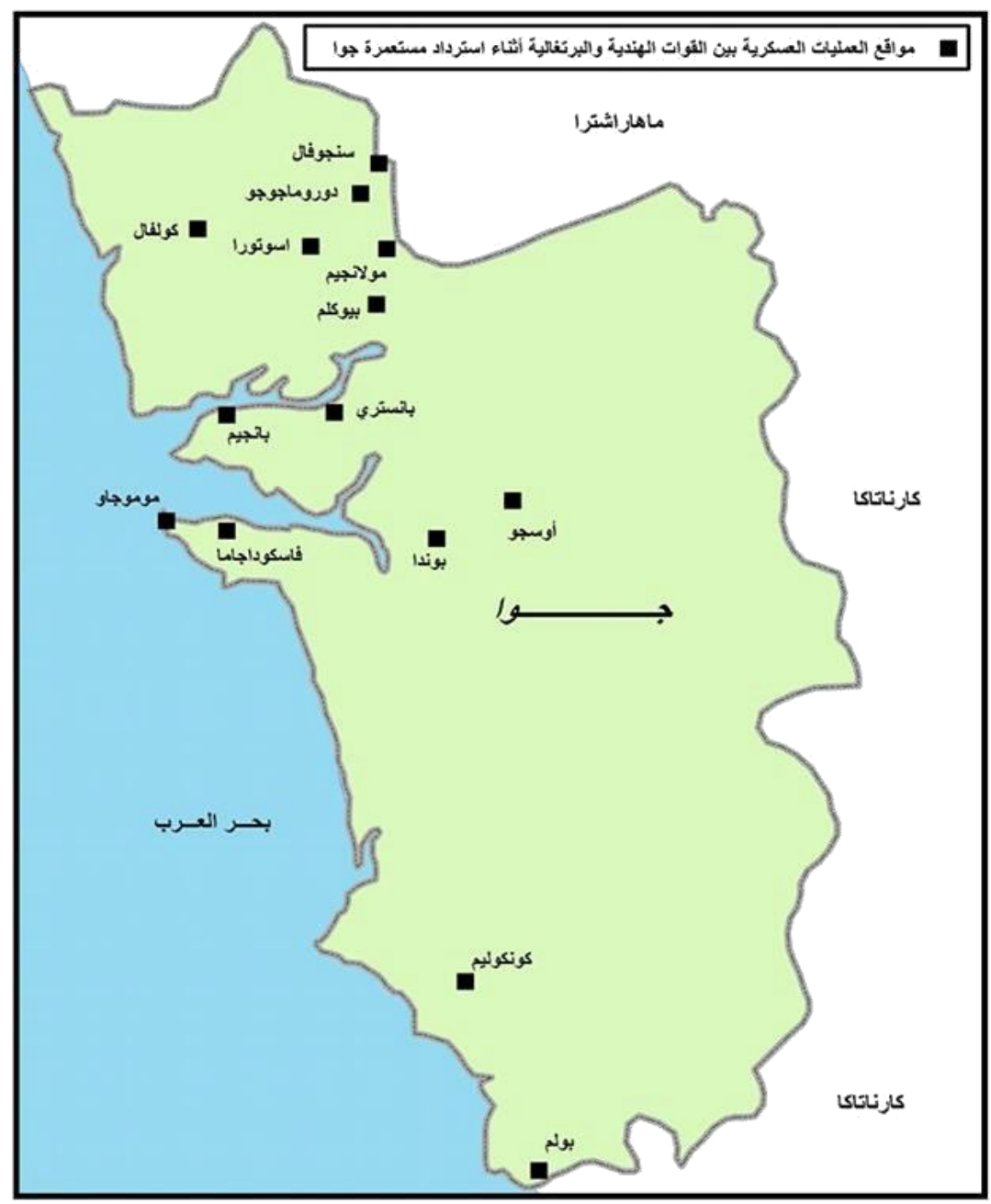

خريطة رقم (ץ) توضح مواقع العمليات العسكرية بين القوات الهندية والبرتغالية أثناء استرداد مستعمرة "جوا"(')

(1) الخريطة من عمل الباحثة باستخدام برنامج GIS الجغرافي. 